\title{
Quantum mechanical scattering by time-periodic potentials
}

Ph.D. thesis

written by

LÓRÁNT Zs. SzABÓ

Department of Theoretical Physics, University of Szeged

Supervisors:

AtTila CZirjáK

research fellow, honorary associate professor

Department of Theoretical Physics, University of Szeged

$\&$

PÉTER FÖLDI

associate professor

Department of Theoretical Physics, University of Szeged

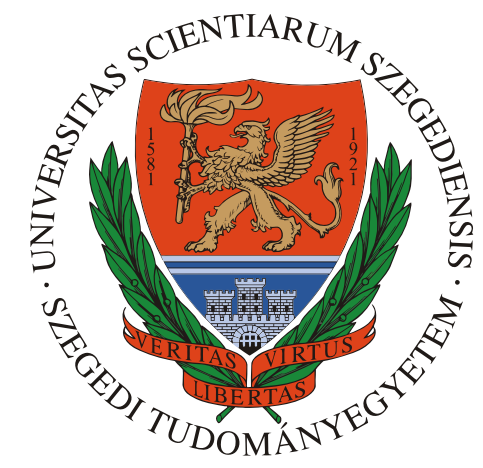

Doctoral School of Physics

Department of Theoretical Physics

Faculty of Science and Informatics

University of Szeged

Szeged, Hungary 


\section{Acknowledgements}

First of all, I would like to express my sincere gratitude to my two co-supervisors, Dr. Attila Czirják and Dr. Péter Földi, for their continuous guidance during my studies. They always encouraged and trusted me even when I faced the most challenging tasks.

I am also grateful to Dr. Mihály Benedict who helped me to improve the thesis through constructive critical remarks. His character, as a professor, has also a great impact on me.

I am thankful to the head of department, Dr. László Fehér who also made my continuous employment possible.

Thanks are also due to Dr. Sándor Varró who gave me a very extensive introduction to the theoretical description of intense light-matter interaction.

Everyone at the Department of Theoretical Physics have my gratitude for creating an inspiring atmosphere. Particularly, I enjoyed my daily work with the fellow inhabitants of office 231, Dr. Tamás F. Görbe and Dr. Gergó Roósz. The joint works with Dr. Piroska Dömötör, Szabolcs Hack and István Magashegyi were also fruitful.

I am forever indebted to my physics teachers Virág Horváthné Érsek in primary school and Irén Domonkosné Balogh in high school for making me interested in physics and, of course, for spending their extra time on me.

The work was supported in part by the Hungarian Scientific Research Fund (OTKA) under the grant no. K-81364, and was sponsored by the EU and the State of Hungary, co-financed by the European Social Fund through projects TÁMOP4.2.2.A-11/1/KONV-2012-0060, TÁMOP-4.2.2.D-15/1/KONV-2015-0024, and the work was also supported by the European Social Fund and the Széchenyi 2020 program under contract no. EFOP-3.6.2-16-2017-00005.

Finally, I would like to express my thanks to my family and friends for their unending support. 


\section{Contents}

$\begin{array}{ll}\text { Introduction } & 1\end{array}$

I Preliminaries 3

1 Floquet's theory 4

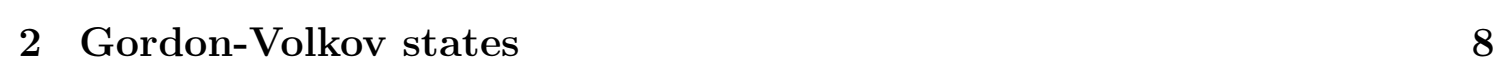

2.1 Electromagnetic gauges . . . . . . . . . . . . . . . . . . . 8

2.2 Gauges in dipole approximation . . . . . . . . . . . . . . 9

2.3 Gordon-Volkov states in dipole approximation . . . . . . . . . . . . . 12

3 The Dirac equation $\quad 14$

3.1 Dirac equation of a free particle . . . . . . . . . . . . . . . . . 14

3.2 Solution for a constant potential barrier . . . . . . . . . . . . 16

3.2 .1 Bound states . . . . . . . . . . . . . . . . . 18

3.2 .2 Scattering states, Klein paradox . . . . . . . . . . . . 20

II Time-periodic scattering models 22

4 Charged particle scattering in a Ramsey-like setup 23

4.1 Introduction . . . . . . . . . . . . . . . . . . . 23

4.2 Model . . . . . . . . . . . . . . . . . . . . . . . . 24

4.3 Floquet solutions . . . . . . . . . . . . . . . . . 26

4.4 Results and discussion . . . . . . . . . . . . . . . . . . . . . 30

4.4.1 Cycle-averaged transmission probability . . . . . . . . . . 31

4.4 .2 Scattering resonances . . . . . . . . . . . . . . . . 33

4.4.3 Shifted. "multiphoton" resonances . . . . . . . . . . . . . . . 35

4.4.4 Phase dependence of the transmission . . . . . . . . . . . . . . . . . . . . . 39

4.5 Summary and conclusions . . . . . . . . . . . . . . . . . . . 39 
5 Laser-assisted electron scattering on a hard sphere 40

5.1 Introduction . . . . . . . . . . . . . . . . . . 40

5.2 Model . . . . . . . . . . . . . . . . . . . . . . . . 41

5.3 Expansion in terms of spherical Volkov states . . . . . . . . . . . . 43

5.4 Spherical Gordon-Volkov states . . . . . . . . . . . . . . . . . . 44

5.4.1 Translation addition theorem of spherical waves ... . . . . . 45

5.4.2 Applving the theorem to the spherical Volkov states . . . . . . 46

5.4 .3 Matching equations . . . . . . . . . . . . . . . . . . . . . 49

5.5 Results in the weak-field limit . . . . . . . . . . . . . . . . . 49

5.6 Summary . . . . . . . . . . . . . . . . . . 52

6 Relativistic scattering by an oscillating barrier $\quad 54$

6.1 Introduction . . . . . . . . . . . . . . . . . 54

6.2 Model . . . . . . . . . . . . . . . . . . . . 55

6.2.1 Solution of the Dirac equation with oscillating potential . . . . 56

6.2 .2 Fitting the solutions . . . . . . . . . . . . . . 58

6.3 Results and discussion ... . . . . . . . . . . 60

6.3.1 Cvcle-averaged reflection and transmission probabilities . . . . 60

6.3.2 Wave-packet generation and propagation . . . . . . . . . . . 64

6.3 .3 Fano-type resonances . . . . . . . . . . . . . . . . . . 67

6.4 Summary . . . . . . . . . . . . . . . . . 70

$\begin{array}{ll}\text { Summary } & 71\end{array}$

\begin{tabular}{ll}
\hline Összefoglalás & 76
\end{tabular}

\begin{tabular}{ll}
\hline Publications & 81
\end{tabular}

$\begin{array}{ll}\text { Bibliography } & 82\end{array}$ 


\section{List of Figures}

3.1 Eigenvalues of the free Dirac equation . . . . . . . . . . . 16

3.2 One-dimensional constant square potential barrier . . . . . . . . . . 17

3.3 Representations of $p$ and $q$ in the $E-V_{0}$ plane . . . . . . . . . . . . 19

$3.4 T$ as a function of $V_{0} \ldots \ldots \ldots \ldots$

4.1 Schematic view of the Ramsev-like setup . . . . . . . . . . . . . 25

$4.2\langle T\rangle$ as a function of $E_{0}$ in a field with $\lambda=800 \mathrm{~nm} \ldots . . \ldots 32$

4.3 Comparison of the transmission spectrum in the two models . . . . . 33

4.4 Localized states in the double-barrier svstem . . . . . . . . . . . . . . 34

$4.5\langle T\rangle$ as a function of $E_{0}$ for different values of $F_{0}$ and $\omega \ldots . . . .35$

$4.6\langle T\rangle$ as a function of $E_{0}$ with the current distributions . . . . . . . . 36

$4.7\langle T\rangle$ as a function of $\varphi_{0}$ for different values of $d \ldots \ldots . \ldots 37$

4.8 Density plot of $j(x, t)$ for maximal and minimal values of $\langle T\rangle$. . . . 38

5.1 Geometrv of the laser-assisted hard sphere scattering . . . . . . . . . 41

5.2 Reference frames in the translational addition theorem . . . . . . . 45

5.3 Density plots of $\log \rho$ in the absence/presence of the laser field . . . . 50

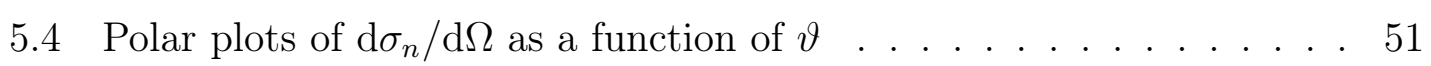

$5.5 \rho$ at the forward direction $(\vartheta=0)$ as a function of $E_{n} \ldots \ldots 52$

6.1 Schematic view of the one-dimensional relativistic scattering . . . . . 56

$6.2\langle T\rangle$ as a function of $V_{0}$ for low $E_{0} \ldots \ldots \ldots \ldots \ldots$. . . . . . . . 61

$6.3\langle T\rangle$ as a function of $V_{0}$ for high $E_{0}$ and zooming into the band gap . . 62

$6.4\langle T\rangle$ as a function of $V_{0}$ for ultrahigh $E_{0} \ldots \ldots \ldots$. . . . . . . . 63

$6.5\langle T\rangle$ as a function of $\omega \ldots \ldots \ldots \ldots$. . . . . . . . . . . . . 64

6.6 Densitv plot of $\rho(z, t), i(z, t)$ for low $\Omega \ldots \ldots \ldots$. . . . . . 65

6.7 Density plot of $\rho(z, t), j(z, t)$ for high $\Omega \ldots \ldots . \ldots 66$

6.8 Fano-tvpe resonances in the transmission spectrum . . . . . . . 68

6.9 Density plot of $\rho(z, t), j(z, t)$ in the case of a Fano-type resonance . . 69 


\section{Introduction}

Scattering processes are of fundamental importance in several areas of physics providing fundamental information, e.g., on the nature of the relevant interaction. In general, scattering is a process when an object (an elementary particle, light) interacts with an other object, then moves towards a possibly different direction respect to the original trajectory. The interaction can be originated from a mechanical collision or another acting force (e.g. Coulomb force) which can be usually derived from a potential. There is a special class of time-periodic scattering processes when we assume that the time dependence of the scattering potential contains a single frequency. Such excitation can be a beam of light (e.g. laser) or a gate-voltage applied to a solid-state device.

The objective of the work presented in this $\mathrm{PhD}$ thesis is the examination of the role of the time-periodic excitation in quantum mechanical scattering problems. If this excitation can not be considered as a small perturbation, anharmonic effects are observable. This complex dynamics can be described by Floquet's theory [1 $[4]$ which is the basis of the theoretical methods presented in this thesis. With this approach, the fundamental quantum effects, like the interference of matter waves in strong external fields, can be examined as well as the appearance of harmonics. The advantage of this method is that the dynamical equations can be reduced to a linear algebraic system of equations, and the interaction is taken into account in a nonperturbative way.

Beside exploring the fundamental effects, our aim is also to examine the specific properties of the quantum systems in question and to seek possible applications. We would like to study two one-dimensional models in which we inquire the response of a de Broglie plane wave to a time-periodic excitation. In the case of relativistic particles, based on the linear dispersion relation of graphene, we can model the electron transport in graphene with an applied periodic gate-voltage. Here, we want to examine what kind of practical applications could there be for a periodic excitation, which show the known relativistic effects, like Klein paradox. As for nonrelativistic particles, the solid-state physical analogy could be the dynamics of the electrons in the conduction band with an applied optical field. Of course, the description of the dynamics of a beam consisting of charged particles naturally arises 
in both cases. After understanding the physical background, it is an important question how the filtering of the energy can be achieved for the outgoing particles.

Additionally, our aim is to study a three-dimensional model, in which charged particles are scattered on a sphere. Considering the possibility of the optical control, we intend to examine the dynamics in the presence of an electromagnetic field. The main quantity to be calculated here will be the differential cross section, whose analysis could give an insight into the dynamics of the scattering process.

The thesis is structured in such a way that the main content of the work is divided into two parts. Part \ contains three brief chapters in which theoretical preliminaries are covered. Part 【I contains the main results of the thesis which are presented in three chapters. In Chapter 4, we present a nonrelativistic one-dimensional model, where charged particles are scattered in a Ramsey-like setup. Next, in Chapter 5 , a three-dimensional electron scattering is discussed in the presence of an external electric field. The final Chapter [6 covers the one-dimensional relativistic model in which Dirac particles are scattered by an oscillating potential barrier. As a final summary, the motivational aspects and methods are followed by the new scientific results to which the author has contributed. 


\section{Part I}

\section{Preliminaries}




\section{CHAPTER 1}

\section{Floquet's theory}

Quantum mechanical systems in external time-periodic fields allow a treatment using Floquet's theory, which is the analog of Bloch's theorem in solid-state physics for time periodicity instead of spatial periodicity. The mathematical foundations of this approach were originally developed in 1883 by G. Floquet to study ordinary differential equations with periodic coefficients, see Ref. [1]. Regarding quantum systems, Floquet's theory was first used in the context of laser-atom interaction by J. H. Shirley in 1965. He considered a quantum system with two discrete states interacting with a semiclassically treated oscillating field with a single frequency [2]. Later on, however, Floquet's theory was reformulated to be applied to polychromatic fields as well (such as multimode laser fields or several monochromatic fields with different frequencies) [5] 7 .

The key feature of the application of Floquet's theorem for the description of light-matter interaction is that it permits the time-dependent Schrödinger equation 1 of an atomic system interacting with a periodic laser field to be reduced to an equivalent infinite-dimensional eigenvalue problem. Using this approach, the atomfield coupling is treated in a completely nonperturbative way.

Let us consider a quantum system whose Hamiltonian $H(t)$ is periodic in time, i.e., $H(t)=H(t+T)$, where $T=2 \pi / \omega$ and $\omega$ is the angular frequency. The field is assumed to be monochromatic and arbitrarily polarized. The corresponding time-dependent Schrödinger equation can be written as

$$
\mathscr{H}_{F}(t)|\Psi(t)\rangle=0
$$

\footnotetext{
${ }^{1}$ In this chapter, we consider only a nonrelativistic framework for the sake of simplicity. However, Floquet's theory can be also applied to relativistic problems described by e.g. the Dirac equation as presented in Chapter 6.
} 
with the operator

$$
\mathcal{H}_{F}(t)=H(t)-i \hbar \frac{\partial}{\partial t},
$$

which is called the Floquet Hamiltonian. As a consequence of Floquet's original theorem [1], the solution can be written as

$$
|\Psi(t)\rangle=\exp (-i \epsilon t / \hbar)|\Phi(t)\rangle
$$

where $|\Phi(t)\rangle$ is called the Floquet state which has the same time-periodicity as that of the Hamiltonian, i.e., it satisfies $|\Phi(t)\rangle=|\Phi(t+T)\rangle$. The quasienergy $\epsilon$ has to be a real parameter and is only defined up to integer multiples of $\hbar \omega$.

Since the Floquet states are time-periodic, it is convenient to introduce them as vectors of the composite Hilbert space $\mathscr{R} \otimes \mathfrak{T}$ made up of the Hilbert space $\mathscr{R}$ of square integrable functions in configuration space and the space $\mathcal{T}$ of functions which are periodic in time with period $T=2 \pi / \omega[9,10]$. For the spatial part $\mathcal{R}$, the inner product is defined by

$$
\left\langle\varphi_{\alpha} \mid \varphi_{\beta}\right\rangle \equiv \int \varphi_{\alpha}^{*}(\mathbf{r}) \varphi_{\beta}(\mathbf{r}) \mathrm{d} \mathbf{r}=\delta_{\alpha \beta}
$$

where the range of the integration is the entire configuration space and $\left|\varphi_{\alpha}\right\rangle,\left|\varphi_{\beta}\right\rangle, \ldots$ are orthonormal basis vectors. The temporal part is a Hilbert space denoted by $\mathcal{T}$ which is spanned by the complete orthonormal set of functions $\exp (i n \omega t)$, with $n=0, \pm 1, \pm 2, \ldots$ being integer numbers. It consists of all periodic functions of time $t$ with the period of $T$. The inner product of the basis functions in $\mathcal{T}$ reads

$$
(n, m)=\frac{1}{T} \int_{0}^{T} \exp [i(m-n) \omega t] \mathrm{d} t=\delta_{n m} .
$$

For the complete Hilbert space $\mathscr{R} \otimes \mathcal{T}$, we can finally introduce a suitably extended inner product, which, for the states $\left|\varphi_{\alpha}^{n}\right\rangle=\left|\varphi_{\alpha}\right\rangle \exp ($ in $\omega t)$ reads

$$
\left\langle\left\langle\varphi_{\alpha}^{n} \mid \varphi_{\beta}^{m}\right\rangle\right\rangle=\frac{1}{T} \int_{0}^{T}\left\langle\varphi_{\alpha}^{n}(t) \mid \varphi_{\beta}^{m}(t)\right\rangle \mathrm{d} t=\delta_{\alpha \beta} \delta_{n m}
$$

here, $\left\langle\varphi_{\alpha}^{n}(t) \mid \varphi_{\beta}^{m}(t)\right\rangle$ denotes the usual inner product (1.4) between state vectors at equal times.

Applying the Floquet Hamiltonian operator to the wave function (1.3), the exponential term cancels out, and one can observe that the Floquet states satisfy the eigenvalue equation

$$
\mathcal{H}_{F}(t)\left|\Phi_{\alpha}(t)\right\rangle=\epsilon_{\alpha}\left|\Phi_{\alpha}(t)\right\rangle,
$$


where each $\left|\Phi_{\alpha}(t)\right\rangle$ is a periodic function of period $T$, and the index $\alpha$ distinguishes different eigenvalues/eigenstates. Moreover, at equal times the Floquet modes form a complete set

$$
\sum_{\alpha}\left|\Phi_{\alpha}(t)\right\rangle\left\langle\Phi_{\alpha}(t)\right|=\mathbb{1}
$$

where $\mathbb{1}$ denotes the identity in the Hilbert space of $\mathscr{R}$ only, i.e., not including the space of time-periodic functions. From Eq. (1.3) and from the periodicity of the Floquet state $\left|\Phi_{\alpha}(t)\right\rangle$, it is clear that the same physical state is obtained from

$$
\left|\Psi_{\alpha}(t)\right\rangle=\exp \left[-i\left(\epsilon_{\alpha}+n \hbar \omega\right) t / \hbar\right] \exp (i n \omega t)\left|\Phi_{\alpha}(t)\right\rangle=\exp \left(-i \epsilon_{\alpha}^{n} t / \hbar\right)\left|\Phi_{\alpha}^{n}(t)\right\rangle
$$

where the shifted states are defined as $\left|\Phi_{\alpha}^{n}(t)\right\rangle=\exp (i n \omega t)\left|\Phi_{\alpha}^{n}\right\rangle$ with a quasienergy $\epsilon_{\alpha}^{n}=\epsilon_{\alpha}+n \hbar \omega$ for any integer number $n$. These states are sometimes referred to as sidebands. Therefore, any quasienergy $\epsilon_{\alpha}$ can be reduced to a point in a "zone" such as $-\hbar \omega / 2 \leq \epsilon \leq+\hbar \omega / 2$. (Analogously, in solid-state physics, the quasimomentum $k$ is only defined up to the reciprocal lattice vector, and it is usually chosen to be in the first Brillouin zone.) Note that the shifted Floquet states $\left|\Phi_{\alpha}^{n}(t)\right\rangle$ satisfy the same eigenvalue equation with their corresponding shifted eigenvalues $\epsilon_{\alpha}^{n}$.

Due to the time periodicity of the Floquet states, we can transform the eigenvalue equation given by Eq. (1.7) into an infinite-dimensional matrix equation by expanding $\left|\Phi_{\alpha}(t)\right\rangle$ as a Fourier series

$$
\left|\Phi_{\alpha}(t)\right\rangle=\sum_{m=-\infty}^{+\infty} e^{i m \omega t}\left|\widetilde{\Phi}_{\alpha}^{m}\right\rangle
$$

where the expansion functions $\left|\widetilde{\Phi}_{\alpha}^{m}\right\rangle$ are the harmonic components of the Floquet state. Inserting Eq. (1.10) into Eq. (1.3), the wave function can be rewritten as the Floquet-Fourier expansion

$$
\left|\Psi_{\alpha}(t)\right\rangle=\exp (-i \epsilon t / \hbar) \sum_{m=-\infty}^{+\infty} e^{i m \omega t}\left|\widetilde{\Phi}_{\alpha}^{m}\right\rangle
$$

The Hamiltonian $H(t)$ can also be expanded as a Fourier series, and the eigenvalue equation can be explicitly given as

$$
\left(\mathscr{H}_{F}-\mathbb{1} \epsilon_{\alpha}\right)\left|\Phi_{\alpha}(t)\right\rangle=0
$$

where the Floquet Hamiltonian matrix $\mathscr{H}_{F}$ is infinite. Concretely, in the orthonormal basis of the composite space $\mathscr{R} \otimes \mathcal{T}$, the matrix of $\mathscr{H}_{F}$ is given by

$$
\left\langle\left\langle\varphi_{\alpha}^{n}\left|\mathscr{H}_{F}\right| \varphi_{\beta}^{m}\right\rangle\right\rangle=\widetilde{H}_{\alpha \beta}^{n-m}+n \hbar \omega \delta_{\alpha \beta} \delta_{n m},
$$


where $\widetilde{H}_{\alpha \beta}^{n-m}$ are the coefficients of the Fourier expansion of the semiclassical Hamiltonian $H$ :

$$
\left\langle\varphi_{\alpha}|H(t)| \varphi_{\beta}\right\rangle=H_{\alpha \beta}(t)=\sum_{n=-\infty}^{\infty} \widetilde{H}_{\alpha \beta}^{n} e^{i n \omega t}
$$

The Greek letters denote the matrix elements corresponding to atomic or molecular eigenstates, while Roman letters stand for Fourier components. If we assume that the Hamiltonian consists of a static plus a time-periodic term, e.g., $H(t)=A+$ $B \cos (\omega t)$, the structure of the Floquet Hamiltonian matrix reads as follows

$$
\mathcal{H}_{F}=\left(\begin{array}{ccccccc}
\ddots & \vdots & \vdots & \vdots & \vdots & \vdots & . \\
\cdots & A-2 \hbar \omega \mathbb{1} & B & 0 & 0 & 0 & \ldots \\
\ldots & B & A-\hbar \omega \mathbb{1} & B & 0 & 0 & \ldots \\
\ldots & 0 & B & A & B & 0 & \ldots \\
\ldots & 0 & 0 & B & A+\hbar \omega \mathbb{1} & B & \ldots \\
\ldots & 0 & 0 & 0 & B & A+2 \hbar \omega \mathbb{1} & \ldots \\
. & \vdots & \vdots & \vdots & \vdots & \vdots & \ddots
\end{array}\right)
$$

where the static term $A$ appears as diagonal blocks which are added to the integer multiples of $\hbar \omega$, and the term $B$ is present as off-diagonal blocks which is the consequence of the identity $\cos \omega t=(1 / 2)[\exp (i \omega t)+\exp (-i \omega t)]$. Each block contains components in the spatial wave basis $\left|\varphi_{\alpha}\right\rangle,\left|\varphi_{\beta}\right\rangle, \ldots$, which are the eigenvectors of the time-independent term $A$.

If the wave functions are written in Floquet form and the boundary conditions are accounted for, the system is well-defined; an infinite system of linear equations has to be solved which can be realized practically by keeping only a finite number $(2 N+1)$ of the harmonic components. The integer number $N$ is usually determined by the prescribed precision of the calculation: it can be arbitrarily refined by taking more harmonic components into account. 


\section{CHAPTER 2}

\section{Gordon-Volkov states}

In this chapter, we review the semiclassical description of an electron interacting with an external field [8]. We consider a field with a wavelength much larger than an actual atomic system. Although, as we shall see, the time dependence of the field can be arbitrary, in our results to be presented in Chapter 4 and 5, we restrict ourselves to consider only sinusoidally oscillating light waves.

\subsection{Electromagnetic gauges}

As is known in classical electrodynamics [11], the Lorentz force acts on moving charged particles. The Lagrangian of a particle with charge $q$ moving with the velocity of $\mathbf{v}=\dot{\mathbf{r}}$ in an electromagnetic field described by the scalar and vector potentials $\phi(\mathbf{r}, t)$ and $\mathbf{A}(\mathbf{r}, t)$ reads

$$
L=\frac{1}{2} m \dot{\mathbf{r}}^{2}+q \dot{\mathbf{r}} \cdot \mathbf{A}(\mathbf{r}, t)-q \phi(\mathbf{r}, t)
$$

where the potentials have the usual connections to the field quantities, that is:

$$
\mathbf{E}=-\frac{\partial \mathbf{A}}{\partial t}-\nabla \Phi, \quad \mathbf{B}=\nabla \times \mathbf{A}
$$

Introducing the canonical momentum $\mathbf{p}=\partial L / \partial \dot{\mathbf{r}}$, the Hamiltonian function is constructed by the usual Legendre transformation which results in

$$
H=\frac{1}{2 m}[\mathbf{p}-q \mathbf{A}(\mathbf{r}, t)]^{2}+q \phi(\mathbf{r}, t) .
$$

For a quantum mechanical description, let us consider the Hamiltonian operator as the quantized version of the classical Hamiltonian (2.3). That is,

$$
\hat{H}=\frac{1}{2 m}[\hat{\mathbf{P}}-q \mathbf{A}(\hat{\mathbf{R}}, t)]^{2}+q \phi(\hat{\mathbf{R}}, t) .
$$


Note that, unlike in the formalism of quantum electrodynamics, the field quantities themselves are not operators. They are real, differentiable functions which can depend on spatial coordinates and time. The framework with these assumptions is said to be the semiclassical description of the light-matter interaction.

Let us assume that the wave function $\Psi$ is the solution of the time-dependent Schrödinger equation $i \hbar(\partial \Psi / \partial t)=\hat{H} \Psi$ with the Hamiltonian defined by Eq. (2.4) . We can also define another wave function $\Psi^{\prime}$ with a gauge transformation of the first kind 1 as the following:

$$
\Psi^{\prime}=\exp \left[\frac{i q}{\hbar} \chi(\mathbf{r}, t)\right] \Psi
$$

where the generating function $\chi(\mathbf{r}, t)$ is a real, differentiable function of $\mathbf{r}$ and $t$. We can rewrite the Schrödinger equation by expressing $\Psi$ from Eq. (2.5), so the "primed" Schrödinger equation is given by

$$
i \hbar \frac{\partial \Psi^{\prime}}{\partial t}=\left\{\frac{1}{2 m}[\mathbf{p}-q(\mathbf{A}+\nabla \chi)]^{2}+q\left(\phi-\frac{\partial \chi}{\partial t}\right)\right\} \Psi^{\prime}
$$

where we can immediately see that if we introduce the "primed" electromagnetic potentials 2

$$
\mathbf{A}^{\prime}=\mathbf{A}+\nabla \chi, \quad \phi^{\prime}=\phi-\frac{\partial \chi}{\partial t},
$$

the form of the Schrödinger equation is unchanged. [For comparison, see the original Hamiltonian (2.4)]. The gauge transformation of the first kind [given by Eq. (2.5)] is a particular case of a unitary transformation, thus, measurable quantities calculated in different gauges must be the same. Of course, both the pairs $(\mathbf{A}, \phi)$ and $\left(\mathbf{A}^{\prime}, \phi^{\prime}\right)$ lead exactly to the same electric and magnetic fields.

\subsection{Gauges in dipole approximation}

Now, more specifically, let us focus on the quantum mechanical formalism describing light-matter interaction. First, let us expand the Hamiltonian operator (2.4) in spatial coordinate basis as follows:

$$
\hat{H}=-\frac{\hbar^{2}}{2 m} \nabla^{2}+i \hbar \frac{q}{2 m}(\mathbf{A} \cdot \nabla+\nabla \cdot \mathbf{A})+\frac{q^{2}}{2 m} \mathbf{A}^{2}+q \phi
$$

where we used the momentum operator $\hat{\mathbf{P}}=-i \hbar \nabla$. Because of the gauge transformations (2.7), we can impose a special condition, the so-called Coulomb (or trans-

\footnotetext{
${ }^{1}$ Here, we use Pauli's terminology of the gauge transformations, see Ref. [12].

${ }^{2}$ This is called the gauge transformation of the second kind.
} 
verse) gauge on the vector potential $\mathbf{A}$, which reads

$$
\nabla \cdot \mathbf{A}=0
$$

It is convenient to use this condition in the absence of charges or currents as sources of the electromagnetic field. Applying Eq. (2.9) to the Hamiltonian (2.8), it is readily seen that the time-dependent Schrödinger equation reads

$$
i \hbar \frac{\partial \Psi(\mathbf{r}, t)}{\partial t}=\left(-\frac{\hbar^{2}}{2 m} \nabla^{2}+i \hbar \frac{q}{2 m} \mathbf{A} \cdot \nabla+\frac{q^{2}}{2 m} \mathbf{A}^{2}+q \phi\right) \Psi(\mathbf{r}, t) .
$$

Note that for weak fields, the term proportional to $\mathbf{A}^{2}$ may be omitted since its contribution to the exact solution is negligible.

Apart from the XUV domain and higher frequencies, the wavelength of the optical fields is much larger than the typical size of an atom. That is, electromagnetic radiation in the optical region $(\lambda \sim 1 \mu \mathrm{m})$ can be considered homogeneous for an atomic system, i.e., the spatial dependence of the field quantities can be omitted. This reduction is called dipole approximation, because in this case, the light-induced transitions can be simply characterized by the matrix elements of the transition dipole moment. In the following, only individual elementary particles (such as electrons) are considered instead of entire atomic systems in the presence of an external field. Therefore, we continue our description considering the charged particle to be a free electron of charge $q=-e$.

Using the dipole approximation in the Hamiltonian (2.10) can lead to an additional simplification. Since the gradient of the scalar potential $\phi=\phi(t)$ always vanishes, we can choose its value to be zero. Additionally, let us perform a gauge transformation of the first kind

$$
\Psi=\exp \left[-\frac{i}{\hbar} \frac{e^{2}}{2 m} \int_{t_{0}}^{t} \mathbf{A}^{2}(\tau) \mathrm{d} \tau\right] \Psi^{v g} .
$$

The resulting time-dependent Schrödinger equation is in the so-called velocity gauge

$$
i \hbar \frac{\partial \Psi^{v g}}{\partial t}=\left[\frac{\hat{\mathbf{P}}^{2}}{2 m}+\frac{e}{m} \mathbf{A}(t) \cdot \hat{\mathbf{P}}\right] \Psi^{v g} .
$$

Here, the second term in the Hamiltonian couples the vector potential $\mathbf{A}(t)$ to the velocity operator $\hat{\mathbf{P}} / m$. Note that Eq. (2.12) is valid no matter how intense the external field is.

Another common form of the time-dependent Schrödinger equation in the dipole approximation can be achieved using a gauge transformation of the first kind by 
taking the generating function $\chi(\mathbf{r}, t)=-\mathbf{r} \cdot \mathbf{A}(t)$, that is

$$
\Psi^{l g}=\exp \left[-\frac{i e}{\hbar} \mathbf{A}(t) \cdot \mathbf{r}\right] \Psi^{v g}
$$

From Eq. (2.7) we can immediately recognize that the vector potential $\mathbf{A}^{\prime}$ is eliminated in exchange for the appearance of a non-zero scalar potential $\phi^{\prime}=-\mathbf{E} \cdot \mathbf{r}$. Therefore, the new time-dependent Schrödinger equation in the so-called length gauge reads

$$
i \hbar \frac{\partial \Psi^{l g}}{\partial t}=\left[\frac{\hat{\mathbf{P}}^{2}}{2 m}+e \mathbf{E}(t) \cdot \hat{\mathbf{R}}\right] \Psi^{l g} .
$$

Here, the electric field $\mathbf{E}(t)$ is coupled to the position operator $\hat{\mathbf{R}}$. The electric dipole moment operator $\hat{\mathbf{D}}=-e \hat{\mathbf{R}}$ appears in the second term of the Hamiltonian [13]. This is the reason why the approximation, in which the electromagnetic field is considered to be homogeneous, is called the dipole approximation.

Let us add a final remark in this section concerning the velocity and length gauges. The Hamiltonian in the length gauge can also be obtained through classical considerations. As is known, two Lagrangians describing the same system can differ by the total derivative of an arbitrary differentiable function [14]. (It can be verified that both Lagrangians will always lead to the exact same equations of motion.) Subtracting the total derivative $e[\mathrm{~d}(\mathbf{r} \cdot \mathbf{A}) / \mathrm{d} t]=e \dot{\mathbf{r}} \cdot \mathbf{A}+\mathbf{r} \cdot(\mathrm{d} \mathbf{A} / \mathrm{d} t)$ from the Lagrangian (2.1) yields

$$
L^{\prime}=\frac{1}{2} m \dot{\mathbf{r}}^{2}+e \mathbf{r} \frac{\mathrm{d} \mathbf{A}}{\mathrm{d} t}+e \phi .
$$

Furthermore, the corresponding Hamiltonian reads

$$
\widetilde{H}=\frac{\widetilde{\mathbf{p}}^{2}}{2 m}+e \mathbf{r} \cdot \mathbf{E}(t)+e \phi
$$

where we assumed that the total derivative of the vector potential can be replaced by the partial derivative, i.e., $\mathrm{d} \mathbf{A} / \mathrm{d} t \approx \partial \mathbf{A} / \partial t$ according to the dipole approximation. The second term in (2.16) is the dipole energy, where the electric field $\mathbf{E}$ appears in its usual form. However, we have already used dipole approximation, thus the gradient of the scalar potential $\phi$ is zero. In the Hamiltonian (2.16), the canonical momentum equals to the kinetic momentum of the particle unlike in Eq. (2.3), where the canonical momentum $\mathbf{p}=m \dot{\mathbf{r}}+e \mathbf{A}(t)$. Finally, let us emphasize that as long as the physical system is treated exactly, both gauges are equivalent, otherwise e.g., taking the external field into account as a perturbation, the final results using different gauges could be entirely different [15, 16]. 


\subsection{Gordon-Volkov states in dipole approximation}

In this section, we give an exact solution to the time-dependent Schrödinger equation describing a free electron in an external field. Using dipole approximation, we recall the time-dependent Schrödinger equation in the velocity gauge [Eq. (2.12)]:

$$
i \hbar \frac{\partial \Psi^{v g}}{\partial t}=\left[\frac{\hat{\mathbf{P}}^{2}}{2 m}+\frac{e}{m} \mathbf{A}(t) \cdot \hat{\mathbf{P}}\right] \Psi^{v g} .
$$

Since the external field depends only on time and $\exp [(i / \hbar) \mathbf{p} \cdot \mathbf{r}]$ is an eigenfunction of the momentum operator $\hat{\mathbf{P}}$ corresponding to the eigenvalue $\mathbf{p}$ (where $\mathbf{p}$ is the momentum of the de Broglie electron wave), we can seek the solution as a modulated plane wave

$$
\Psi_{p}^{V}(\mathbf{r}, t)=\frac{1}{(2 \pi \hbar)^{3 / 2}} \exp \left(\frac{i}{\hbar} \mathbf{p} \cdot \mathbf{r}\right) f_{p}(t)
$$

where $f_{p}(t)$ is a function which depends only on time. Substituting Eq. (2.18) into Eq. (2.17), we obtain the following first order differential equation for the function $f_{p}(t)$

$$
i \hbar \frac{\mathrm{d} f_{p}(t)}{\mathrm{d} t}=\left[\frac{p^{2}}{2 m}+\frac{e}{m} \mathbf{p} \cdot \mathbf{A}(t)\right] f_{p}(t),
$$

which is readily solved by integration:

$$
f_{p}(t)=\exp \left[-\frac{i}{\hbar}\left(\frac{p^{2}}{2 m} t+\frac{e}{m} \int_{t_{0}}^{t} \mathbf{A}\left(t^{\prime}\right) \mathrm{d} t^{\prime}\right)\right] .
$$

Substituting Eq. (2.20) into the ansatz (2.18), the so-called Gordon-Volkov [17, 18] (or sometimes simply Volkov) wave function reads

$$
\Psi_{p}^{V}(\mathbf{r}, t)=\frac{1}{(2 \pi \hbar)^{3 / 2}} \exp \left\{\frac{i}{\hbar} \mathbf{p} \cdot[\mathbf{r}-\boldsymbol{\alpha}(t)]-\frac{i}{\hbar} E t\right\}
$$

where $E=p^{2} /(2 m)$ is the electron energy, and we introduced

$$
\boldsymbol{\alpha}(t)=\frac{e}{m} \int_{t_{0}}^{t} \mathbf{A}\left(t^{\prime}\right) \mathrm{d} t^{\prime}
$$

which is a vector corresponding to the displacement of a classical electron from its oscillation center in the electric field.

It is also possible to apply the unitary transformation

$$
\Psi_{p}^{K H}=\exp \left[-\frac{i}{\hbar} \boldsymbol{\alpha}(t) \cdot \mathbf{p}\right] \Psi_{p}^{V}
$$


to Eq. (2.17), which is called Kramers-Henneberger transformation [19, 20]. It corresponds to a spatial translation characterized by the vector $\boldsymbol{\alpha}(t)$. The new frame (Kramers-Henneberger frame) moves with respect to the laboratory frame in the same way as a classical electron oscillates in the electric field. In the KramersHenneberger frame, the Volkov wave function is a plane wave given by

$$
\Psi_{p}^{K H}(\mathbf{r}, t)=\frac{1}{(2 \pi \hbar)^{3 / 2}} \exp \left[\frac{i}{\hbar}(\mathbf{p} \cdot \mathbf{r}-E t)\right]
$$

Additionally, the Volkov solution of the original Schrödinger equation (2.10) can be written by applying the unitary transformation (2.11) to the Volkov state (2.21) as follows

$$
\Psi_{p}^{V}(\mathbf{r}, t)=\frac{1}{(2 \pi \hbar)^{3 / 2}} \exp \left\{\frac{i}{\hbar} \mathbf{p} \cdot[\mathbf{r}-\boldsymbol{\alpha}(t)]-\frac{i}{\hbar} E t-\frac{i}{\hbar} \frac{e^{2}}{2 m} \int_{t_{0}}^{t} \mathbf{A}^{2}(\tau) \mathrm{d} \tau\right\}
$$

Sometimes only the compact form

$$
\Psi_{p}^{V}(\mathbf{r}, t)=\frac{1}{(2 \pi \hbar)^{3 / 2}} \exp \left(\frac{i}{\hbar} \mathbf{p} \cdot \mathbf{r}\right) \exp \left\{-\frac{i}{\hbar} \int_{t_{0}}^{t} \frac{1}{2 m}\left[\mathbf{p}+e \mathbf{A}^{2}(\tau)\right]^{2} \mathrm{~d} \tau\right\}
$$

is used in the literature for the sake of brevity, where the second exponential expression is the modulator function $f_{p}(t)$ appearing in Eq. (2.18), which is also called the Volkov phase.

Finally, based on Refs. [17, 18, 21 23], we add a few remarks regarding the Volkov states. They form a complete set and they are orthogonal, where the normalization condition is similar to the case of plane waves, i.e., they are normalized to the Dirac delta function:

$$
\int \Psi_{p^{\prime}}^{V *}(\mathbf{r}, t) \Psi_{p}^{V}(\mathbf{r}, t) \mathrm{d}^{3} r=\delta_{3}\left(\mathbf{p}-\mathbf{p}^{\prime}\right)
$$

Relativistic description of light-matter interaction can be obtained through a similar procedure: Volkov solutions also exist for the Klein-Gordon or the Dirac equation [17, 18]. Recently, after many decades, these relativistic Volkov states were proved to be orthogonal and they form a complete set as well [21 23]. 


\section{CHAPTER 3}

\section{The Dirac equation}

A wide range of phenomena in physics cannot be correctly and thoroughly accounted for without connecting special relativity and quantum mechanics. The fine structure of the spectral lines of a hydrogen atom is one of the remarkable examples, where these two theories should proceed together since it could not be explained exactly by solving the Schrödinger equation. Attempting to fit the relativistic covariance into a correct quantum mechanical equation was one of the hot research topics in theoretical physics during the 1920s.

The relativistic covariant wave equation describing an electron was found by P. A. M. Dirac in 1928. He was not satisfied with the earlier attempts of Klein, Gordon, Fock, and Kudar to construct a relativistic theory as it could result in a negative probability density for the position of the electron. Dirac was also able to reproduce the results of Pauli's spin model by assuming that the electron is a point charge which should be described by a relativistic wave equation. As we can see it from a period of many decades, the Dirac equation has been proven to be the proper single particle quantum mechanical wave equation of all spin- $\frac{1}{2}$ massive particles such as electrons.

As an introduction to our results to be presented in Chapter 6, we briefly review the solution of the Dirac equation for a free electron and for the case where the electron is scattered on a constant potential barrier.

\subsection{Dirac equation of a free particle}

Neglecting any external potential, i.e., considering a free electron of mass $m$, the time-dependent Dirac equation reads as follows [24]:

$$
\hat{H}_{D} \Psi(\mathbf{r}, t)=i \hbar \frac{\partial \Psi(\mathbf{r}, t)}{\partial t}
$$


with the Dirac Hamiltonian

$$
\hat{H}_{D}=c \sum_{k=1}^{3} \alpha_{k} \hat{p}_{k}+\beta m c^{2}
$$

where $\hat{p}_{k}$ are the Cartesian components of the momentum operator. The Dirac matrices $\alpha_{k}$ and $\beta$ are Hermitian and satisfy the following relations:

$$
\left[\alpha_{k}, \alpha_{l}\right]^{+}=2 \delta_{k l} \mathbb{1}, \quad\left[\alpha_{k}, \beta\right]^{+}=0, \quad \alpha_{k}^{2}=\beta^{2}=\mathbb{1},
$$

where $[., .]^{+}$denotes the anticommutator. These conditions imply that the dimension of these $N \times N$ square matrices must be even [25]. Moreover, the possible smallest value of $N$ is 4 . Therefore, the spinor valued wave function (also called Dirac spinor or bispinor) $\Psi$ must be a four-component vector as well 1 One of the possible explicit representations for the matrices above is the standard (Dirac) representation, which reads

$$
\alpha_{k}=\left(\begin{array}{cc}
0 & \sigma_{k} \\
\sigma_{k} & 0
\end{array}\right), \quad \beta=\left(\begin{array}{cc}
\mathbb{1} & 0 \\
0 & -\mathbb{1}
\end{array}\right),
$$

where the usual Pauli matrices $\sigma_{k}(k=1,2,3)$ appear. Other representations (e.g. Weyl or Majorana) of the algebra associated with the Dirac equation are unitarily equivalent [26].

Now, let us focus on solving the free Dirac equation. We make a plane wave ansatz

$$
\Psi(\mathbf{r}, t)=u \exp [i(\mathbf{p} \cdot \mathbf{r}-E t)]
$$

since the Dirac equation is a first order linear differential equation with only constant coefficients. As it can be shown, the quantities

$$
E_{ \pm}= \pm \sqrt{\mathbf{p}^{2} c^{2}+m^{2} c^{4}}
$$

are the two (doubly degenerated) energy eigenvalues of the Dirac Hamiltonian (3.2) which appear in the time evolution. The four-component eigenspinors read

$$
u_{1}^{+}=N\left(\begin{array}{c}
\chi^{\uparrow} \\
\frac{c \boldsymbol{\sigma} \cdot \mathbf{p}}{E_{+}+m c^{2}} \chi^{\uparrow}
\end{array}\right), \quad u_{2}^{+}=N\left(\begin{array}{c}
\chi^{\downarrow} \\
\frac{c \boldsymbol{\sigma} \cdot \mathbf{p}}{E_{+}+m c^{2}} \chi^{\downarrow}
\end{array}\right)
$$

and

$$
u_{1}^{-}=N\left(\begin{array}{c}
-\frac{c \boldsymbol{\sigma} \cdot \mathbf{p}}{-E_{-}+m c^{2}} \chi^{\uparrow} \\
\chi^{\uparrow}
\end{array}\right), \quad u_{2}^{-}=N\left(\begin{array}{c}
-\frac{c \boldsymbol{\sigma} \cdot \mathbf{p}}{-E_{-}+m c^{2}} \chi^{\downarrow} \\
\chi^{\downarrow}
\end{array}\right) .
$$

\footnotetext{
${ }^{1}$ Note that this is not a four-vector in the relativistic sense.
} 


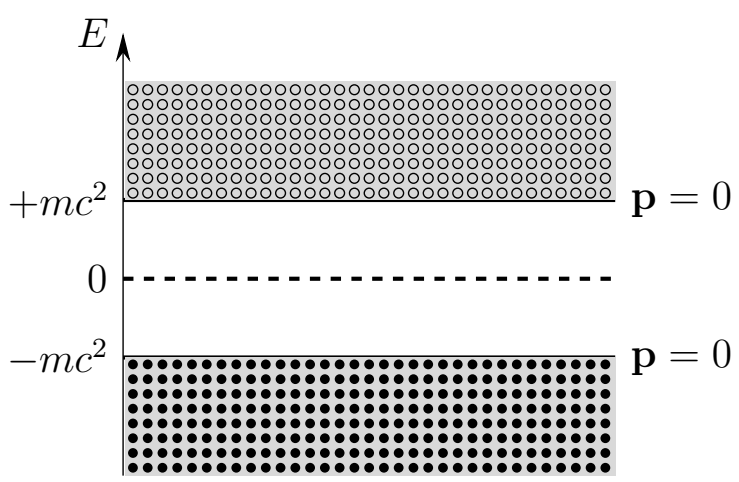

Figure 3.1: Schematic layout of the eigenvalues of the free Dirac equation. The black filled circles represent the occupied negative energy states with $E<m c^{2}$ which form the "Dirac sea". The hollow circles are states with positive energies.

Equations (3.7) and (3.8) are the eigenfunctions associated with the positive and negative eigenenergies, respectively. $\chi^{\uparrow}=(1,0)$ and $\chi^{\downarrow}=(0,1)$ are the two basic two-component spinors. The normalization constant $N$ can be explicitly given by

$$
N=\sqrt{\frac{E_{+}+m c^{2}}{2 E_{+}}},
$$

with the condition $u^{\dagger} u=1$, where the dagger denotes the conjugate transpose.

Beside the energy $\left(E_{+}\right)$of a relativistic particle, the opposite of it $\left(E_{-}\right)$also becomes one of the eigenenergies. According to the usual interpretation, these negative energy states with $E<m c^{2}$ are all occupied by electrons and form the so-called Dirac sea, see Fig. 3.1. Because of the Pauli exclusion principle (stating that two identical fermions cannot be in the same quantum state), this also prevents an electron losing energy and dropping into the negative energy states.

\subsection{Solution for a constant potential barrier}

In this section, we calculate the spectrum of eigenvalues for Dirac particles in a one-dimensional potential barrier 2 of height $V_{0}$ and width $a$. For that purpose, we divide e.g., the $z$ axis into three domains I, II and III as sketched in Fig. 3.2, so that the Dirac spinors depend only on $z$. The one-dimensional time-independent Dirac equation in the three regions reads

$$
\begin{aligned}
& \left(c \alpha_{3} \hat{p}_{3}+\beta m c^{2}\right) \psi(z)=E \psi(z), \quad \text { for }|z| \geq a / 2, \\
& \left(c \alpha_{3} \hat{p}_{3}+\beta m c^{2}+V_{0}\right) \psi(z)=E \psi(z), \quad \text { for }|z| \leq a / 2 .
\end{aligned}
$$

\footnotetext{
${ }^{2}$ In his book [25], W. Greiner presented the solutions for a constant rectangular potential well instead of a barrier.
} 


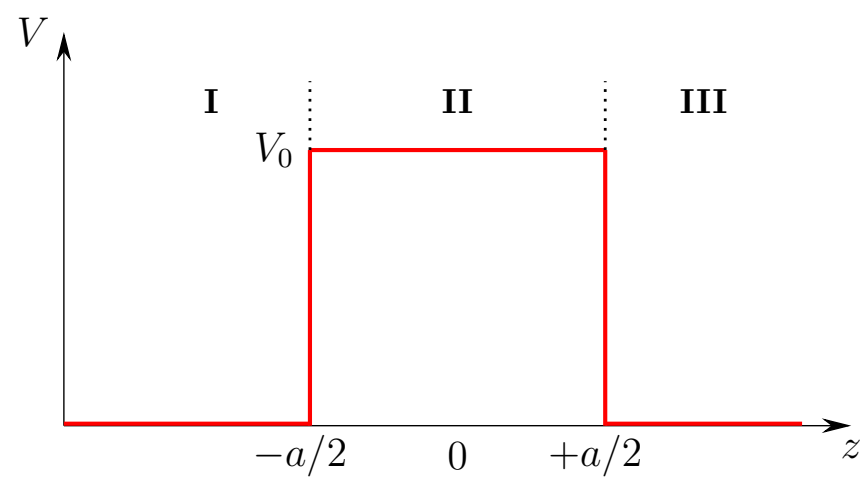

Figure 3.2: One-dimensional square potential barrier with constant height $V=V_{0}$ localized between $z=-a / 2$ and $z=+a / 2$.

In region II, a constant potential of magnitude $V_{0}$ is added to the free Hamiltonian in Eq. (3.10b).

Since by assumption no spin-flip occurs at the boundary of the barrier, we can restrict our discussion to solutions with e.g., spin up electrons. The energies of the solutions can take all allowed values from $-\infty$ up to $+\infty$. We seek the solutions of the Dirac equations (3.10a ) and (3.10b) as right and left propagating plane waves. Thus, they are given by

$$
\begin{aligned}
& \psi_{\mathrm{I}}(z)=A e^{i p z / \hbar}\left(\begin{array}{c}
1 \\
0 \\
\frac{p c}{E+m c^{2}} \\
0
\end{array}\right)+A^{\prime} e^{-i p z / \hbar}\left(\begin{array}{c}
1 \\
0 \\
\frac{-p c}{E+m c^{2}} \\
0
\end{array}\right) \\
& \psi_{\mathrm{II}}(z)=B e^{i q z / \hbar}\left(\begin{array}{c}
1 \\
0 \\
\frac{q c}{E-V_{0}+m c^{2}} \\
0
\end{array}\right)+B^{\prime} e^{-i q z / \hbar}\left(\begin{array}{c}
1 \\
0 \\
\frac{-q c}{E-V_{0}+m c^{2}} \\
0
\end{array}\right) \text {, } \\
& \psi_{\mathrm{III}}(z)=C e^{i p z / \hbar}\left(\begin{array}{c}
1 \\
0 \\
\frac{p c}{E+m c^{2}} \\
0
\end{array}\right)+C^{\prime} e^{-i p z / \hbar}\left(\begin{array}{c}
1 \\
0 \\
\frac{-p c}{E+m c^{2}} \\
0
\end{array}\right) \text {, }
\end{aligned}
$$

with dispersion relations $p^{2}=E^{2} / c^{2}-m^{2} c^{2}$ and $q^{2}=\left(E-V_{0}\right)^{2} / c^{2}-m^{2} c^{2}$. At the borders of the barrier, the wave functions must be continuous. This requirement stems from the continuity equation. Therefore, we get the following condition at 
the two boundaries of the potential barrier:

$$
\psi_{\mathrm{I}}\left(-\frac{a}{2}\right)=\psi_{\mathrm{II}}\left(-\frac{a}{2}\right), \quad \psi_{\mathrm{II}}\left(+\frac{a}{2}\right)=\psi_{\mathrm{III}}\left(+\frac{a}{2}\right) .
$$

Defining the parameter

$$
\xi=\frac{p c}{E+m c^{2}} \frac{E-V_{0}+m c^{2}}{q c}=\sqrt{\frac{\left(E-m c^{2}\right)\left(E-V_{0}+m c^{2}\right)}{\left(E+m c^{2}\right)\left(E-V_{0}-m c^{2}\right)}},
$$

we can write the fitting equations in the following matrix form

$$
\begin{aligned}
& \left(\begin{array}{c}
A \\
A^{\prime}
\end{array}\right)=\frac{1}{2}\left(\begin{array}{cc}
\frac{\xi+1}{\xi} e^{i(p-q) a / 2 \hbar} & \frac{\xi-1}{\xi} e^{i(p+q) a / 2 \hbar} \\
\frac{\xi-1}{\xi} e^{-i(p+q) a / 2 \hbar} & \frac{\xi+1}{\xi} e^{i(q-p) a / 2 \hbar}
\end{array}\right)\left(\begin{array}{c}
B \\
B^{\prime}
\end{array}\right), \\
& \left(\begin{array}{c}
B \\
B^{\prime}
\end{array}\right)=\frac{1}{2}\left(\begin{array}{ll}
(1+\xi) e^{i(p-q) a / 2 \hbar} & (1-\xi) e^{-i(p+q) a / 2 \hbar} \\
(1-\xi) e^{i(p+q) a / 2 \hbar} & (1+\xi) e^{-i(p-q) a / 2 \hbar}
\end{array}\right)\left(\begin{array}{c}
C \\
C^{\prime}
\end{array}\right),
\end{aligned}
$$

and by inserting Eq. (3.14b) into Eq. (3.14a) we can eliminate $B$ and $B^{\prime}$. Thus, we have two equations with four unknown coefficients $A, A^{\prime}, C, C^{\prime}$.

Depending on the value of $E$, we can distinguish two cases:

- $|E|<m c^{2}$, i.e. $p$ is imaginary, or

- $|E|>m c^{2}$, i.e. $p$ is real.

\subsubsection{Bound states}

First, we consider the case where $p$ is imaginary and assume that $\operatorname{Im} p=\kappa>0$. These solutions are generally called bound states. Equations (3.14a and (3.14b) are significantly simplified since the coefficients $A$ and $C^{\prime}$ have to vanish, so that $\psi_{\mathrm{I}}$ and $\psi_{\text {III }}$ do not increase exponentially; i.e., they have to be normalizable. Thus, the fitting equation reduces to

$$
0=\frac{1}{4 \xi} e^{i p a / \hbar} C\left[(1+\xi)^{2} e^{-i q a / \hbar}-(1-\xi)^{2} e^{i q a / \hbar}\right]
$$

Since $C \neq 0$ (otherwise the whole wave function will be zero), we obtain

$$
\frac{1+\xi}{1-\xi} e^{-i q a / \hbar}=\frac{1-\xi}{1+\xi} e^{i q a / \hbar}
$$




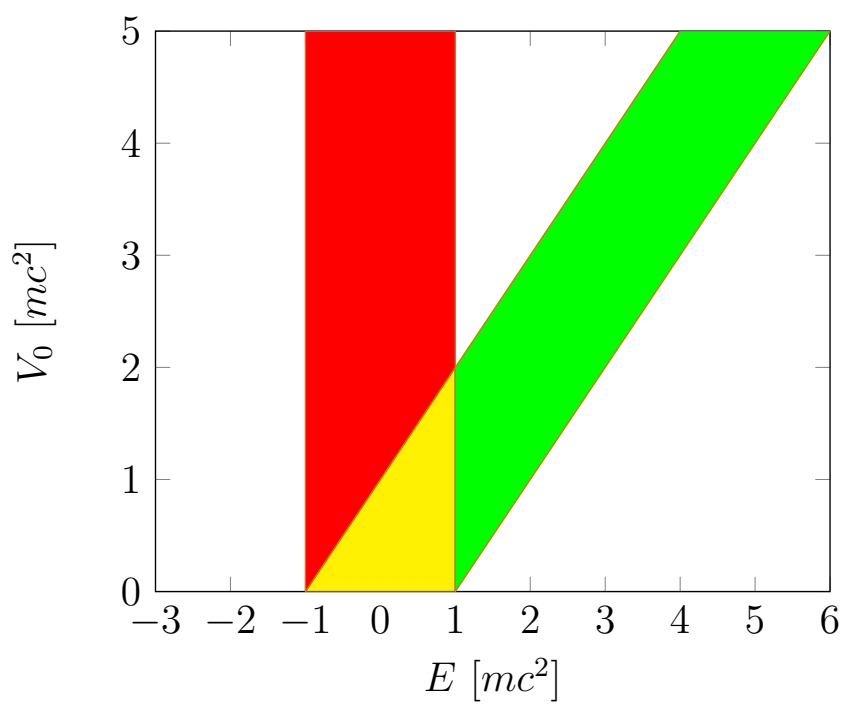

Figure 3.3: Representations of the wave numbers $p$ and $q$ in the $E-V_{0}$ plane. The white regions mean real values. The wave numbers $p$ and $q$ are purely imaginary for values denoted by red and green colors, respectively. The yellow colored area means that both wave numbers are purely imaginary.

As long as $q$ is real, i.e., $E<-m c^{2}+V_{0}$, which is denoted by the red area in Fig. 3.3, $\xi$ is purely imaginary (since $p$ is imaginary). Thus Eq. (3.16) means that

$$
\frac{1+\xi}{1-\xi} e^{-i q a / \hbar}=\left(\frac{1+\xi}{1-\xi} e^{-i q a / \hbar}\right)^{*}
$$

This can also be expressed as

$$
\operatorname{Im}\left(\frac{1+\xi}{1-\xi} e^{-i q a / \hbar}\right)=0 .
$$

Introducing $\Gamma$ as the imaginary part of $\xi$, i.e., $\xi=i \Gamma$ and using Eqs. (3.13) and (3.18), we finally have

$$
c q \cot \left(\frac{q a}{\hbar}\right)=-\frac{E V_{0}}{c \kappa}-\kappa c .
$$

This equation determines the energy eigenvalues of the bound states. One can solve Eq. (3.19) numerically and thus determine the energy spectrum of the bound solutions for various parameters.

Note that Eq. (3.16) has no solution if $q$ is imaginary, i.e., $-m c^{2}+V_{0}<E<m c^{2}$, which is denoted by the yellow area in Fig. 3.3. As we can see from Eq. (3.13), in this case $\xi$ is real and

$$
\frac{(1+\xi)^{2}}{(1-\xi)^{2}} e^{2 \zeta a} \neq 1
$$

where $q=i \zeta$, with $\zeta>0$. 


\subsubsection{Scattering states}

Now, let us consider the scattering states, where the wave vector $p$ is real. Again, depending on the value of $q$, there are several domains:

- $q$ and $\xi$ are real, which can be in three cases: for $E<-m c^{2}$, for $E>m c^{2}+V_{0}$ and for $-m c^{2}+V_{0}<E<m c^{2}+V_{0}$, and they are represented by the white regions in Fig. 3.3 .

- $q$ and $\xi$ are purely imaginary for $-m c^{2}+V_{0}<E<m c^{2}+V_{0}$. This is the green area in Fig. 3.3 .

We will discuss both cases successively. First, we choose one of the coefficients $A, A^{\prime}, C, C^{\prime}$ freely. We assume that from the right hand side no wave enters the potential; thus, $C^{\prime}=0$. $C$ is interpretable as the transmitted part of a wave which arrives from the left with amplitude $A$. The term proportional to $A^{\prime}$ stems from the wave reflected by the potential. The amplitude of the incoming wave can be chosen to be 1 , and for real wave vector $q$, the transmission probability reads

$$
T=|C|^{2}=\left[\cos ^{2}\left(\frac{q a}{\hbar}\right)+\left(\frac{1+\xi^{2}}{2 \xi}\right)^{2} \sin ^{2}\left(\frac{q a}{\hbar}\right)\right]^{-1} .
$$

It can be rewritten in the form

$$
T=\left[1+\left(\frac{1-\xi^{2}}{2 \xi}\right)^{2} \sin ^{2}\left(\frac{q a}{\hbar}\right)\right]^{-1} \leq 1
$$

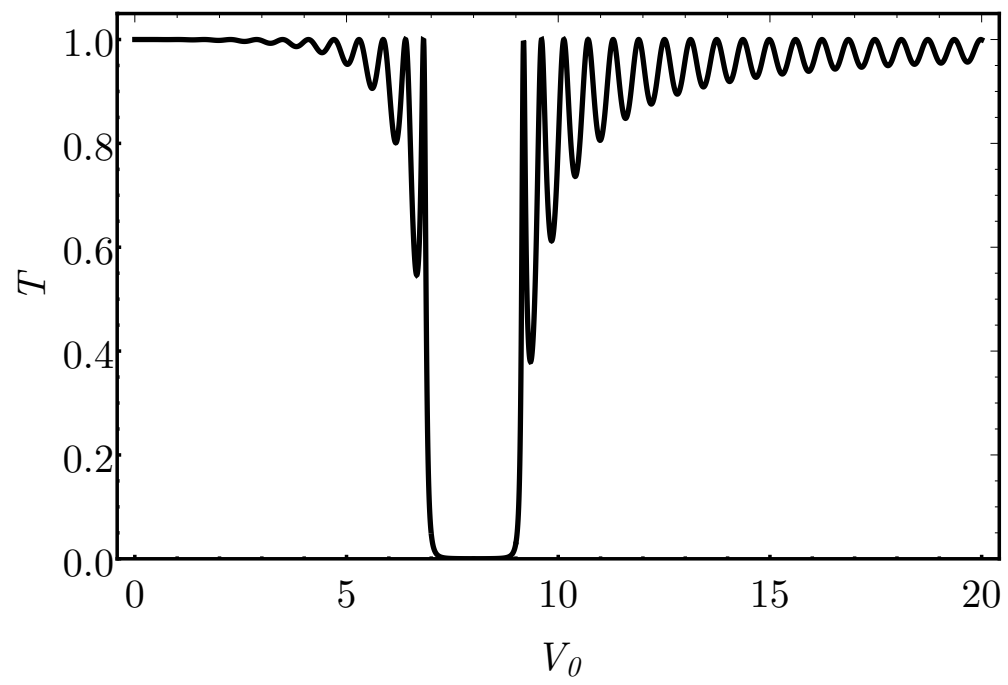

Figure 3.4: Transmission probability $T$ as a function of the barrier height $V_{0}$. For increasing value of $V_{0}$, the transmission probability surprisingly increases as well. 
On the other hand, when $q$ is purely imaginary, the transmission probability is given by

$$
T=\left[1+\left(\frac{1+\Gamma^{2}}{2 \Gamma}\right)^{2} \sinh ^{2}\left(\frac{\zeta a}{\hbar}\right)\right]^{-1} \leq 1
$$

Figure 3.4 shows the transmission probability as the function of $V_{0}$. It clearly shows that for increasing barrier heights the transmission probability increases. Furthermore, in the case of the infinitely high barrier, i.e., $V_{0} \rightarrow \infty$, the transmission probability approaches unity. An extensive discussion of this counterintuitive phenomenon (called Klein paradox [27]) can be found in Refs. [28, 29]. 


\section{Part II}

\section{Time-periodic scattering models}




\section{CHAPTER 4}

\section{Charged particle scattering in a Ramsey-like setup}

In this chapter, we present a scattering model, where a monoenergetic beam of moving charged particles interact with two separated oscillating fields. Time-periodic linear potential is assumed to model the light-particle interaction using a nonrelativistic, semiclassical description based on Gordon-Volkov states. Applying Floquet's theory, we calculate transmission probabilities as a function of the laser field parameters. The transmission resonances in this Ramsey-like setup are interpreted as if they originated from a corresponding static double-potential barrier with heights equal to the ponderomotive potential resulting from the oscillating field. Due to the opening of new Floquet channels, the resonances are repeated at input energies when the corresponding frequency is shifted by an integer multiple of the exiting frequency. These narrow resonances can be used as precise energy filters. The fine structure of the transmission spectra is determined by the phase difference between the two oscillating light fields, allowing for the optical control of the transmission.

\subsection{Introduction}

Optical control of quantum mechanical particles offers a wide variety of promising applications, including ultrafast electronics [32 34], imaging [35, 36], or quantum computation [37, 38]. Among the first phenomena of describing the coupling of free electrons to light was the Kapitza-Dirac effect in the 1930s [39]. In this elastic process, diffraction of electrons is observed in a standing light wave which acts as an effective diffraction grating [40, 41]. Beams of electrons can also be manipulated by optical fields [42, 44 47], while the properties of oscillating plasmonic near-fields can be probed by measuring electron spectra from nanostructures [48, 49]. Recently, photon-induced near-field electron microscopy revealed that the initial kinetic energy

\footnotetext{
${ }^{1}$ See, e.g., Refs. [7, 30, 31], where the scattering of electrons in the presence of an external field is described by Gordon-Volkov states.
} 
distribution of short electron pulses broadens through induced photon sidebands [36, 50].

Interferometry induced by spatially separated electromagnetic fields is a very important tool for the control of quantum mechanical particles (see, e.g., Ref. [51]). Here, we present a theoretical description of a Ramsey-like setup [43], where, instead of being bound to nuclei, free charged particles interact with two separated periodic electric fields in a nonrelativistic framework. In more detail, similarly to Ref. [44], we describe the scattering of a monoenergetic particle wave on two localized optical fields. However, the main focus is on the calculated transmission spectra which are thoroughly investigated. Resonant tunneling is observed which is also known in static scattering problems in the context of nanostructures [52 54]. Let us recall that in the vicinity of metallic nano-particles, the net electromagnetic field can become localized (e.g., in Ref. [55] a diameter of $\sim 10 \mathrm{~nm}$ was reported for the case of a nanoscale tip) and the space dependence of the field can be neglected. Motivated by this, we use dipole approximation (see Chapter 2.2); i.e, we assume that the field has only time dependence.

As a first approach, we create a static scattering model, where we consider a rectangular potential barrier with the height of the ponderomotive potential $U_{p}$. Its transmission spectrum is a good approximation for the time-dependent problem. We also investigate the induced photon sidebands and the space- and time-dependent probability current density.

This chapter is organized as follows. In Secs. 4.2 and 4.3 we describe the theoretical framework with Gordon-Volkov states and derive the wave equations using Floquet's theory. In Sec. 4.4 we show that a static scattering model can be thought as a good approximation for the time-dependent model regarding the transmission spectra. Transmission resonances are analyzed through induced "photon" sidebands and through space- and time-dependent probability current for various parameter ranges. At the end of the chapter, we summarize our findings and draw conclusions.

\subsection{Model}

We consider a one-dimensional nonrelativistic scattering model, where a beam of monoenergetic free charged particles is assumed to interact with two spatially separated linearly polarized time-periodic electric fields (see Fig. 4.11). The direction of the matter wave propagation is chosen to be the $x$ axis, which, for the sake of simplicity, is divided into five regions. In region 1, the potential is zero, the Hamiltonian reads

$$
H_{1}=\frac{p^{2}}{2 m}
$$




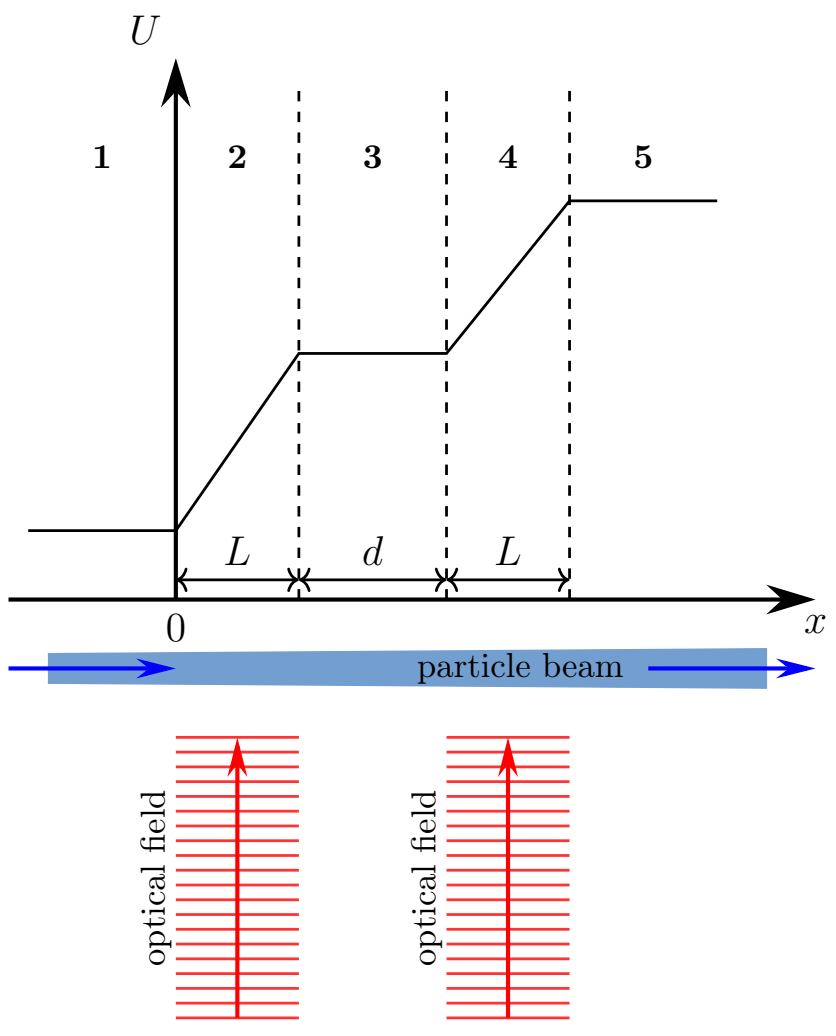

Figure 4.1: Schematic view of the setup we consider. In region 1, we have an incident monoenergetic free particle wave propagating towards the oscillating timedependent potential localized in a finite region with length $L$, inducing reflected and transmitted waves in regions 1 and 5, respectively. In the interaction regions (2 and 4), superpositions of Gordon-Volkov states [see Eq. (4.11)] are present.

where $p=-i \hbar \partial / \partial x$ is the $x$ component of the canonical momentum operator. We assume here an incident plane wave with energy $E_{0}$ and the corresponding momentum $\hbar k_{0}=\sqrt{2 m E_{0}}$ :

$$
\psi_{\text {in }}(x, t)=e^{i k_{0} x-(i / \hbar) E_{0} t}
$$

which is a particular solution of the time-dependent Schrödinger equation generated by $H_{1}$. The charged particles are assumed to interact with the laser field in regions 2 and 4, inducing free reflected and transmitted waves in regions 1 and 5, respectively, and both left and right propagating waves in region 3. In more detail, using dipole approximation and length gauge (see Eq. 2.14), in region 2 we have

$$
H_{2}(x, t)=\frac{p^{2}}{2 m}+e x F(t)
$$

where the external electric field is assumed to have oscillating time dependence: $F(t)=F_{0} \cos (\omega t)$. At the boundary of regions 2 and $3(x=L), F(t)$ becomes zero, 
and, correspondingly, the gradient of the potential also vanishes in region 3. Since the potential has to be continuous, we can write

$$
H_{3}(t)=\frac{p^{2}}{2 m}+e L F(t)=H_{2}(L, t)
$$

Note that the time dependence of the spatially constant potential corresponds to an overall, time-dependent phase factor for any wave function, and we still have free propagation in region 3 . In region 4 , where the second interaction takes place, the potential of the laser field is superimposed on the oscillation of $H_{3}$ :

$$
H_{4}(x, t)=H_{3}(t)+e \tilde{x} \tilde{F}(t)
$$

where $\tilde{x}=x-d-L$, and the electric field has the same amplitude and frequency as in region 2: $\tilde{F}(t)=F_{0} \cos \left(\omega t+\varphi_{0}\right)$. As we shall see later, the phase difference $\varphi_{0}$ (which is zero for the example shown in Fig. 4.1) can be used to control the transmission probability. Finally, the Hamiltonian in region 5 describes free propagation again; $H_{5}$ is spatially constant but oscillates in time, with its potential part being equal to that of $H_{4}$ evaluated at the boundary of regions 4 and 5 .

\subsection{Floquet solutions}

Since we consider time-periodic Hamiltonians, it is plausible to use Floquet's theory, which was introduced in Chapter 1. That is, in all regions, we are seeking solutions of the time-dependent Schrödinger equation in the form

$$
\psi_{j}(x, t)=\exp \left(-\frac{i E_{j} t}{\hbar}\right) \Phi_{j}(x, t)
$$

where $E_{j}$ is the Floquet quasienergy of "band" or "channel" $j$, where the index $j$ is an integer 2 . The Floquet state $\Phi_{j}(x, t)$ is a periodic function: $\Phi_{j}(x, t)=\Phi_{j}(x, t+\tau)$, with a time period of $\tau=2 \pi / \omega$. Since the global Hamiltonian (which can be obtained by applying $H_{1}, \ldots, H_{5}$ in their respective domains, i.e., regions $1, \ldots, 5$ ) is periodic in time, global Floquet-type solutions (that are defined on the whole $x$ axis) of the time-dependent Schrödinger equation exist. Additionally, we can express $\Phi_{j}(x, t)$ as a Fourier series,

$$
\Phi_{j}(x, t)=\sum_{n=-\infty}^{\infty} \chi_{n}^{(j)}(x) e^{-i n \omega t}
$$

where the expansion functions $\chi_{n}^{(j)}(x)$ do not depend on time.

\footnotetext{
${ }^{2}$ In this context, the terms Floquet "channel", "mode", and "(side)band" are synonyms.
} 
Particularly, even in region 1, where the potential is zero, there exist solutions of the Floquet form given by Eq. (4.6). We demonstrate this by taking into account also the corresponding boundary condition for $x<0$. For that region, the physical situation requires one to have a superposition of the incident right propagating free plane wave as given by Eq. (4.2) plus the reflected waves. As one can easily see, one of the Floquet quasienergies $E_{j}$ should be equal to $E_{0}$, the energy of the incoming wave, which is arbitrary. Therefore, the wave function can be written as

$$
\Psi_{1}(x, t)=\psi_{i n}(x, t)+\sum_{n} r_{n} e^{-i k_{n} x} e^{-i \omega_{n} t}
$$

where the wave numbers corresponding to different Floquet quasienergies are defined as follows,

$$
k_{n}=\sqrt{\frac{2 m E_{n}}{\hbar^{2}}}
$$

and $E_{n}=E_{0}+n \hbar \omega$, where $n=(\ldots,-2,-1,0,1,2, \ldots)$. The frequencies appearing in the time evolution are

$$
\omega_{n}=E_{n} / \hbar=E_{0} / \hbar+n \omega .
$$

We note here, that below a certain integer $n$, the wave number $k_{n}$ will be purely imaginary, which describes evanescent waves, with decaying amplitude as $x \rightarrow-\infty$. The Floquet quasienergies (or frequencies) with different integers $n$ serve as a plane wave basis set of the wave functions. In the following, we construct the solutions of all the other regions using this basis set.

The fundamental solutions of the time-dependent Schrödinger equation with the Hamiltonian given by Eq. (4.3) are the previously introduced Gordon-Volkov states in the length gauge 3 :

$$
\psi_{q, \varphi_{0}}^{V}(x, t)=e^{-i\left[\alpha \sin 2\left(\omega t+\varphi_{0}\right)-\beta(q) \cos \left(\omega t+\varphi_{0}\right)+\gamma x \sin \left(\omega t+\varphi_{0}\right)\right]} e^{i[q x-\varepsilon(q) t / \hbar]} .
$$

Here, we have used notations similar to those used in Ref. [31]:

$$
\mathcal{E}(q)=\frac{\hbar^{2} q^{2}}{2 m}+U_{p}, \quad U_{p}=\frac{e^{2} F_{0}^{2}}{4 m \omega^{2}}
$$

and

$$
\alpha=-\frac{U_{p}}{2 \hbar \omega}, \quad \beta(q)=-\frac{e q F_{0}}{m \omega^{2}}, \quad \gamma=\frac{e F_{0}}{\hbar \omega} .
$$

The ponderomotive potential $U_{p}$ is the classical cycle-averaged energy of the free charged particle in a sinusoidal oscillating electric field. According to Eq. (4.12), the

\footnotetext{
${ }^{3}$ In order to obtain the Volkov state in the length gauge, one can apply the unitary transformation (2.13) to the expression of the Volkov state given by Eq. (2.26).
} 
wave number $q$ is related to $\mathscr{E}(q)$ through the dispersion relation

$$
q=\sqrt{\frac{2 m\left(\mathcal{E}-U_{p}\right)}{\hbar^{2}}}
$$

and each $\mathscr{E}(q)$ is doubly degenerate due to the two possible propagation directions.

In region 2 , the wave function for a given energy reads

$$
\psi_{2}(x, t)=a \psi_{q, 0}^{V}(x, t)+b \psi_{-q, 0}^{V}(x, t)
$$

where the initial phase $\varphi_{0}$ is set to zero. More generally, we can write

$$
\Psi_{2}(x, t)=\sum_{n}\left[a_{n} \psi_{q_{n}, 0}^{V}(x, t)+b_{n} \psi_{-q_{n}, 0}^{V}(x, t)\right]
$$

where $a_{n}$ and $b_{n}$ denote the coefficients of right (or decaying) and left propagating (or rising) wave modes, respectively. The wave number $q_{n}$ is defined in the same way as $k_{n}$ in Eq. (4.9). In order to achieve the Fourier series form (4.7), we use the Jacobi-Anger identities

$$
\begin{aligned}
e^{i x \sin \theta} & =\sum_{s=-\infty}^{\infty} J_{s}(x) e^{i s \theta}, \\
e^{i x \cos \theta} & =\sum_{s=-\infty}^{\infty} i^{s} J_{s}(x) e^{i s \theta},
\end{aligned}
$$

where $J_{s}$ denotes the Bessel function of the first kind [56]. As a result, the wave function in region 2 reads

$$
\begin{aligned}
\Psi_{2}(x, t)= & \sum_{n, p, s} J_{s}(\alpha) i^{2 s-n+p}\left\{a_{p} J_{2 s-n+p}\left[\beta\left(q_{p}\right)\right] e^{i q_{p} x}+\right. \\
& \left.+b_{p} J_{2 s-n+p}\left[\beta\left(-q_{p}\right)\right] e^{-i q_{p} x}\right\} e^{-i \gamma x \sin \omega t} e^{-i n \omega t} .
\end{aligned}
$$

We note that the factor $\exp [-i \gamma x \sin (\omega t)]$ can also be expanded using the JacobiAnger formulas leading to one more summation index in Eq. (4.19). However, since in the fitting equations this factor is always 1 or canceled out, we omit the expansion for the sake of brevity.

After the first interaction region, the particle is in region 3, outside the influence of the laser field. It propagates further in this intermediate zone with an altered energy due to the effect of the electric field in region 2. This corresponds to a timeperiodic oscillating rectangular potential (see, e.g. Ref. [57]). Since the commutator $\left[H_{3}(t), H_{3}\left(t^{\prime}\right)\right]=0$, the solution of the time-dependent Schrödinger equation with the Hamiltonian (4.4) can be constructed by direct time-domain integration. Considering the double degeneracy of the wave numbers, as well as the desirable Floquet 
form, the total wave function in region 3 reads

$$
\Psi_{3}(x, t)=\sum_{n}\left(u_{n} e^{i k_{n} x}+v_{n} e^{-i k_{n} x}\right) e^{-i \gamma L \sin \omega t} e^{-i n \omega t} .
$$

Describing the second interaction of the particle wave with the electric field (in region 4 ) is very similar to the first one in region 2 . We obtain

$$
\Psi_{4}(x, t)=\sum_{n}\left[c_{n} \psi_{q_{n}, \varphi_{0}}^{V}(x, t)+d_{n} \psi_{-q_{n}, \varphi_{0}}^{V}(x, t)\right] e^{-i \gamma L \sin \omega t}
$$

where $c_{n}$ and $d_{n}$ correspond to right and left propagating modes, respectively. Using the Jacobi-Anger identities again, we can transform the wave function into the Floquet form

$$
\begin{aligned}
\Psi_{4}(x, t)= & \sum_{n, p, s} J_{s}(\alpha) i^{2 s-n+p}\left\{c_{p} J_{2 s-n+p}\left[\beta\left(q_{p}\right)\right] e^{i q_{p} x}+d_{p} J_{2 s-n+p}\left[\beta\left(-q_{p}\right)\right] e^{-i q_{p} x}\right\} \\
& \times e^{-i \gamma x \sin \left(\omega t+\varphi_{0}\right)} e^{-i \gamma L \sin (\omega t)} e^{-i(n-p) \varphi_{0}} e^{-i n \omega t} .
\end{aligned}
$$

Finally, the wave function in region 5 consists of free modes with two additional oscillating phase factors:

$$
\Psi_{5}(x, t)=\sum_{n} t_{n} e^{i k_{n} x} e^{-i \gamma L \sin \left(\omega t+\varphi_{0}\right)} e^{-i \gamma L \sin (\omega t)} e^{-i n \omega t} .
$$

These are the transmitted waves which are propagating right (see Fig. 4.1).

We constructed wave functions with purely exponential time dependencies using Floquet's theory. For practical reasons, we use local space coordinates; i.e., the origin is redefined in each region [e.g., see the introduction of $\tilde{x}$ in Eq. (4.5)]. The origins of the first and the second regions coincide, which is the zero of the global coordinate system (see Fig. 4.1). Therefore, the continuity boundary conditions for the wave functions and for their derivatives read as follows

$$
\begin{gathered}
\Psi_{1}(0, t)=\Psi_{2}(0, t), \quad \Psi_{2}(L, t)=\Psi_{3}(0, t), \\
\Psi_{3}(d, t)=\Psi_{4}(0, t), \quad \Psi_{4}(L, t)=\Psi_{5}(0, t) . \\
\partial_{x} \Psi_{1}(0, t)=\partial_{x} \Psi_{2}(0, t), \partial_{x} \Psi_{2}(L, t)=\partial_{x} \Psi_{3}(0, t), \\
\partial_{x} \Psi_{3}(d, t)=\partial_{x} \Psi_{4}(0, t), \partial_{x} \Psi_{4}(L, t)=\partial_{x} \Psi_{5}(0, t) .
\end{gathered}
$$

Considering these boundary conditions for each Floquet channel, we obtain an infinite system of linear equations for the unknown coefficients. However, since the Bessel functions (appearing in the expressions of the wave functions) decrease as a 
function of their index, it is sufficient to take only a finite number of frequencies into account.

As an example, the equation describing the continuity of the wave function at the boundary of the first and second region, for the $n$th Floquet channel reads

$$
\delta_{n 0}+r_{n}=\sum_{p, s} J_{s}(\alpha) i^{2 s-n+p}\left\{a_{p} J_{2 s-n+p}\left[\beta\left(q_{p}\right)\right]+b_{p} J_{2 s-n+p}\left[\beta\left(-q_{p}\right)\right]\right\}
$$

where the factor $\exp [-i \gamma x \sin (\omega t)]$ equals unity at $x=0$. The fitting equation originating from the continuity of the derivatives is a bit more complex. The wave function $\Psi_{2}(x, t)$ has two coordinate-dependent factors. The derivatives read as follows:

$$
\frac{\partial}{\partial x}\left\{e^{-i \gamma x \sin (\omega t)} e^{ \pm i q_{p} x}\right\}=e^{-i \gamma x \sin (\omega t)} e^{ \pm i q_{p} x}\left[-i \gamma \sin (\omega t) \pm i q_{p}\right]
$$

At the boundary $x=0$, the derivative is

$$
-\frac{\gamma}{2}\left(e^{i \omega t}-e^{-i \omega t}\right) \pm i q_{p}
$$

Therefore, after shifting the summation indices, the fitting equation for the derivatives reads

$$
\begin{aligned}
& i k_{0} \delta_{n 0}+r_{n}\left(-i k_{n}\right)=\sum_{p, s} J_{s}(\alpha) i^{2 s-n+p+1}\left\{a _ { p } J _ { 2 s - n + p } [ \beta ( q _ { p } ) ] \left(q_{p}+\right.\right. \\
& \left.\left.+\frac{\gamma(2 s-n+p)}{\beta\left(q_{p}\right)}\right)+b_{p} J_{2 s-n+p}\left[\beta\left(-q_{p}\right)\right]\left(-q_{p}+\frac{\gamma(2 s-n+p)}{\beta\left(-q_{p}\right)}\right)\right\} .
\end{aligned}
$$

When fitting at the boundary of regions 2 and $3, \exp [-i \gamma L \sin (\omega t)]$ cancels out. This factor and $\exp \left[-i \gamma L \sin \left(\omega t+\varphi_{0}\right)\right]$ in regions 4 and 5 are also found to be trivial in the corresponding equations.

\subsection{Results and discussion}

We investigate time-averaged transmission spectra for different field parameters. As we shall see, the main features of the transmission probability as a function of the energy of the incoming particles can be understood using an appropriate static model. More details can be seen by exploring the role of the different scattering channels. Besides the time-averaged quantities, we also study the dynamics of the wave packets generated by the interaction of the particle wave with the optical fields. 


\subsubsection{Cycle-averaged transmission probability}

The usual nonrelativistic probability current density in one dimension is defined as

$$
j(x, t)=\frac{\hbar}{m} \operatorname{Im}\left[\Psi^{*}(x, t) \frac{\partial \Psi(x, t)}{\partial x}\right] .
$$

The time-dependent transmission (reflection) probability is given by the ratio of the transmitted (reflected) current to the incoming one. By using Eqs. (4.2) and (4.23), one can realize that the time dependence of the probability currents contain factors $\exp [-i(n-m) \omega t]$, i.e., the transmission probability is a periodic function of time.

As we noted before, integer indices $n$, which correspond to imaginary wave numbers $k_{n}$, mean evanescent modes. It can be readily seen from Eq. (4.30), that these waves do not carry probability currents, neither do they make any contributions to the transmission probability. The cycle-averaged current components of reflection and transmission (normalized to the incoming current) are given by

$$
j_{n}^{R}=\frac{k_{n}}{k_{0}}\left|r_{n}\right|^{2}, \quad j_{n}^{T}=\frac{k_{n}}{k_{0}}\left|t_{n}\right|^{2}
$$

where wave numbers $k_{n}$ are defined in Eq. (4.9). Thus, the cycle-averaged reflection and transmission probabilities read

$$
\langle R\rangle=\sum_{n=n_{0}}^{\infty} j_{n}^{R}, \quad\langle T\rangle=\sum_{n=n_{0}}^{\infty} j_{n}^{T},
$$

where $n_{0}$ is the lowest Floquet index, for which the wave number $k_{n}$ is real.

The total probability must be conserved, which is formulated in one dimension as

$$
\frac{\partial \rho(x, t)}{\partial t}+\frac{\partial j(x, t)}{\partial x}=0,
$$

where we define the probability density as $\rho=\Psi^{*} \Psi$. Accordingly,

$$
\langle R\rangle+\langle T\rangle=1
$$

should always hold for any system parameters [58]. This condition also serves as an accuracy indicator of our calculations. The infinite system of equations has to be truncated in accord with an acceptable arbitrary limit of error. For the results to be presented in the following, $|1-\langle T\rangle-\langle R\rangle| \leq 10^{-6}$ is chosen. This condition can always be met by increasing the number of modes (Floquet channels) that are taken into account. For the parameters we used, the highest-order Floquet index was around 25 .

In Fig. 4.2, the cycle-averaged transmission probability $\langle T\rangle$ is plotted as a func- 


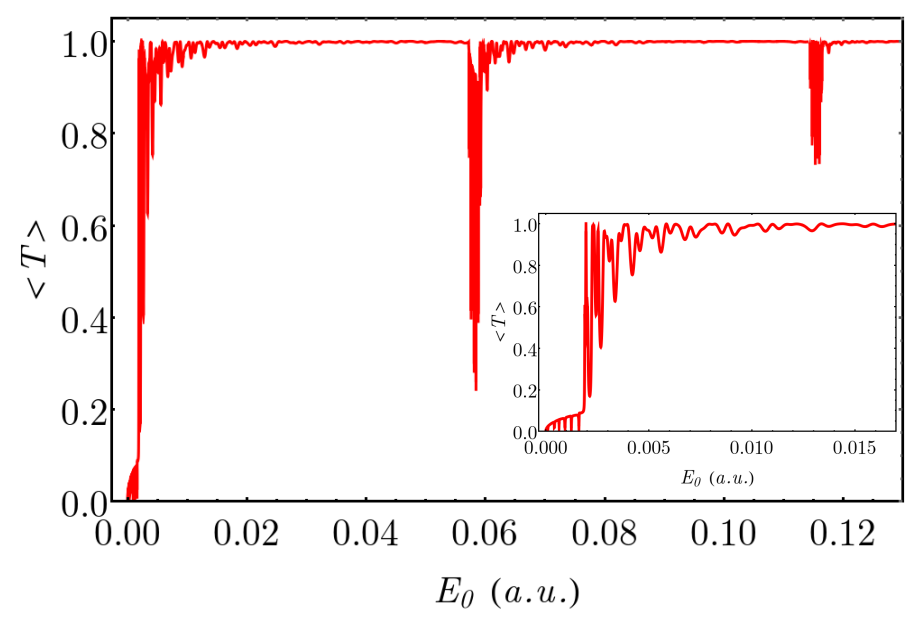

Figure 4.2: Cycle-averaged transmission probability $\langle T\rangle$ as a function of the energy of the incoming particle $E_{0}$. Parameters in atomic units are $F_{0}=4.88 \times 10^{-3}$, $L=200, d=400, \varphi_{0}=\pi$, and $\omega=0.05732$, corresponding to a wavelength of $800 \mathrm{~nm}$. The inset shows the detailed transmission spectrum in the low-energy domain.

tion of $E_{0}$, which denotes the energy of the incoming particle. The parameters correspond to localized optical fields $(L \approx 10 \mathrm{~nm}, d \approx 20 \mathrm{~nm}$ ) that can be realized experimentally [55]. As we can see, in this case the transmission spectrum is complex; there are numerous maxima and minima. The most important parameter here is the ratio of the de Broglie wavelength, $\lambda_{d B}=2 \pi / k_{0}$, of the incoming particle and the separation of the interaction regions, $d$. When, e.g., $d=n\left(\lambda_{d B} / 2\right)$, with a large integer $n$, increasing $E_{0}$ by a few percent of its initial value can result in a similar ratio of $d$ and $\lambda_{d B}$, with $n$ replaced by $n+1$. Since the length of $d$ corresponds again to an integer multiple of $\lambda_{d B} / 2$, the interference pattern will be approximately the same. Therefore, for $d \gg \lambda_{d B}$, whenever we see, e.g., a peak in the transmission spectrum, it will be repeated multiple times within a short energy interval. This is the case for the parameter range shown in Fig. 4.2. In order to simplify the interpretation, in the following we consider the regime where $d$ is not too large in comparison to $\lambda_{d B}$, which leads to a less complex interference pattern, the understanding of which can be straightforwardly transferred to different parameter regimes as well. Let us note that by increasing $d$, it is not only the number of the peaks in the transmission spectra that is seen to increase, but the widths of the individual peaks also change. Larger separation of the interaction regions results in narrower peaks, which is general for Ramsey-like setups, and allows, e.g., precise energy filtering. Besides these quantitative differences, according to our results, the physical picture that explains the interference pattern for $d \geq \lambda_{d B}$ is still valid for $d \gg \lambda_{d B}$, and all the results, including the $\varphi_{0}$ dependence of the transmission, hold also in this case.

Figure 4.3 shows the cycle-averaged transmission probability $\langle T\rangle$ as a function 


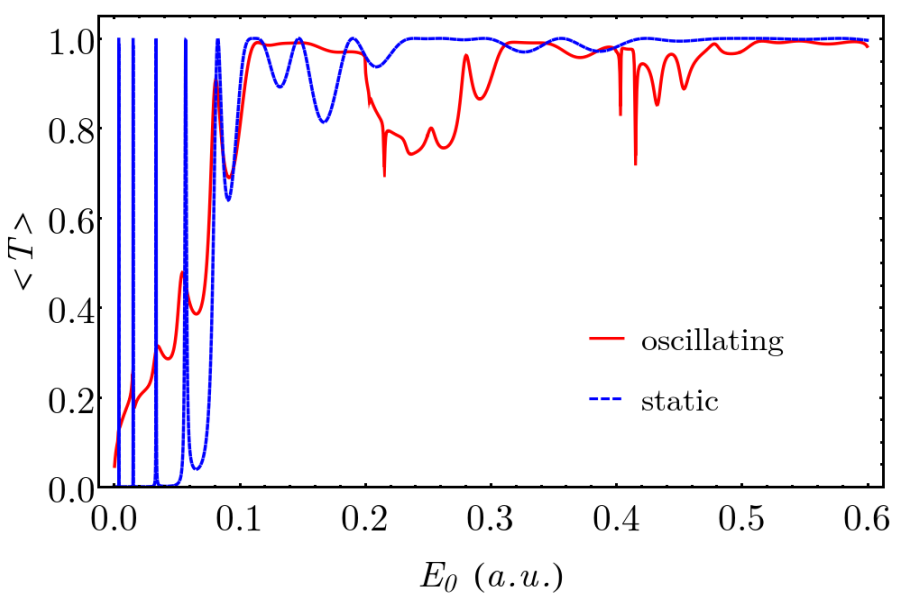

Figure 4.3: Cycle-averaged transmission probability $\langle T\rangle$ (red solid line) and transmission probability for the corresponding static double barrier (blue dashed line, see the main text for more details) as a function of the energy of the incoming particle $E_{0}$ in atomic units. Parameters are $F_{0}=0.1, L=10, d=30, \omega=0.2$ and $\varphi_{0}=\pi$. For low energies, the cycle-averaged transmission probability has peaks at the same input energies where transmission resonances occur in the static double barrier model.

of the energy of the incoming particle. (This is denoted by the red solid line, while the meaning of the dashed blue line is explained in the next subsection.) Increasing this energy means that the transmission probability approaches unity as expected. However, before the saturation happens, a system of transmission peaks and dips is observed at particular values of $E_{0}$. The details of the transmission spectrum are explained in successive steps in the next subsections.

\subsubsection{Scattering resonances}

As we can see, in regions 2 and 4 of Fig. 4.1 (where the oscillating field is localized) the wave numbers defined by Eq. (4.14) are exactly the same as in the case of a static rectangular potential barrier with a height of the ponderomotive potential $U_{p}$ defined in Eq. (4.12), where $U_{p} \geq 0$ holds for any charged particle. Along this line, as a first approximation, we can replace the two oscillating linear potentials with a static, symmetric rectangular double-barrier system [59, 60]. The first consequence of this model is a correct prediction for the overall $E_{0}$ dependence of the timeaveraged transmission probability: when $E_{0} \ll U_{p},\langle T\rangle$ is close to zero, while for input energies considerably above $U_{p}$, it is not far from unity. (See the dashed blue line in Fig. 4.3.) Clearly, the transition between $\langle T\rangle=0$ and 1 takes place around $U_{p}$.

Additional aspects of the transmission spectra can also be understood using the static model described above. By determining the transmission probability of an incoming particle of energy $E_{0}$ for two rectangular barriers of height $U_{p}$ as a static 
scattering process, we obtain multiple sharp resonances at certain energies, as shown in Fig. 4.3 by the blue dashed line.

Transmission resonances are generally related to the presence of bound states, quasibound states, or other localized solutions. In order to understand the transmission spectra shown in Fig. 4.3, it is instructive to find the eigenstates and eigenenergies of the static double-barrier system. To this end, we consider a discretized version of the model, where the time-independent Schrödinger equation is solved with two spatially separated potential barriers of height $U_{p}$. A periodic boundary condition is used: the Hamiltonian matrix is constructed in such a way that the rightmost grid point is connected to the leftmost one.

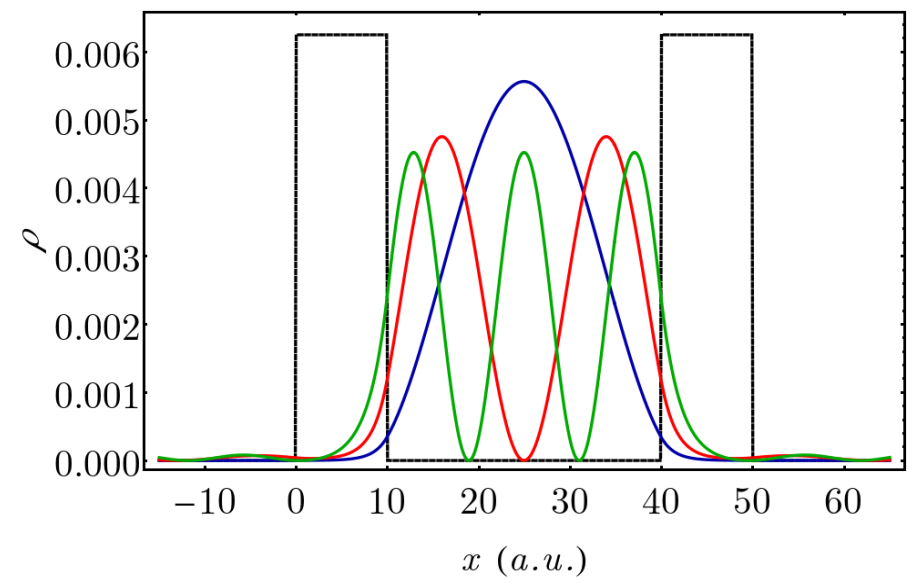

Figure 4.4: Probability densities of the first three localized states in the doublebarrier system. Localized states with increasing eigenenergies are denoted by blue, red, and green lines, respectively. As a reference, the potential barriers are drawn by black dashed lines.

Figure 4.4 shows the probability densities calculated for three such eigenstates which are found to be localized between the two potential barriers that are indicated by black dashed lines in the figure. These states correspond to the same energies, where the transmission spectrum (in Fig. 4.3) has pronounced peaks. In other words, the reason for the transmission resonances observed for the static potential barriers is the existence of these localized states.

Returning to Fig. 4.3, now it is clearly seen that the previously introduced scattering problem with oscillating potential also has transmission resonances around these particular energies. That is, the static model can be viewed as a first approximation for low energies (below $E_{0}=\hbar \omega$ ). However, as it is clear by comparing the red and the blue curves in Fig. 4.3, for higher energies, the oscillation of the potential results in a structured transmission spectrum that cannot be explained by the static model. The physical processes determining this part of the spectra are examined in the following subsection. 


\subsubsection{Shifted, "multiphoton" resonances}

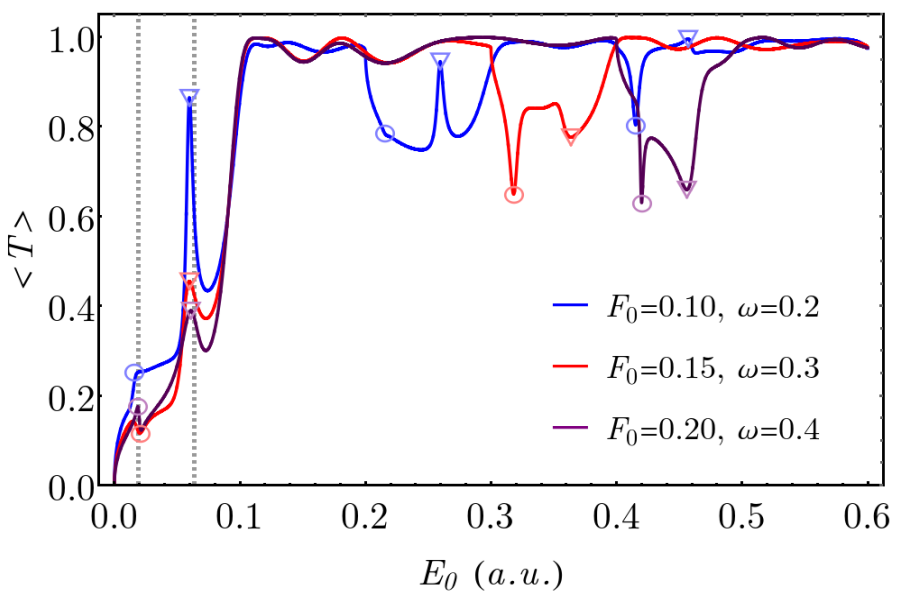

Figure 4.5: Cycle-averaged transmission probabilities $\langle T\rangle$ as a function of the incoming particle's energy $E_{0}$ in atomic units. Parameters: $L=10, d=10$, and $\varphi_{0}=\pi$. The open circles and triangles correspond to the first and second scattering resonances, respectively.

As a next step, we investigate the scattering process by varying the parameters so that the pondoromotive energy $U_{p}$ defined by Eq. (4.12) is kept constant. In this way the static model introduced in the previous subsection is unchanged (by definition), and we can explore effects beyond this approximation. (In other words, we are to explain the difference between the two curves in Fig. 4.3.) Figure 4.5 shows that for different electric-field amplitudes and angular frequencies of oscillation, the locations of the resonances (below $E_{0}=\hbar \omega$ ) stay approximately the same. In more detail, the parameters in this figure correspond to only two static scattering resonance energies (at $E_{0}=0.0193$ and 0.0643 a.u.), which are denoted by gray dashed lines as references. As we can see, the static barriers indeed mean good approximation for the expected resonance energies when $E_{0}<\hbar \omega$.

For larger input energies, however, there are even more peaks and dips in the transmission probability for the oscillating case. In Fig. 4.5, circles and triangles correspond to the static scattering resonance energies shifted by $n \hbar \omega$. These resonances can be explained by noticing, that after losing an integer multiple of the energy quanta $\hbar \omega$, the energy of the scattered particle coincides with the energy of one of the previously shown localized states. In this sense, the open circles and triangles correspond to the first and second scattering resonance energies, respectively. Note that this explains the energy value at which these resonances appear, but the behavior of the transmission probabilities at these energies (e.g., whether we experience a peak or a dip) needs a more detailed description (see the next subsection).

As an additional interesting feature, Fig. 4.6 shows the transmission probability 


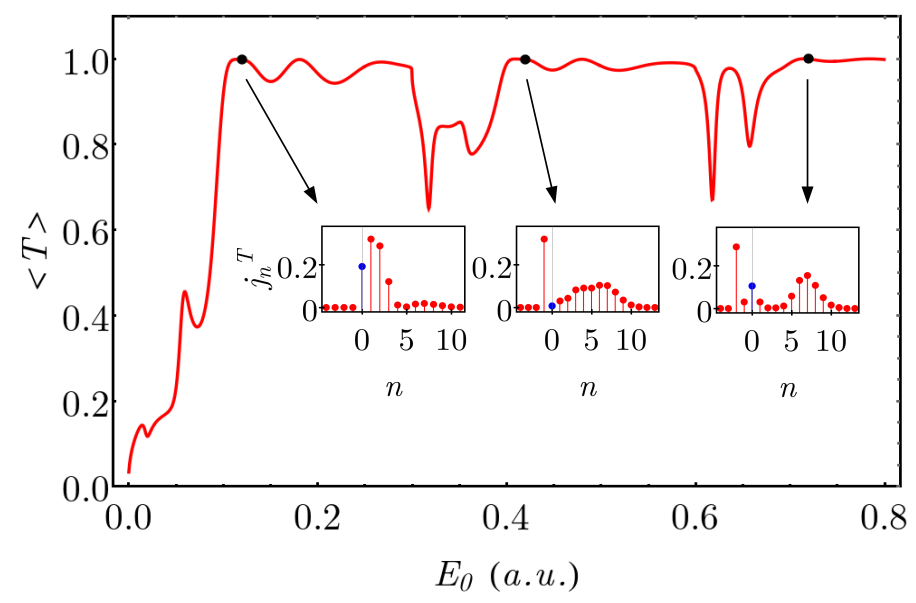

Figure 4.6: Cycle-averaged transmission probability $\langle T\rangle$ as a function of incoming particle's energy $E_{0}$ in atomic units. Parameters: $F_{0}=0.1, L=10, d=10$, $\omega=0.3$, and $\varphi_{0}=\pi$. All the insets show the individual current contributions $j_{n}^{T}$ of the Floquet channels to the transmission probability for different values of $E_{0}$.

as well as the contributions of every single Floquet channel to it at different energies. Although the transmission probability is almost unity at the three specified energies, they correspond to entirely different probability current distributions as is shown by the insets of Fig. 4.6. The blue dot in the insets marks the probability current of the central Floquet channel $(n=0)$.

When the incoming energy $E_{0}$ reaches $\hbar \omega$, the scattering channel $n=-1$ opens and can also contribute to the transmission probability. The same happens after every single additional energy quantum $\hbar \omega$ : a previously evanescent wave mode transforms into a propagating one. This phenomenon is due to the emission of "photons", where the particle can transmit energy to its environment. Therefore, the probability currents $j_{n}^{T}$ can be also called the "multiphoton" components of transmission.

\subsubsection{Phase dependence of the transmission}

So far, Figs. 4.3, 4.5, and 4.6 show transmission spectra when the two localized electric fields have a phase difference $\varphi_{0}$ of $\pi$, which corresponds to a symmetric oscillating trapezoid potential. In the following, we inspect the phase difference dependence of the scattering process.

Figure 4.7 shows the transmission probability as a function of $\varphi_{0}$ for different separation distances (denoted by $d$ ) of the optical fields. The quasiperiodicity of the time-averaged transmission probability as a function of $d$ (with a period of $\lambda_{d B} / 2$ ) clearly shows the fact that we have already mentioned earlier: for two values of $d$ for which $2 d_{1} / \lambda_{d B}$ and $2 d_{2} / \lambda_{d B}$ differs by only an integer, the interference pattern is very similar, leading to similar transmission probabilities. According to our calculation, 


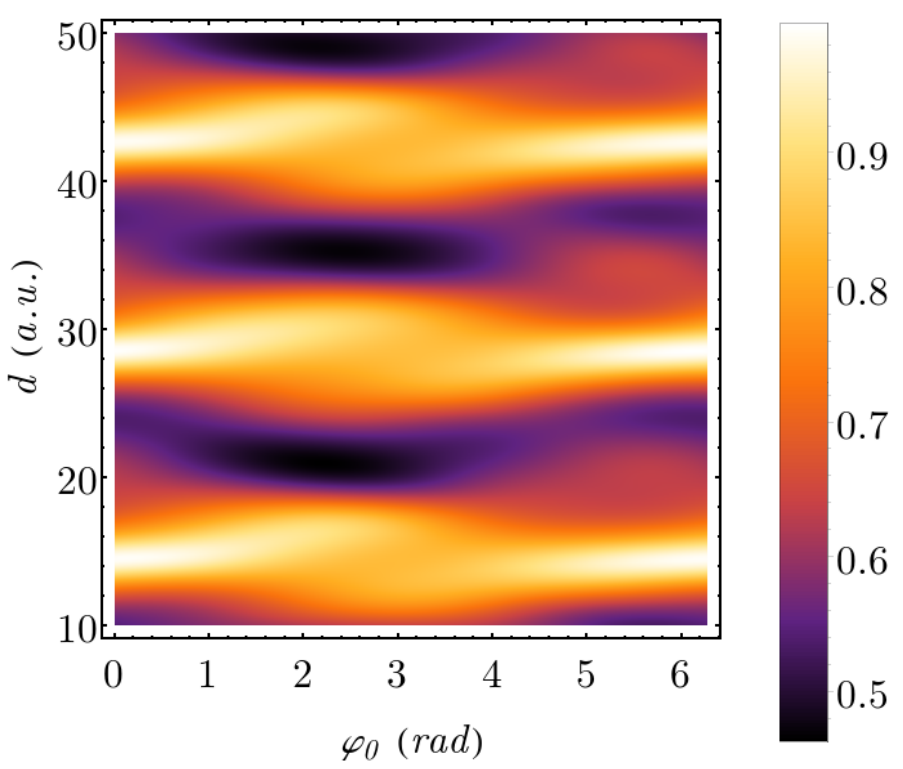

Figure 4.7: Transmission probabilities $\langle T\rangle$ as a function of the phase difference $\varphi_{0}$ for different lengths $d$ of region 3. System parameters: $E_{0}=0.025, \lambda_{d B}=28.0993$, $F_{0}=0.1, L=10$, and $\omega=0.2$.

when all other parameters are fixed, $\langle T\rangle$ can change $50 \%$ as a function of $\varphi_{0}$, and this behavior is observable also for experimentally relevant parameter ranges.

In order to understand the detailed role of the phase difference in the scattering process, we analyze the space and time dependence of the probability current density. Generally, due to the population of various Floquet channels, the solution will obviously not be monoenergetic, propagating wave packets emerge. As a physical picture, we may consider that the wave packets generated in region 2 approach the second optical field, where, depending on the relative phase difference $\varphi_{0}$, the slope of the potential experienced by the wave-packets will be different. In other words, the wave packets entering region 4 will either experience an "attractive" potential that forces them to move towards region 5 (and consequently increase the transmission probability), or a "repulsive" one leading to reflection. As a consequence, focusing on transmission resonances, we can observe that transmission peaks can transform into dips and vice versa as we sweep through $\varphi_{0}$. Clearly, this is only a first approach (since, e.g., oppositely moving wave-packets in region 3 can interfere), but it can capture the essential mechanism beyond the $\varphi_{0}$ dependence of $\langle T\rangle$.

As an illustration, Figs. 4.8(a) and 4.8(b) show density plots of $j(x, t)$ for two different $\varphi_{0}$ values (all other parameters are the same, see the caption). Figures 4.8(a) and 4.8(b) correspond to the maximum and minimum of $\langle T\rangle$, respectively. In both cases, the ripples in region 1 are related to the interference of the incoming and reflected waves. Two optical cycles are shown, and the \pm signs in the interaction regions show the sign of the classical force that corresponds to the oscillating 

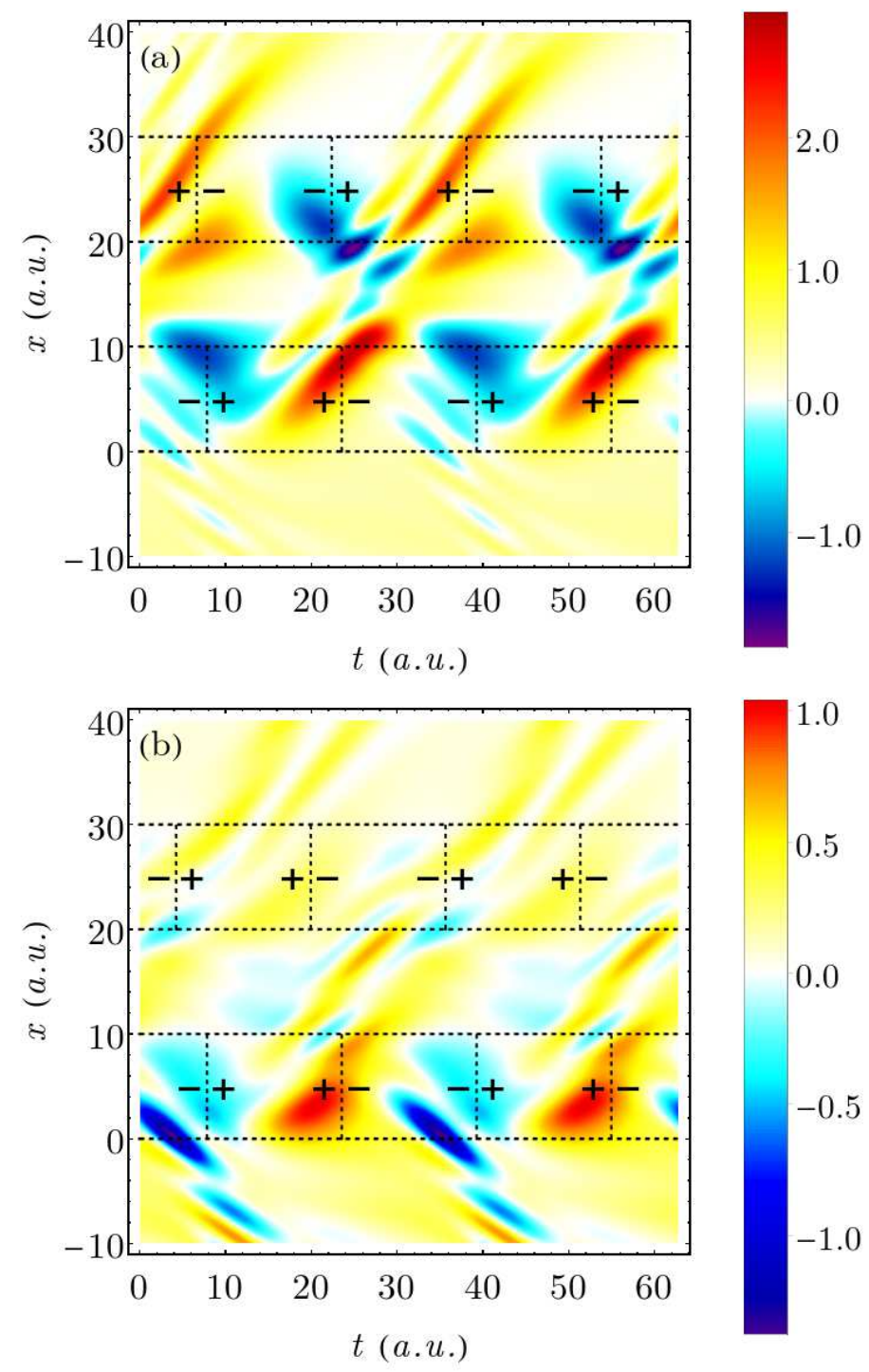

Figure 4.8: Density plot of $j(x, t)$ as a function of time and coordinate $x$. For parameters $E_{0}=0.06, F_{0}=0.1, L=10, d=10$, and $\omega=0.2$, panels (a) and (b) correspond to the maximal and minimal transmission probabilities, respectively. Numerically: $\langle T\rangle=0.8941$ at $\varphi_{0}=3.3772$ in panel $(\mathrm{a})$, and $\langle T\rangle=0.3920$ at $\varphi_{0}=0.7226$ in panel (b). Horizontal dashed lines indicate the boundaries of the different regions, and vertical ones correspond to the zeros of the classical force exerted on the charged particle. The sign of this force is also shown in the various space-time regions.

potential. As we can see, when the transmission probability is minimal, the most pronounced wave packet reaches region 4 in a time interval when the oscillating potential repels it. On the other hand, as is shown by Fig. 4.8(a), the maximum of $\langle T\rangle$ corresponds to the case when the wave packet in the second interaction region is pushed towards region 5. Note that for higher input energies and stronger optical fields more structured wave packets are generated in the outermost region. Additionally, when $E_{0} \gg U_{p}$ (or $E_{0} \ll U_{p}$ ), $\langle T\rangle$ is very close to unity (or zero) and consequently cannot have strong $\varphi_{0}$ dependence. Therefore, in order to control the 
transmission by changing $\varphi_{0}$, the parameters of the electric fields must correspond to a ponderomotive potential close to the characteristic kinetic energy, $E_{0}$, of the particle beam.

As a possible application, let us emphasize that the time-averaged transmission probability can strongly depend on the phase difference $\varphi_{0}$ also at the transmission resonances. For large enough separation of the interaction regions, these resonance peaks are narrow, and, consequently, for a realistic, nonmonoenergetic particle beam, they can serve as narrow band energy filters. More interestingly, the properties of these energy filters can be controlled by changing only $\varphi_{0}$, without modifying any other parameters of the experimental setup.

\subsection{Summary and conclusions}

We presented a nonrelativistic time-periodic scattering problem where a charged particle, e.g., an electron was assumed to be scattered on two spatially localized time-periodic optical fields. Considering dipole approximation and using Floquet's theory, the cycle-averaged transmission probabilities were calculated with different system parameters. Results showed a very sophisticated spectrum, which was explained in successive steps. First, we recognized that a double-potential-barrier system (with barrier heights being equal to the ponderomotive potentials) serves as a fair approximation for low energies. We determined the energies of the scattering resonances in the static model and identified them in the spectrum of the time-dependent model. We also explained the additional resonances occurring at higher energies through the behavior of the probability currents belonging to different Floquet channels. Finally, we explained the phase difference dependence of the transmission probability by inspecting the temporal behavior of the generated wave packets.

The results presented here point out how optical fields can control moving charged particles. Although we used the context of a beam propagating in free space, understanding the basic phenomena that govern interferometric processes induced by separated fields is crucial also from the viewpoint of ultrafast, light-induced electronics, i.e., when the charged particles move in a solid. Although our model focuses on the most important, qualitative aspects of the interaction, it can provide an adequate first approach to more complex systems as well. With acceptable increase of numerical costs, our method can also treat two-dimensional problems or bichromatic excitation. As an important generalization, the spatial dependence of the exciting fields can also be taken into account. 


\section{CHAPTER 5}

\section{Laser-assisted electron scattering on a hard sphere}

In this chapter, we discuss a three-dimensional time-periodic model, where the scattering of electrons is investigated on a hard sphere in the presence of a laser field of arbitrary intensity. We use spherical Gordon-Volkov states, which have already been introduced in Ref. [61]. However, we give an alternative derivation based on the translational addition theorem of spherical waves [62 64]. Eventually, either derivation requires the efficient computation of the same integral. The computational method presented here is based on an analytic integration which results in summations of hypergeometric functions. In the case of the weak field limit, closed form formulas can be obtained [61], which can be verified with the numerically exact model. Additional results are analyzed through differential scattering cross sections.

\subsection{Introduction}

Laser-assisted electron scattering has been widely studied in the past, primarily in the context of multiphoton Bremsstrahlung and plasma heating [65, 66]. Recently, the application of this process has received a growing importance in various branches of research aiming, for instance, the generation of ultrashort (even attosecond) electron pulses [67 69], four-dimensional imaging and ultrafast electron microscopy [70, 71], or photon-induced near field electron microscopy [36, 50, 72]. The theoretical description of laser-assisted scattering processes of charged particles relies on the nonperturbative treatment of the interaction with the laser field [61, 73, 74], which is usually based on Volkov states (see Chapter 21).

The structure of this chapter is the following. In Sec. 5.2, we describe the setup of the hard sphere scattering model, and in Sec. 5.3, we present an ansatz as the solution of the Schrödinger equation following the work of Varró and Ehlotzky [61]. The expansion of the spherical waves is derived with the translational addition theorem in Sec. 5.4. We show that the scattered wave function can be written in 
the Floquet form, and we present a novel efficient method of computing an integral appearing in the Floquet wave function. Finally, we analyzed the numerical results involving differential cross sections in the weak field limit in Sec. 5.5.

\subsection{Model}

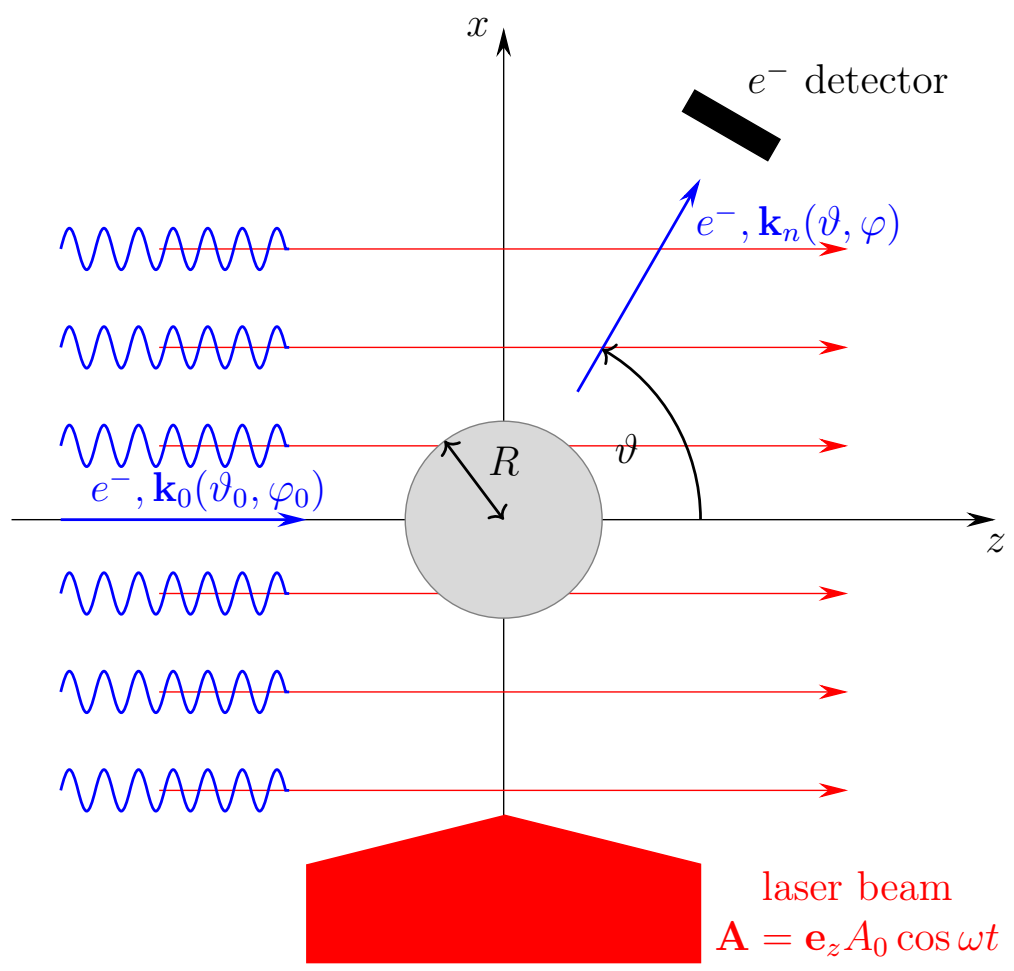

Figure 5.1: Schematic model of the electron scattering on a nano-particle in the presence of a linearly polarized laser field. The electrons are modeled as a (de Broglie) plane wave, and they are scattered by an impenetrable hard sphere of radius $R$.

We consider electron scattering on a nano-particle in the presence of a lowfrequency laser field, modeled as a plane wave with linear polarization in the $z$ direction, see Figure 5.1. In this setup, the nano-particle is assumed to be a hard sphere of radius $R$; i.e., the potential energy is infinitely large inside the sphere, while it is zero everywhere else. This simplification rules out any kind of dielectric effects, e.g., near-field enhancement or polarization, therefore, the sphere merely acts as an obstacle in this model. The electrons are considered to be independent, and they are described by the Schrödinger equation. We must emphasize that in contrast to the scattering model presented in Chapter 4, the laser field is not assumed to be localized in a finite area, that is, the incident electrons are effected in the entire domain. In

\footnotetext{
${ }^{1}$ This condition is required to allow the usage of the dipole approximation; thus, the field can be considered homogeneous.
} 
other words, they are not free particles in the laboratory frame. Their interaction with the laser field is taken into account by the usual minimal coupling. Choosing the Coulomb gauge and using the dipole approximation, the vector potential depends only on time and reads

$$
\mathbf{A}=\left(0,0, A_{0} \cos \omega t\right) .
$$

The incident electrons of charge $-e$ and mass $2 M$ propagate towards an arbitrary direction. Let us recall from Chapter 2 that by means of the unitary transformation [Eq. (2.11)], we can eliminate the interaction term proportional to $A^{2}$ in the Hamiltonian. The Schrödinger equation in velocity gauge reads

$$
\left[\frac{\mathbf{p}^{2}}{2 M}+\frac{e}{M} \mathbf{A} \cdot \mathbf{p}\right] \Psi=i \hbar \frac{\partial}{\partial t} \Psi .
$$

Next, the Kramers-Henneberger transformation can be applied (see Eq. (2.23)), which results in a coordinate translation given by the vector

$$
\boldsymbol{\alpha}(t)=\mathbf{e}_{z} \frac{e A_{0}}{M \omega} \sin \omega t
$$

Outside the sphere, this transforms Eq. (5.2) into the free-particle Schrödinger equation:

$$
-\frac{\hbar^{2}}{2 M} \nabla^{2} \Phi=i \hbar \frac{\partial \Phi}{\partial t}
$$

where the Volkov wave function is denoted by $\Phi$ in the Kramers-Henneberger frame. The space-shifted solution of Eq. (5.4) given as

$$
\Psi=\Phi(x, y, z-a \sin \omega t, t)
$$

yields the solution $\Psi$ of Eq. (5.2) in the laboratory frame (see Fig. 5.1). Here, $a=e A_{0} / M \omega$ denotes the amplitude of the coordinate translation.

Since we consider an impenetrable sphere with a radius $R$, we specify the following boundary condition:

$$
\left.\Phi(x, y, z-a \sin \omega t, t)\right|_{r=R}=0,
$$

which must hold for all values of $t$ and for all polar angles $\vartheta$ and $\varphi$. That is, the wave function must vanish at the surface of the hard sphere for every time instant.

\footnotetext{
${ }^{2}$ Since later we use the letter $m$ as a summation index, the electron mass is denoted by $M$.
} 


\subsection{Expansion in terms of spherical Volkov states}

Because of the geometry of the scattering process, it is convenient to introduce spherical polar coordinates $(r, \vartheta, \varphi)$ taking the $z$-axis as the polar axis, as shown in Fig. 5.1. The boundary condition (5.6) can be also formulated in an easier way. If we express the Schrödinger equation (5.2) in these coordinates, the term representing the interaction with the radiation field is independent of the azimuth angle $\varphi$ as is the boundary condition (5.6). However, choosing the incoming electron wave to depend on $\varphi$, the total scattering wave function must be $\varphi$ dependent as well, which means that there is no cylindrical symmetry with respect to the $z$-axis. If we write $\mathbf{r} \equiv r(\sin \vartheta \cos \varphi, \sin \vartheta \sin \varphi, \cos \vartheta)$, and similarly represent the wave vector of the incoming free electron by $\mathbf{k}_{0} \equiv k_{0}\left[\sin \vartheta_{0} \cos \varphi_{0}, \sin \vartheta_{0} \sin \varphi_{0}, \cos \vartheta_{0}\right)$ then we find $\mathbf{k}_{0} \cdot \mathbf{r}=k_{0} r\left[\sin \vartheta_{0} \sin \vartheta \cos \left(\varphi-\varphi_{0}\right)+\cos \vartheta \cos \vartheta_{0}\right]$.

Now, let us focus on finding the solution of the Schrödinger equation. In view of the previous considerations, we attempt to solve Eq. (5.4) with the time-periodic boundary condition (5.6) in Floquet form by the ansatz

$$
\begin{aligned}
\Phi= & \exp \left[i\left(\mathbf{k}_{0} \cdot \mathbf{r}-\omega_{0} t\right)\right]+\sum_{n=-\infty}^{\infty} \sum_{l=0}^{\infty} \sum_{m=-l}^{l} A(n, l, m) \\
& \times h_{l}^{(1)}\left(k_{n} r\right) P_{l}^{m}(\cos \vartheta) \exp (i m \varphi) \exp \left[-i\left(\omega_{0}+n \omega\right) t\right],
\end{aligned}
$$

where we have an incident free electron wave in the Kramers-Henneberger frame with energy $E_{0}=\hbar \omega_{0}$ plus the sum of Fourier decomposed outgoing spherical waves (or partial waves) given by $h_{l}^{(1)}\left(k_{n} r\right) P_{l}^{m}(\cos \vartheta) \exp (i m \varphi)=f_{n, l, m}(r, \vartheta, \varphi)$ which satisfy the Helmholtz equation

$$
\left[\nabla^{2}+k_{n}^{2}\right] f_{n, l, m}(r, \vartheta, \varphi)=0
$$

The spherical Hankel functions of the first kind are denoted by $h_{l}^{(1)}\left(k_{n} r\right)$ and the products $P_{l}^{m}(\cos \vartheta) \exp (i m \varphi)$ are the ordinary spherical harmonics $Y_{l}^{m}(\vartheta, \varphi)$ (apart from a normalization factor), where $P_{l}^{m}(\cos \vartheta)$ is the associated Legendre polynomial.

In the laser field, the wave numbers $k_{n}$ of the scattered electrons are given by

$$
k_{n}=\frac{\sqrt{2 M\left(E_{0}+n \hbar \omega\right)}}{\hbar}=k_{0} \sqrt{1+n \frac{\omega}{\omega_{0}}},
$$

which can be real or purely imaginary, depending on the value of the integer $n$ for a given ratio $\omega / \omega_{0}$, similarly to the one-dimensional model in Chapter 4 . If the wave numbers $k_{n}$ are purely imaginary, the spherical Hankel functions represent 
exponential decay of the partial waves. This means that the laser field can induce evanescent partial electron waves bound to the outer surface of the sphere. At this stage, the coefficients $A(n, l, m)$ in Eq. (5.7) are unknown, and have to be determined by means of the boundary condition (5.6).

Applying Eq. (5.5) to Eq. (5.7), the total wave function $\Psi$ can be written in the space-translated form

$$
\begin{aligned}
\Psi= & \exp \left\{i\left[\mathbf{k}_{0} \cdot \mathbf{r}-k_{0} \cos \left(\vartheta_{0}\right) a \sin (\omega t)\right]\right\}+\sum_{n=-\infty}^{\infty} \sum_{l=0}^{\infty} \sum_{m=-l}^{l} A(n, l, m) \\
& \times h_{l}^{(1)}\left[k_{n} r(t)\right] P_{l}^{m}[\cos \vartheta(t)] \exp (i m \varphi) \exp \left[-i\left(\omega_{0}+n \omega\right) t\right],
\end{aligned}
$$

where $r(t)$ and $\vartheta(t)$ are the space-shifted spherical coordinates. Equation (5.10) clearly shows that the wave function is a superposition of an incoming plane GordonVolkov state and outgoing spherical Gordon-Volkov states with energies $E_{0}+n \hbar \omega$. In other words, because of the Kramers-Henneberger transformation, the free plane wave describing the incident electrons is transformed into a plane Gordon-Volkov state [see Eq. (2.21) in Chapter 2] and the partial spherical waves become spherical Gordon-Volkov states. In Eq. (5.10), the explicit expressions for $r(t)$ and $\vartheta(t)$ are given by

$$
\begin{gathered}
r(t)=\sqrt{r^{2}-2 r \alpha(t) \cos \vartheta+\alpha(t)^{2}} \\
\cos \vartheta(t)=\frac{z-\alpha(t)}{r(t)}=\frac{r \cos \vartheta-\alpha(t)}{\sqrt{r^{2}-2 r \alpha(t) \cos \vartheta+\alpha(t)^{2}}},
\end{gathered}
$$

where we recall that the magnitude of the space shift is given by

$$
\alpha(t)=a \sin \omega t, \quad a=\frac{e A_{0}}{M \omega} .
$$

\subsection{Spherical Gordon-Volkov states}

In order to be able to evaluate the coefficients $A(n, l, m)$ from the boundary condition Eq. (5.6), we first have to determine the explicit form of the spherical GordonVolkov states $h_{l}^{(1)}\left[k_{n} r(t)\right] P_{l}^{m}[\cos \vartheta(t)] \exp (i m \varphi)$ in terms of the ordinary spherical waves $h_{l}^{(1)}\left[k_{n} r\right] P_{l}^{m}[\cos \vartheta] \exp (i m \varphi)$. This calculation was already carried out by the authors of Ref. [61]. Here, we present an alternative approach based on the expansion of the space-translated spherical Gordon-Volkov states without the need of using subsidiary variables. For actual calculations, this method was found to be more practical.

A few works about the translational (and rotational) addition theorems for spherical waves have been published in the early $60 \mathrm{~s}[62[64]$. The authors of these papers 
showed 3 how the spherical wave functions $z_{\nu}(k R) P_{\nu}^{\mu}(\cos \theta) \exp (i \mu \varphi)$ with reference to the origin $O$ can be expanded in terms of spherical wave functions with reference to the origin $O^{\prime}$, where $O^{\prime}$ has the coordinates $\left(R_{0}, \theta_{0}, \phi_{0}\right)$ with respect to $O$. The notation $z_{\nu}(k R)$ stands for the spherical Bessel, Neumann, or Hankel function of the first or second kind. Since the scattered wave function is described by outgoing spherical waves, we focus on the spherical Hankel function of the first kind, i.e., $z_{\nu}(k R)=h_{\nu}^{(1)}(k R)$. In the next subsection, we show the result of the expansion following the works $[62-64]$.

\subsubsection{Translation addition theorem of spherical waves}

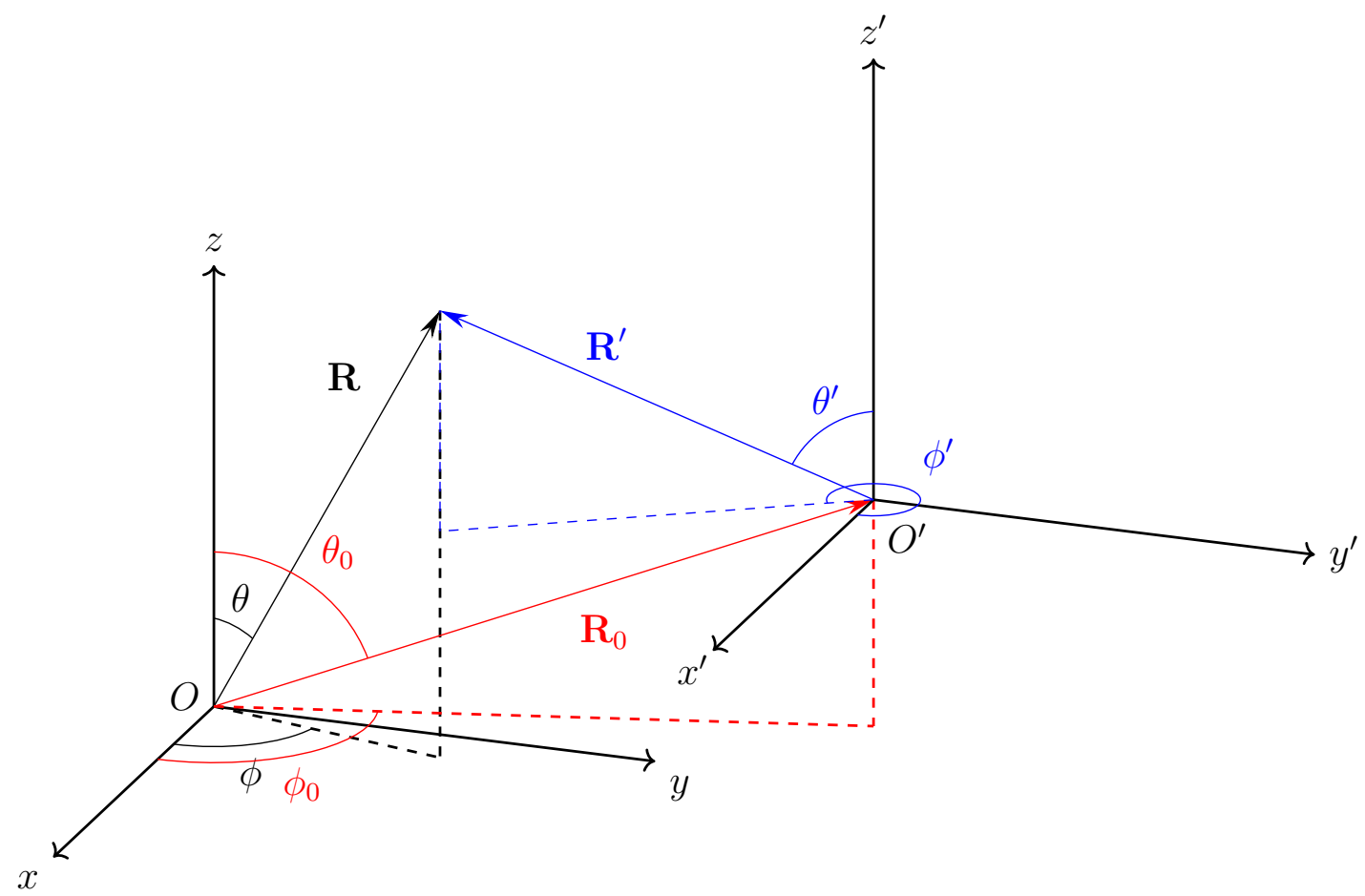

Figure 5.2: The two reference frames we consider in the translational addition theorem of spherical waves. $O$ denotes the origin of a reference frame $K$ with coordinates $(R, \theta, \phi)$. In this frame, $O^{\prime}$ at $\left(R_{0}, \theta_{0}, \phi_{0}\right)$ denotes the origin of a second reference frame $K^{\prime}$, which uses the coordinates $\left(R^{\prime}, \theta^{\prime}, \phi^{\prime}\right)$.

Let $O$ denote the origin of a reference frame $K$ with coordinates $(R, \theta, \phi)$. In this frame, let $O^{\prime}$ at $\left(R_{0}, \theta_{0}, \phi_{0}\right)$ represent the origin of a second reference frame $K^{\prime}$ having coordinates $\left(R^{\prime}, \theta^{\prime}, \phi^{\prime}\right)$. The orientation of $K^{\prime}$ is such that a rigid translation of $K$ by the vector $\mathbf{R}_{0}=\left(R_{0}, \theta_{0}, \phi_{0}\right)$ takes it into the frame $K^{\prime}$. In other words, the corresponding axes of the two reference frames are parallel, see Fig. 5.2. For the

\footnotetext{
${ }^{3}$ Here and in Subsec. 5.4.1 we use a notation based on Stein's work for the expansion of spherical waves, see Ref. [63].
} 
values $-\nu \leq \mu \leq \nu$, where $\nu \geq 0$, the addition theorem reads

$$
\begin{aligned}
& h_{\nu}^{(1)}(k R) P_{\nu}^{\mu}(\cos \theta) \exp (i \mu \varphi)=\sum_{n=0}^{\infty} \sum_{m=-n}^{n} \sum_{p=|n-\nu|}^{n+\nu}(-1)^{m} i^{n+p-\nu}(2 n+1) \boldsymbol{a}_{n, \nu}^{m, \mu}(p) \\
& \times h_{p}^{(1)}\left(k r_{>}\right) j_{n}\left(k r_{<}\right) P_{p}^{\mu+m}\left(\cos \theta_{>}\right) P_{n}^{-m}\left(\cos \theta_{<}\right) \exp \left[i(\mu+m) \phi_{>}-i m \phi_{<}\right],
\end{aligned}
$$

where

$$
\left\{\begin{array}{ll}
r_{>}=R^{\prime}, & r_{<}=R_{0} \\
\theta_{>}=\theta^{\prime}, & \theta_{<}=\theta_{0} \\
\phi_{>}=\phi^{\prime}, & \phi_{<}=\phi_{0}
\end{array}\right\} \quad \text { if } R^{\prime} \geq R_{0},
$$

and

$$
\left\{\begin{array}{ll}
r_{>}=R_{0}, & r_{<}=R^{\prime} \\
\theta_{>}=\theta_{0}, & \theta_{<}=\theta^{\prime} \\
\phi_{>}=\phi_{0}, & \phi_{<}=\phi^{\prime}
\end{array}\right\} \quad \text { if } R^{\prime} \leq R_{0} .
$$

The symbols $\boldsymbol{a}_{n, \nu}^{m, \mu}(p)$ are the so-called Gaunt coefficients [75], which appear in the linear expansion of the product of two associated Legendre polynomials:

$$
P_{n}^{m}(\cos \theta) P_{\nu}^{\mu}(\cos \theta)=\sum_{p=|n-\nu|}^{n+\nu} \boldsymbol{a}_{n, \nu}^{m, \mu}(p) P_{p}^{m+\mu}(\cos \theta) .
$$

Their explicit form [64] can be expressed as

$$
\begin{aligned}
\boldsymbol{a}_{n, \nu}^{m, \mu}(p)= & (-1)^{m+\mu}(2 p+1) \sqrt{\frac{(n+m) !(\nu+\mu) !(p-m-\mu) !}{(n-m) !(\nu-\mu) !(p+m+\mu) !}} \\
& \times\left[\begin{array}{lll}
n & \nu & p \\
0 & 0 & 0
\end{array}\right]\left[\begin{array}{ccc}
n & \nu & p \\
m & \mu & -m-\mu
\end{array}\right],
\end{aligned}
$$

where the Wigner 3-j symbol appears, see, e.g., Ref. [76].

\subsubsection{Applying the theorem to the spherical Volkov states}

As we have seen earlier, the Kramers-Henneberger transformation shifts the coordinate system into an accelerating frame with a time-periodic space translation with respect to the laboratory frame. In the previous subsection, we showed that the translation addition theorem allows to express a spherical wave in a reference frame $K$ in terms of spherical waves in an other one denoted by $K^{\prime}$.

We use the translation addition theorem (5.14) for the spherical Gordon-Volkov states $h_{l}^{(1)}\left[k_{n} r(t)\right] P_{l}^{m}[\cos \vartheta(t)] \exp (i m \varphi)$, by identifying $K^{\prime}$ and $K$ as the laboratory frame and the Kramers-Henneberger frame, respectively. It can be easily seen that 
the translation vector with Cartesian coordinates reads

$$
\mathbf{R}_{0}=[0,0,-a \sin (\omega t)]
$$

We note that in Eq. (5.19), since the radius is a positive number, we must distinguish two cases:

$$
\begin{aligned}
& R_{0}=a \sin \omega t, \quad \theta_{0}=\pi, \quad \text { if } 0 \leq t \bmod T \leq \frac{T}{2}, \\
& R_{0}=-a \sin \omega t, \quad \theta_{0}=0, \quad \text { if } \frac{T}{2} \leq t \bmod T \leq T,
\end{aligned}
$$

where $T=2 \pi / \omega$ is the time period of the oscillation. Substituting the spherical coordinates of the vector (5.19) into Eq. (5.14), and rewriting the indices, we obtain

$$
\begin{aligned}
& h_{l}^{(1)}\left[k_{n} r(t)\right] P_{l}^{m}[\cos \vartheta(t)] \exp (i m \varphi)=\sum_{l^{\prime}=0}^{\infty} \sum_{m^{\prime}=-l^{\prime}}^{l^{\prime}} \sum_{p=\left|l^{\prime}-l\right|}^{l^{\prime}+l}(-1)^{m^{\prime}} i^{l^{\prime}+p-l}\left(2 l^{\prime}+1\right) \boldsymbol{a}_{l^{\prime}, l}^{m^{\prime}, m}(p) \\
& \times h_{p}^{(1)}\left(k_{n} r\right) j_{l^{\prime}}\left[k_{n} a \sin (\omega t)\right] P_{p}^{m+m^{\prime}}(\cos \vartheta) P_{l^{\prime}}^{-m^{\prime}}(\cos \pi) \exp \left[i\left(m+m^{\prime}\right) \varphi\right],
\end{aligned}
$$

where we assumed $r>a$ according to the condition in Eq. (5.15). If we look at the expansion (5.21), we can immediately notice that because of the equality $P_{l^{\prime}}^{-m^{\prime}}(\cos \pi)=(-1)^{l^{\prime}} \delta_{m^{\prime} 0}$, we can make a simplification by ignoring the summation over $m^{\prime}$ and taking only $m^{\prime}=0$. On the other hand, if we take $P_{l^{\prime}}^{-m^{\prime}}(\cos 0)=\delta_{m^{\prime} 0}$, because of the parity property of the spherical Bessel function $j_{l^{\prime}}(x)=(-1)^{l^{\prime}} j_{l^{\prime}}(-x)$, the two cases in Eq. (5.20) lead to the same result. Therefore, the simplified expansion reads

$$
\begin{aligned}
h_{l}^{(1)}\left[k_{n} r(t)\right] & P_{l}^{m}[\cos \vartheta(t)] \exp (i m \varphi)=\sum_{l^{\prime}=0}^{\infty} \sum_{p=\left|l^{\prime}-l\right|}^{l^{\prime}+l} i^{l^{\prime}+p-l}\left(2 l^{\prime}+1\right) \boldsymbol{a}_{l^{\prime}, l}^{0, m}(p) \\
& \times h_{p}^{(1)}\left(k_{n} r\right) j_{l^{\prime}}\left[-k_{n} a \sin (\omega t)\right] P_{p}^{m}(\cos \vartheta) \exp (i m \varphi)
\end{aligned}
$$

Only the spherical Bessel function depends on time on the right-hand side of Eq. (5.22). Multiplying both sides in the formula (8.534) of Gradshteyn and Ryzhik [56] by a Legendre polynomial, we can express $j_{l^{\prime}}\left[-k_{n} a \sin (\omega t)\right]$ with a projection as follows

$$
j_{l^{\prime}}\left[-k_{n} a \sin (\omega t)\right]=\frac{1}{2 i^{l^{\prime}}} \int_{-1}^{1} P_{l^{\prime}}(x) \exp \left[-i k_{n} a \sin (\omega t) x\right] \mathrm{d} x
$$

which is the integral representation of the spherical Bessel function. Using the Jacobi-Anger identity in the exponential term, and substituting Eq. (5.23) into 
Eq. (5.22), the Fourier decomposed spherical Volkov state reads

$$
\begin{aligned}
& h_{l}^{(1)}\left[k_{n} r(t)\right] P_{l}^{m}[\cos \vartheta(t)] \exp (i m \varphi)=\sum_{l^{\prime}=0}^{\infty} \sum_{p=\left|l^{\prime}-l\right|}^{l^{\prime}+l} \sum_{s=-\infty}^{\infty} \frac{1}{2} i^{p-l}\left(2 l^{\prime}+1\right) \boldsymbol{a}_{l^{\prime}, l}^{0, m}(p) \\
& \times\left[\int_{-1}^{1} P_{l^{\prime}}(x) J_{s}\left(-k_{n} a x\right) \mathrm{d} x\right] h_{p}^{(1)}\left(k_{n} r\right) P_{p}^{m}(\cos \vartheta) \exp (i m \varphi) \exp (i s \omega t) .
\end{aligned}
$$

In order to avoid numerical integration in Eq. (5.24), we use the power series expansion of the Legendre polynomial

$$
P_{l}(x)=2^{l} \sum_{k=0}^{l}\left(\begin{array}{l}
l \\
k
\end{array}\right)\left(\begin{array}{c}
\frac{l+k-1}{2} \\
l
\end{array}\right) x^{k} .
$$

The integral of a product of a power function and a Bessel function of the first kind results in an expression involving Lommel functions [56], which can be rewritten as

$$
\begin{aligned}
& \int_{-1}^{1} x^{k} J_{s}\left(-k_{n} a x\right) \mathrm{d} x=2^{-1-s}\left[(-1)^{k}\left(k_{n} a\right)^{s}+\left(-k_{n} a\right)^{s}\right] \\
& \times \Gamma\left(\frac{k+s+1}{2}\right){ }_{1} \widetilde{F}_{2}\left[\frac{k+s+1}{2} ; \frac{k+s+3}{2}, s+1 ;-\frac{\left(k_{n} a\right)^{2}}{4}\right],
\end{aligned}
$$

where ${ }_{1} \widetilde{F}_{2}$ is the regularized hypergeometric function defined by

$$
{ }_{1} \widetilde{F}_{2}=\frac{{ }_{1} F_{2}\left(a_{1} ; b_{1}, b_{2} ; z\right)}{\Gamma\left(b_{1}\right) \Gamma\left(b_{2}\right)},
$$

here, ${ }_{1} F_{2}\left(a_{1} ; b_{1}, b_{2} ; z\right)$ is a generalized hypergeometric function. Thus, the integral in Eq. (5.24) can be computed with a finite sum of hypergeometric functions. We note that a similar integral also appears in recent works on laser-assisted electron scattering, see e.g., Refs. [73, 74]. Since the scattered wave function is built up by sums of spherical Volkov states, using Eqs. (5.10) and (5.24), we can formulate it in the Floquet form as

$$
\begin{aligned}
\Psi_{\text {scatt. }}= & \sum_{n, l, m} A(n, l, m) \sum_{l^{\prime}, p, s} \frac{1}{2} i^{p-l}\left(2 l^{\prime}+1\right) \boldsymbol{a}_{l^{\prime}, l}^{0, m}(p) \mathscr{P}\left(l^{\prime}, s \mid k_{n} a\right) \\
& \times h_{p}^{(1)}\left(k_{n} r\right) P_{p}^{m}(\cos \vartheta) \exp (i m \varphi) \exp \left\{-i\left[\omega_{0}+(n-s) \omega\right] t\right\},
\end{aligned}
$$

where

$$
\mathscr{P}\left(l^{\prime}, s \mid k_{n} a\right)=\int_{-1}^{1} P_{l^{\prime}}(x) J_{s}\left(-k_{n} a x\right) \mathrm{d} x .
$$




\subsubsection{Matching equations}

We can also rewrite the wave function of the incident electrons using the JacobiAnger identity and the formula (8.534) of Gradshteyn and Ryzhik [56] as follows

$$
\begin{aligned}
& \Psi_{\text {inc. }}=\sum_{n, l, m} J_{n}\left(k_{0} a \cos \vartheta_{0}\right) i^{l}(2 l+1) \frac{(l-m) !}{(l+m) !} j_{l}\left(k_{0} r\right) \\
& \times P_{l}^{m}\left(\cos \vartheta_{0}\right) P_{l}^{m}(\cos \vartheta) \exp \left[i m\left(\varphi-\varphi_{0}\right)\right] \exp \left(-i \omega_{n} t\right),
\end{aligned}
$$

where the angular frequencies read $\omega_{n}=\omega_{0}+n \omega$. Then, according to Eq. (5.10), the total wave function can be written as an incoming wave $\Psi_{\text {inc. plus a scattered }}$ wave $\Psi_{\text {scatt. }}$ in the laboratory frame.

Taking into account Eqs. (5.30) and (5.28), we can finally rewrite the boundary condition (5.6) in the form

$$
\left[\Psi(r, \vartheta, \varphi, t)=\Psi_{\text {inc. }}+\Psi_{\text {scatt. }}\right]_{r=R}=0
$$

for all values of $\vartheta, \varphi$ and $t$. Using the orthogonality of the associated Legendre polynomials and the orthogonality of the different Fourier components in $t$, we obtain the following matching equations

$$
\begin{aligned}
2 J_{n^{\prime \prime}}\left(k_{0} a \cos \vartheta_{0}\right) i^{p^{\prime}} j_{p^{\prime}}\left(k_{0} R\right) P_{p^{\prime}}^{m}\left(\cos \vartheta_{0}\right) \exp \left(-i m \varphi_{0}\right)+\sum_{n, l, l^{\prime}} A(n, l, m) i^{p^{\prime}-l} \\
\times \frac{2 l^{\prime}+1}{2 p^{\prime}+1} a_{l^{\prime}, l}^{0, m}\left(p^{\prime}\right) \mathscr{P}\left(l^{\prime}, n-n^{\prime \prime} \mid k_{n} a\right) h_{p^{\prime}}^{(1)}\left(k_{n} R\right) \frac{\left(p^{\prime}+m\right) !}{\left(p^{\prime}-m\right) !}=0
\end{aligned}
$$

for a fixed set of values $n^{\prime \prime}, p^{\prime}, m$. From this coupled system of linear equations, the unknown coefficients $A(n, l, m)$ can be evaluated with high precision, if we include sufficient number of partial waves (indexed by $p^{\prime}, m$ ) and Floquet channels (indexed by $\left.n^{\prime \prime}\right)$.

\subsection{Results in the weak-field limit}

In the following, we consider the low intensity limiting case where $\left|k_{n} a\right| \ll 1$. It can be easily shown [61] that the coefficients $A(n, l, m)$ can be explicitly given by

$$
A(n, l, m)=-i^{l}(2 l+1) \frac{(l-m) !}{(l+m) !} \frac{j_{l}\left(k_{0} R\right)}{h_{l}^{(1)}\left(k_{n} R\right)} P_{l}^{m}\left(\cos \vartheta_{0}\right) e^{-i m \varphi_{0}} J_{n}\left(k_{0} a \cos \vartheta_{0}\right)
$$

In three-dimensional scattering problems, the process is often characterized by differential cross sections. In some way, they can be considered as the threedimensional analogous quantities of the previously introduced one-dimensional trans- 

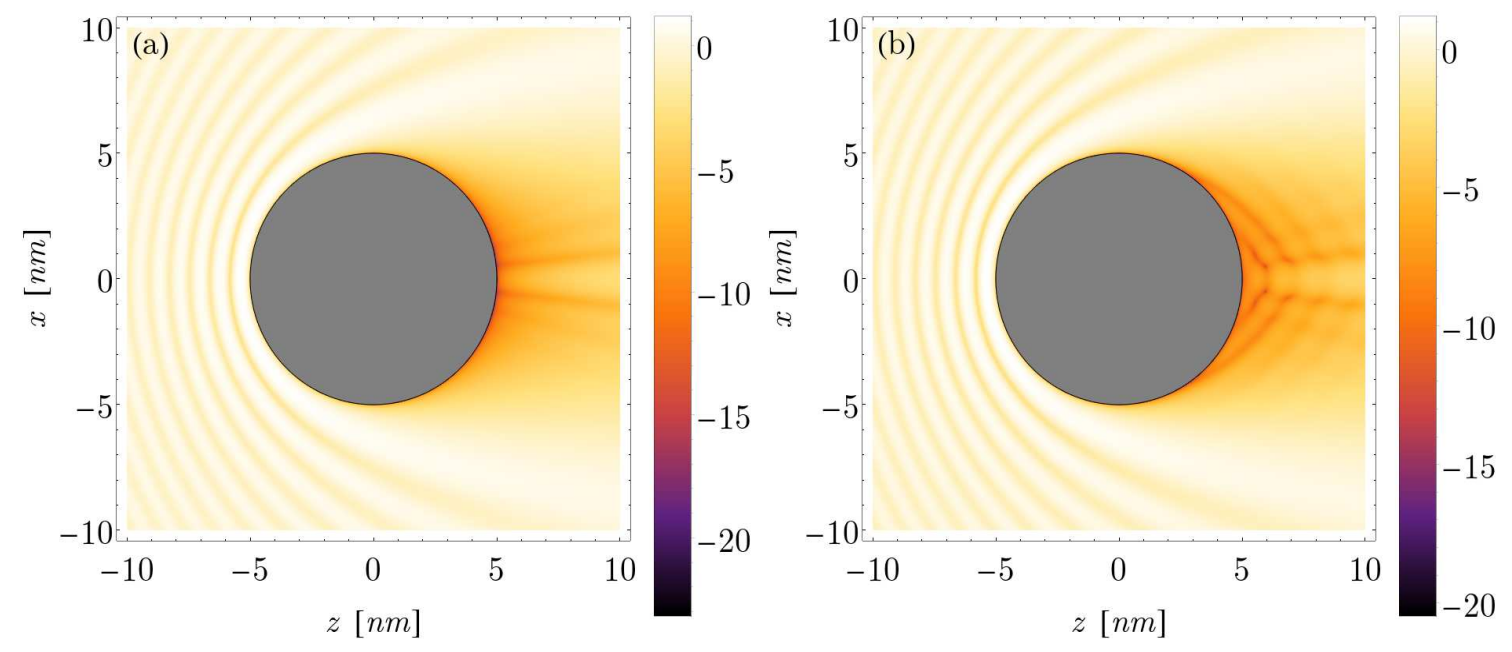

Figure 5.3: Density plots of the logarithm of the probability density in the $x-z$ plane in the absence and presence of the laser field shown in panel (a) and (b), respectively. The incoming electron energy $E_{0}=0.5 \mathrm{eV}$ and the hard sphere has a radius of $5 \mathrm{~nm}$.

mission probabilities. The total differential cross sections can be obtained through the asymptotic form of the scattered wave function. Inserting Eq. (5.33) into the expression of the scattered wave function and taking the limit $r \rightarrow \infty$, the total differential cross sections read

$$
\frac{\mathrm{d} \sigma_{n}}{\mathrm{~d} \Omega}=\frac{k_{n}}{k_{0}}\left|\frac{1}{k_{n}} \sum_{l=0}^{\infty}(2 l+1) \frac{j_{l}\left(k_{0} R\right)}{h_{l}^{(1)}\left(k_{n} R\right)} P_{l}\left(\cos \gamma_{0}\right)\right|^{2} J_{n}^{2}\left(k_{0} a \cos \vartheta_{0}\right),
$$

where

$$
\cos \gamma_{0}=\cos \vartheta \cos \vartheta_{0}+\sin \vartheta \sin \vartheta_{0} \cos \left(\varphi-\varphi_{0}\right),
$$

and $n$ denotes the index of each Floquet channel. Since the wave function (5.10) is expressed in terms of a nested infinite series, it is obvious that the numerical evaluation requires that only a finite number of terms should be taken into account. The accuracy of the wave function and the total differential cross sections depends on the truncation of the infinite series. In the following results, the boundary condition (5.31) is accurately satisfied, i.e., the real and the imaginary parts of the wave function on the boundary are less than $10^{-6}$, if we choose the upper limit of the series to be $N=15-20$, depending on various parameters.

Figure 5.3 shows the logarithm of the probability densities of the total wave function (5.10) for two cases: in the absence and presence of the laser field (in the weak-field limit) in panel (a) and panel (b), respectively. In both cases, the electron wave impinges the hard sphere with a diameter of $10 \mathrm{~nm}$ from a direction with a polar angle $\vartheta_{0}=0$, which corresponds to a beam coming in along the vector of linear polarization of the laser field. This is also a configuration for which a 


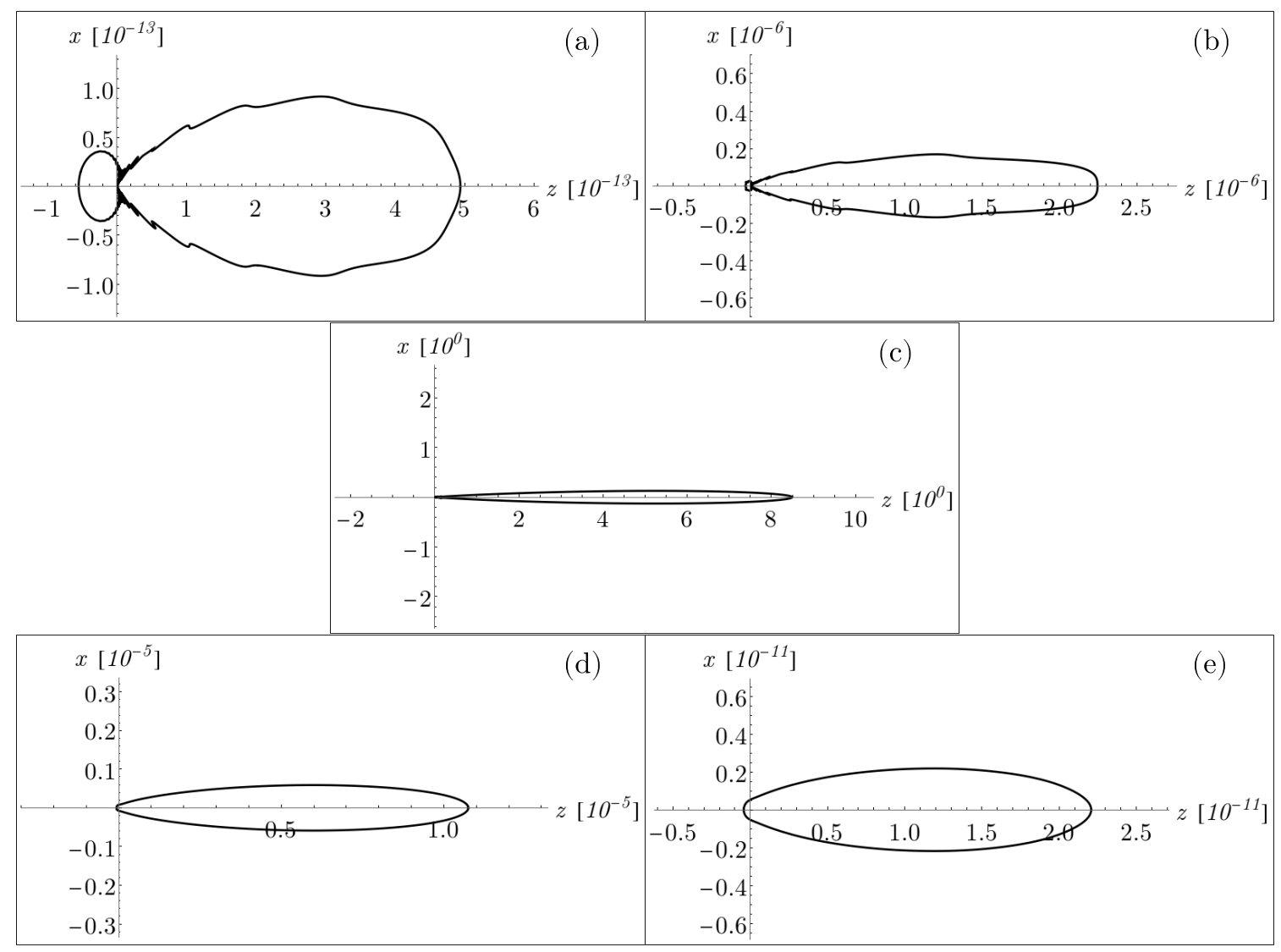

Figure 5.4: Polar plots of the total differential cross section as a function of the polar angle, in relative units normalized to the maximum of the $n=0$ case, for (a) $n=-2$, (b) $n=-1$, (c) $n=0$, (d) $n=1$, (e) $n=2$. Parameters: incoming electron energy $E_{0}=4 \mathrm{eV}$, photon energy $\hbar \omega=1.5 \mathrm{eV}$, field strength $2.5711 \times 10^{7} \mathrm{~V} / \mathrm{m}$.

maximum of interaction between the electron and radiation field can be expected. The probability densities, which are calculated in the $x-z$ plane at $y=0$, show an interference pattern. Without the external field, the process can be viewed as the Mie scattering of electrons, where the de Broglie wavelength is comparable with the size of the nano-sphere. The electrons are scattered back to the opposite direction of incidence, which causes the interference pattern in front of the sphere. However, in the presence of the laser field, interference fringes appear also in the "shadow" region behind the nano-sphere, due to the interaction between the laser field and the electrons. Here, the collision of the electrons and the hard sphere induces reflected waves causing the interference.

In order to gain more insight into the dynamics of the laser-assisted scattering process, it is worth examining the angular distribution of the total differential cross section. In Fig. 5.4, the total differential cross section of the $n$th scattering channel is presented as a function of the polar angle $\vartheta$ in a polar plot. Since we chose $\vartheta_{0}=0$ for the incoming electrons, it is straightforward to study the directional dependence in the $x-z$ plane where the azimuth $\varphi$ is zero. From panel (a) to (e), the total 
differential cross section for each Floquet channel from $n=-2$ to $n=2$ is shown in relative units normalized to the $n=0$ case. It is clearly seen, that the more energy is lost or gained by the electrons in the form of "photons", the wider (and in the case of energy loss also the more complex) the angular dependence becomes, along with increasing probability of backscattering.

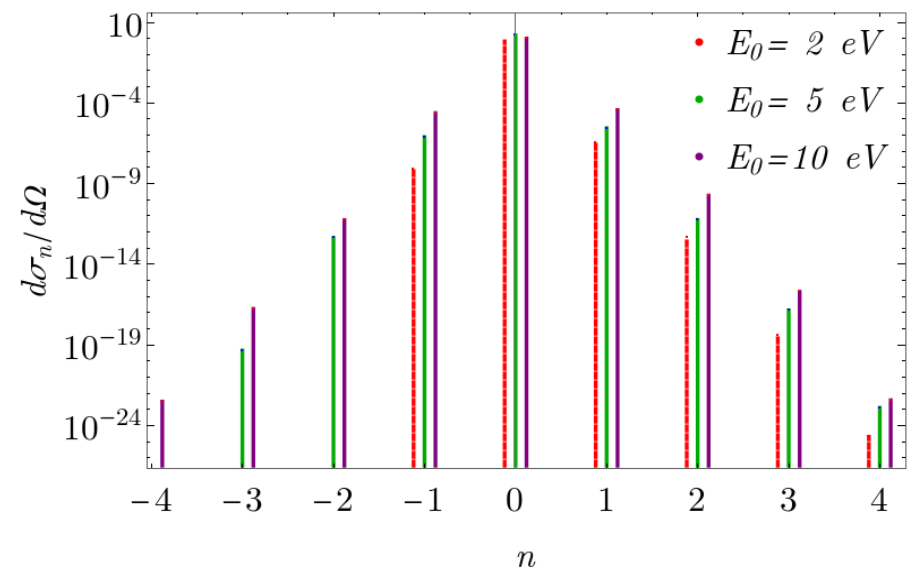

Figure 5.5: Total differential cross section (in relative units) at the forward direction $(\vartheta=0)$ as a function of the scattered electron energy $E_{n}$ in the weak-field limit. The different colored lines mean different incident electron energies. The photon energy $\hbar \omega=1.5 \mathrm{eV}$.

In Fig. 5.5, we focus on forward scattering, where the scattering angle $\vartheta$ is chosen to be zero and the field strength takes such a value that the weak field limit condition can still be considered to be satisfied. The total differential cross section is plotted as a function of the electron energy in the $n$th channel. The positive and the negative values of $n$ correspond to "photon" absorption and emission, respectively. It is clearly shown by this plot that the sidebands corresponding to the indices $n \neq 0$ get more populated with increasing incoming electron energy [36].

If the low intensity assumption is released, then the linear system of equations becomes coupled, and, in order to ensure convergence, we can truncate the system of equations only at much larger values of $n, l, m$. In this case, the calculations can only be carried out with high-performance computation. At a qualitative level, we expect that for higher intensities, the higher order sidebands get more populated at the expense of the central $(n=0)$ band's significant reduction, and that the interference patterns in the electron probability density become more pronounced.

\subsection{Summary}

Based on the work [61], we have presented a three-dimensional model which describes the scattering of monoenergetic electrons on a hard sphere in the presence of a linearly polarized laser field. We gave an alternative derivation of spherical 
Gordon-Volkov states using the translational addition theorem of spherical waves. We also gave an analytic expression in order to allow the practical application of this approach. We presented and analyzed the scattering process by inspecting the total differential scattering cross sections. We concluded that the sidebands are more populated for increasing electron energies, similarly to the one-dimensional Ramsey-like model. 


\section{CHAPTER 6}

\section{Relativistic scattering by an oscillating barrier}

In this chapter, transport properties of massive Dirac particles are investigated through an oscillating rectangular barrier. Like in the previous models, the Floquet quasienergies appear both in transmission and reflection as sidebands around the incoming electron's energy. We take all relevant sidebands into account and present time-averaged transmission probabilities in a wide energy range. Most qualitative features of scattering on a static barrier - like Klein paradox - are still visible, but the transmission probability in the evanescent regime observably increases due to the oscillation of the potential. The strongly inelastic scattering process is shown to lead to multiple Fano-type resonances and temporal trapping of the particles inside the oscillating potential. We also present a detailed study of the time evolution of the wave packets generated in the scattering process. The results can be relevant for graphene with an induced energy gap.

\subsection{Introduction}

Photon-assisted tunneling [77, 78] is a remarkable example showing that the presence of an alternating field can lead to strongly inelastic processes. Nonrelativistic quantum mechanical scattering on barriers with oscillating height has been investigated intensively, mainly in the context of traversal time and photon assisted transport, see, e.g., Refs. [78 80]. It has also been proven that Floquet's theory provides an efficient tool for the investigation of various time-dependent scattering processes [57, 81]. Fano-type resonances [82, 83] can appear in this context due to transitions between sideband states and bound states. Developments in the experimental techniques during the last decade enable that these results have the potential of direct applications in the rapidly expanding field of meso- and nanoscale quantum devices [3, 84].

Much of the theoretical works published so far studied transport through time- 
dependent potentials in a nonrelativistic framework [57, 78 $\underline{81}$, 85, 86]. Transport related problems with oscillating spin-orbit interaction have been studied, e.g., in Refs. [87-89]. A few recent papers [90 92], treating massless Dirac particle scattering on time-harmonic potentials, are inspired by the unique electronic dispersion relation of graphene [93, 94]. In this single layer of hexagonal carbon atoms, as has been demonstrated experimentally 95 97], the carriers exhibit striking relativistic features like Zitterbewegung [98, 99], Klein paradox [27, 100 103], and Klein tunneling [104, 105].

The substrate-induced band gap in epitaxially grown graphene [106] opened the way for its usage as an electronic material. This induced band gap leads to a finite mass for its charge carriers which obey the massive Dirac equation, and the energy dispersion relation is no longer linear in momentum. Based on this, Klein tunneling of massive Dirac fermions through a static barrier [107], and massive Dirac electron tunneling through a time-periodic potential in single layer graphene [108] were studied.

This chapter is organized as follows. In Sec. 6.2, we define the model and derive the equations for the amplitudes, to be solved numerically, from the one-dimensional Dirac equation using Floquet's theory. In Sec. 6.3, we present the physical contents of the numerical solution (e.g., Klein tunneling) in terms of the cycle-averaged transmission probabilities. We explore the details of the scattering with the help of spaceand time-dependent charge current and electron density. Finally, we analyze and explain in detail the Fano-type resonances [82, 83] found in the transmission curves. We close the chapter by summarizing the results and drawing conclusions in Sec. 6.4

\subsection{Model}

We consider a relativistic one-dimensional model where a constant plus a harmonically varying potential is applied:

$$
V(t)=V_{0}+V_{1}(t)=V_{0}+\hbar \Omega \cos \omega t
$$

Outside the oscillation region the potential is zero, see Fig. 6.1, A monoenergetic spin-polarized free electron wave is assumed to impinge the oscillating potential barrier, i.e, in the standard representation (which was discussed earlier in Chapter 


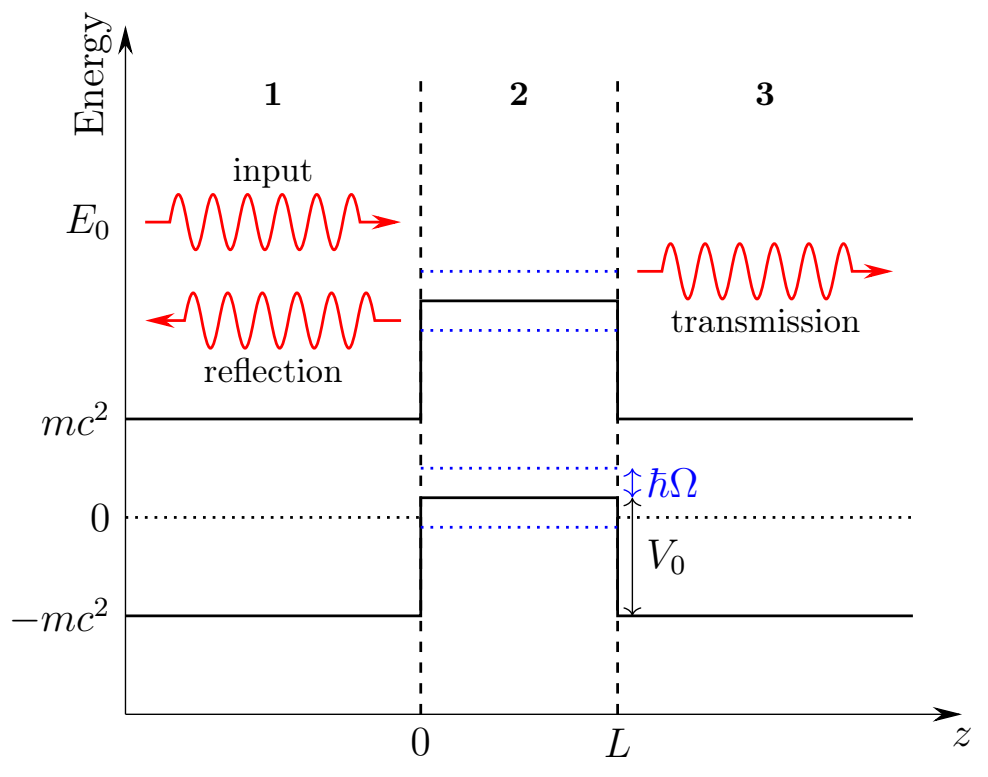

Figure 6.1: Schematic view of the one-dimensional scattering problem we consider. The harmonic oscillation of the potential has an amplitude of $\hbar \Omega$ and angular frequency of $\omega$. That is, $V(t)=V_{0}+\hbar \Omega \cos \omega t$ in region 2 , while the potential is zero in regions 1 and 3 . A monoenergetic electron wave is assumed to impinge the oscillating barrier inducing reflected and transmitted waves in region 1 and 3, respectively. The input energy $E_{0}$ is always larger than $m c^{2}$, but the magnitudes of $E_{0}, V_{0}$ and $\hbar \Omega$ relative to each other were varied in our calculations.

3), we have

$$
\psi_{\text {in }}(z, t)=e^{i k_{0} z-i E_{0} t / \hbar}\left(\begin{array}{c}
1 \\
0 \\
\frac{c \hbar k_{0}}{E_{0}+m c^{2}} \\
0
\end{array}\right)
$$

where the direction of propagation has been chosen to be the $z$ axis. The spinor above is a solution of the Dirac equation with $\hbar k_{0}= \pm \sqrt{E_{0}^{2}-m^{2} c^{4}} / c$. According to the geometry shown in Fig. 6.1, we choose the positive sign here.

Note that in one dimension, it is sufficient to consider two-component spinors only, since two of the bispinor components are always zero. However, for the sake of clarity, we continue with the full four-component bispinor form.

\subsubsection{Solution of the Dirac equation with oscillating potential}

Inside the region $0<z<L$ the time-dependent Dirac equation reads

$$
i \hbar \frac{\partial}{\partial t} \psi(z, t)=H(t) \psi(z, t)
$$


with the Hamiltonian

$$
H(t)=H_{0}+V_{1}(t)=c \alpha_{3}\left(-i \hbar \frac{\partial}{\partial z}\right)+\beta m c^{2}+V_{0}+V_{1}(t)
$$

where the standard $\alpha_{3}$ and $\beta$ matrices appear. Since the commutator $\left[H(t), H\left(t^{\prime}\right)\right]=$ 0 holds for any time instant, an eigenstate defined by

$$
H_{0} \varphi=\mathscr{E} \varphi
$$

can be used to construct a solution to Eq. (6.3):

$$
\varphi(t)=\varphi(0) \exp \left[-\frac{i}{\hbar}\left(\varepsilon t+\int_{0}^{t} V_{1}\left(t^{\prime}\right) \mathrm{d} t^{\prime}\right)\right] .
$$

For a fixed value of wave number $k$, (i.e., spatial dependence of $e^{i k z}$ ), we have

$$
\mathcal{E}^{ \pm}(k)= \pm \sqrt{m^{2} c^{4}+\hbar^{2} k^{2} c^{2}}+V_{0},
$$

which are both doubly degenerate (due to the two possible spin directions). Since the interaction is independent of spin [the terms $V_{0}+V_{1}(t)$ are proportional to the unit matrix in Eq. (6.3)], the solutions of Eq. ([6.3) that correspond to the monoenergetic incoming spinor (6.2) as a boundary condition, have nonzero components at the same positions as $\psi_{\text {in. }}$. Therefore it is sufficient to consider only

$$
\begin{gathered}
\varphi^{ \pm}(z, t)=e^{i k z} u^{ \pm}(k) \exp \left[-i\left(\frac{\mathcal{E}^{ \pm} t}{\hbar}+\frac{\Omega}{\omega} \sin \omega t\right)\right], \\
u^{+}(k)=\left(\begin{array}{c}
1 \\
0 \\
\frac{c \hbar k}{\mathcal{E}^{+}(k)-V_{0}+m c^{2}} \\
0 \\
c \hbar k \\
u^{-}(k)=\left(\begin{array}{c}
\frac{c \hbar}{\mathcal{E}^{-}(k)-V_{0}+m c^{2}} \\
0 \\
1 \\
0
\end{array}\right),
\end{array}\right.
\end{gathered}
$$

that clearly satisfy Eq. (6.3). Using Eq. (6.7), it is readily seen that the Dirac spinors above do not depend on $V_{0}$. Thus, e.g., the wave function of the incoming electron described by Eq. (6.2) can be rewritten as $\psi_{\text {in }}(z, t)=e^{i k_{0} z-i E_{0} t / \hbar} u^{+}\left(k_{0}\right)$. [In this case 
$\mathcal{E}^{+}\left(k_{0}\right)=E_{0} \cdot$

Note that the only restriction in Eqs. (6.7) (6.10) concerning $k$ is that $\hbar^{2} k^{2} \geq$ $-m^{2} c^{2}$ [ensuring that $\mathcal{E}^{ \pm}$are real, see Eq. (6.7)]. This means that evanescent solutions with purely imaginary $k$ are also allowed.

Using the Jacobi-Anger identity

$$
\exp \left(-i \frac{\Omega}{\omega} \sin \omega t\right)=\sum_{n=-\infty}^{\infty} J_{n}\left(\frac{\Omega}{\omega}\right) e^{-i n \omega t}
$$

where $J_{n}$ denote Bessel functions of the first kind, we see that the frequencies appearing in the time evolution are given by $\mathcal{E}^{ \pm}(k) / \hbar+n \omega$, with integer $n$. Note that since the differential operator given by Eq. (6.4) is periodic in time $(\mathcal{T}=2 \pi / \omega)$, Floquet's theory [1, 2] can be applied. The states (6.8) are orthogonal in the spinor sense; they can be considered as elements of a time-dependent basis. Apart from the factors $\exp \left(-i \mathcal{E}^{ \pm}(k) t / \hbar\right)$, these solutions are periodic, thus $\mathcal{E}^{ \pm}(k)$ can be called the (nonequivalent) Floquet quasienergies. The term nonequivalent means here that, e.g., $\tilde{\mathscr{E}}^{-}(k)=\mathcal{E}^{-}(k)+n \hbar \omega$ can also play the role of a Floquet quasienergy (with $n$ being an integer), but states corresponding to $\tilde{\mathscr{E}}^{-}$and $\mathcal{E}^{-}$are dynamically equivalent as was discussed in Chapter 1, On the other hand, $\mathcal{E}^{+}(k)$ and $\mathscr{E}^{-}(k)$ correspond to qualitatively different dynamical behaviors (unless their difference is an integer multiple of $\hbar \omega)$.

\subsubsection{Fitting the solutions}

In the previous subsection plane wave solutions of the Dirac equation in periodic external field were obtained. It was shown that for a given (real or purely imaginary) value of $k$, Eq. (6.3) is satisfied by the spinors $\varphi^{ \pm}(z, t)$ given by Eq. (6.8). However, as we shall see, in order to obtain a solution to the problem over the whole $z$ axis, several (in principle an infinite number of) different wave vectors are needed.

According to the previous subsection, in region 2 (where the potential oscillates) whenever a frequency $\mathcal{E} / \hbar$ appears in the time evolution, the harmonics $\mathscr{E} / \hbar+n \omega$ are also present $(n=\ldots,-2,-1,0,1,2, \ldots)$. However, if we want to impose continuity of the spinor valued wave function at the boundaries $(z=0$ and $z=L)$, the linear algebraic equations have nontrivial solutions only if the input frequency equals to one of the harmonics mentioned above. In other words, the frequencies we have to take into account are

$$
\omega_{n}=E_{n} / \hbar=E_{0} / \hbar+n \omega,
$$

where $E_{0}$ is the well-defined energy of the input spinor, see Eq. (6.2). In region 1, the only right propagating spinor (see Fig. 6.1) is the input; a particular solution of 
the Dirac equation corresponding to frequencies $\omega_{n}$ is given by

$$
\Psi_{1}(z, t)=\psi_{\text {in }}(z, t)+\sum_{\omega_{n}>0} r_{n} e^{-i k_{n} z} u^{+}\left(-k_{n}\right) e^{-i \omega_{n} t}+\sum_{\omega_{n}<0} r_{n} e^{-i k_{n} z} u^{-}\left(-k_{n}\right) e^{-i \omega_{n} t}
$$

where

$$
k_{n}= \begin{cases}\sqrt{\frac{E_{n}^{2}-m^{2} c^{4}}{\hbar^{2} c^{2}}}, & \text { if } E_{n}^{2}>m^{2} c^{4} \\ i \sqrt{\frac{m^{2} c^{4}-E_{n}^{2}}{\hbar^{2} c^{2}}}, & \text { if } E_{n}^{2}<m^{2} c^{4} .\end{cases}
$$

The signs here have been chosen such that the terms proportional to $r_{n}$ in Eq. (6.13) describe either reflected or evanescent waves (with exponentially decaying amplitude as $z \rightarrow-\infty$.) Analogously, in region 3 :

$$
\Psi_{3}(z, t)=\sum_{\omega_{n}>0} t_{n} e^{i k_{n} z} u^{+}\left(k_{n}\right) e^{-i \omega_{n} t}+\sum_{\omega_{n}<0} t_{n} e^{i k_{n} z} u^{-}\left(k_{n}\right) e^{-i \omega_{n} t}
$$

The problem is somewhat more complicated in region 2 , where

$$
k_{n}^{\prime}= \begin{cases}\sqrt{\frac{\left(E_{n}-V_{0}\right)^{2}-m^{2} c^{4}}{\hbar^{2} c^{2}}}, & \text { if }\left(E_{n}-V_{0}\right)^{2}>m^{2} c^{4} \\ i \sqrt{\frac{m^{2} c^{4}-\left(E_{n}-V_{0}\right)^{2}}{\hbar^{2} c^{2}}}, & \text { if }\left(E_{n}-V_{0}\right)^{2}<m^{2} c^{4}\end{cases}
$$

are the solutions of

$$
\mathcal{E}^{ \pm}\left(k_{n}\right)=E_{n}
$$

Additionally, in this case, due to the oscillation of the potential, a given wave number $k_{n}^{\prime}$ corresponds to not only a single $\omega_{n}$. For the sake of simplicity, we collect the coefficients of the two types of spinors given by Eqs. (6.9) and (6.10) separately, and write

$$
\Psi_{2}(z, t)=\Psi_{2}^{+}(z, t)+\Psi_{2}^{-}(z, t)
$$

The first term here is given by

$$
\Psi_{2}^{+}(z, t)=\sum_{\omega_{n}>0} e^{-i \omega_{n} t-i(\Omega / \omega) \sin \omega t}\left[a_{n} e^{i k_{n}^{\prime} z} u^{+}\left(k_{n}^{\prime}\right)+b_{n} e^{-i k_{n}^{\prime} z} u^{+}\left(-k_{n}^{\prime}\right)\right]
$$

where, as we can see, both propagation directions appear. Additionally, due to the finite size of the region, exponentially growing spatial dependence is also allowed. Next we insert the Jacobi-Anger expansion (6.11) and obtain an equation where the frequencies $\omega_{n}$ appear explicitly. For the sake of brevity, we present this step only 
for the terms containing the spinor $u^{-}$:

$$
\Psi_{2}^{-}(z, t)=\sum_{\omega_{n}<0} \sum_{m} J_{m}\left(\frac{\Omega}{\omega}\right) e^{-i \omega_{n+m} t}\left[a_{n} e^{i k_{n}^{\prime} z} u^{-}\left(k_{n}^{\prime}\right)+b_{n} e^{-i k_{n}^{\prime} z} u^{-}\left(-k_{n}^{\prime}\right)\right] \text {. }
$$

The condition of continuity at $z=0(z=L)$ now can be formulated by evaluating $\Psi_{1}(0, t)$ and $\Psi_{2}(0, t)\left[\Psi_{2}(L, t)\right.$ and $\left.\Psi_{3}(L, t)\right]$. Working in frequency domain, as an example, the contribution of $\Psi_{2}^{-}(z=0)$ to the frequency component $\omega_{l}$ is given by

$$
\sum_{\omega_{n}<0} J_{l-n}\left(\frac{\Omega}{\omega}\right)\left[a_{n} u^{-}\left(k_{n}^{\prime}\right)+b_{n} u^{-}\left(-k_{n}^{\prime}\right)\right] .
$$

By comparing these coefficients for each $\omega_{l}$ at the boundaries and for each propagating direction, we obtain an infinite system of linear equations for the unknown coefficients $\left\{r_{n}, t_{n}, a_{n}, b_{n}\right\}$. However, since the Bessel functions $J$ for a given argument generally decrease as a function of their index, correct numerical solutions could be obtained by taking only a finite number of frequencies into account. If we consider a set $\left\{\omega_{n}: n=-N, \ldots, 0, \ldots N\right\}$, there will be $8 N+4$ fitting equations and the same number of unknowns. As we shall see in the next section, the time averages of the transmission and reflection probabilities provide an efficient tool for monitoring the accuracy of the numerical method: If their sum is not as close to unity as we require, $N$ has to be increased.

\subsection{Results and discussion}

In this section, the obtained results will be shown based on the model discussed in the previous section. Note that the parameter ranges we use are ideal to see and identify the physical processes that are responsible for the effects to be presented. To this end, we use "natural units" (i.e., $\hbar=1, m=1$, and $c=1$ ) for the figures.

\subsubsection{Cycle-averaged reflection and transmission probabilities}

The time-dependent reflection and transmission probabilities are given by the ratio of the transmitted and reflected currents to the incoming one:

$$
\begin{aligned}
& R(t)=\frac{j_{r}(t)}{j_{\text {in }}}=\frac{E_{0}+m c^{2}}{2 c \hbar k_{0}} \widetilde{\Psi_{1}^{\dagger}} \alpha_{3} \widetilde{\Psi_{1}}(0, t), \\
& T(t)=\frac{j_{t}(t)}{j_{\text {in }}}=\frac{E_{0}+m c^{2}}{2 c \hbar k_{0}} \Psi_{3}^{\dagger} \alpha_{3} \Psi_{3}(L, t),
\end{aligned}
$$

where

$$
\widetilde{\Psi_{1}}=\Psi_{1}-\psi_{\text {in }}
$$


i.e., the reflected (or exponentially decaying) part of $\Psi_{1}$. Since the time dependence of both $T$ and $R$ contains factors $\exp \left[-i\left(\omega_{n}-\omega_{m}\right) t\right]=\exp [-i \omega(n-m) t]$, these functions are periodic, $T(t+\tau)=T(t), R(t+\tau)=R(t)$, with $\tau=2 \pi / \omega$. First we calculate the time average of the reflection and transmission probabilities,

$$
\langle T\rangle=\frac{1}{\tau} \int_{0}^{\tau} T(t) \mathrm{d} t, \quad\langle R\rangle=\frac{1}{\tau} \int_{0}^{\tau} R(t) \mathrm{d} t .
$$

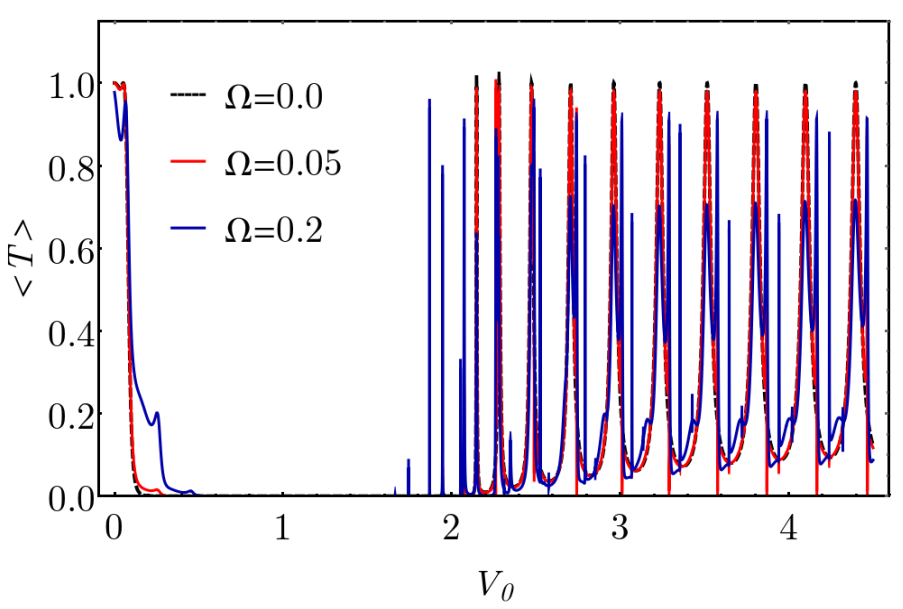

Figure 6.2: $\langle T\rangle$ as a function of barrier height $V_{0}$ for the indicated values of the oscillation amplitude $\Omega$. Additional parameters: $E_{0}=1.1 m c^{2}, \omega=0.2, L=10$. The physical meaning of the spikes will be discussed later in Subsec. 6.3.3.

Inserting Eqs. (6.13) and (6.15) into Eqs. (6.22a) and (6.22b) leads to products of sums, which reduce to

$$
\begin{aligned}
& \langle T\rangle=\sum_{\Im\left(k_{n}\right)=0}\left|t_{n}\right|^{2} \frac{2 c \hbar k_{n}}{E_{n}+m c^{2}}, \\
& \langle R\rangle=\sum_{\Im\left(k_{n}\right)=0}\left|r_{n}\right|^{2} \frac{2 c \hbar k_{n}}{E_{n}+m c^{2}},
\end{aligned}
$$

since the integral $(1 / \tau) \int_{0}^{\tau} \exp (i n \omega t) d t=\delta_{n 0}$ for any integer values of $n$. Because of the time-periodicity of the scattering problem, the cycle average of the incoming current should be equal to $\left\langle j_{t}\right\rangle-\left\langle j_{r}\right\rangle=\left|\left\langle j_{t}\right\rangle\right|+\left|\left\langle j_{r}\right\rangle\right|$. In other words,

$$
\langle T\rangle+\langle R\rangle=1
$$

should hold for any system parameters similarly to Chapter 4 . This requirement can be used to monitor the accuracy of our calculations. Since we truncate the infinite system of equations, it is not necessary that Eq. (6.26) is satisfied. However, if the populations of the states that are neglected due to the truncation are negligible, 
the error can be kept below an acceptable limit. For the results to be presented in the following, $|1-\langle T\rangle-\langle R\rangle| \leq 10^{-6}$, and to achieve this limit, it was sufficient to truncate the system at $N \approx 25$ depending on various parameters.
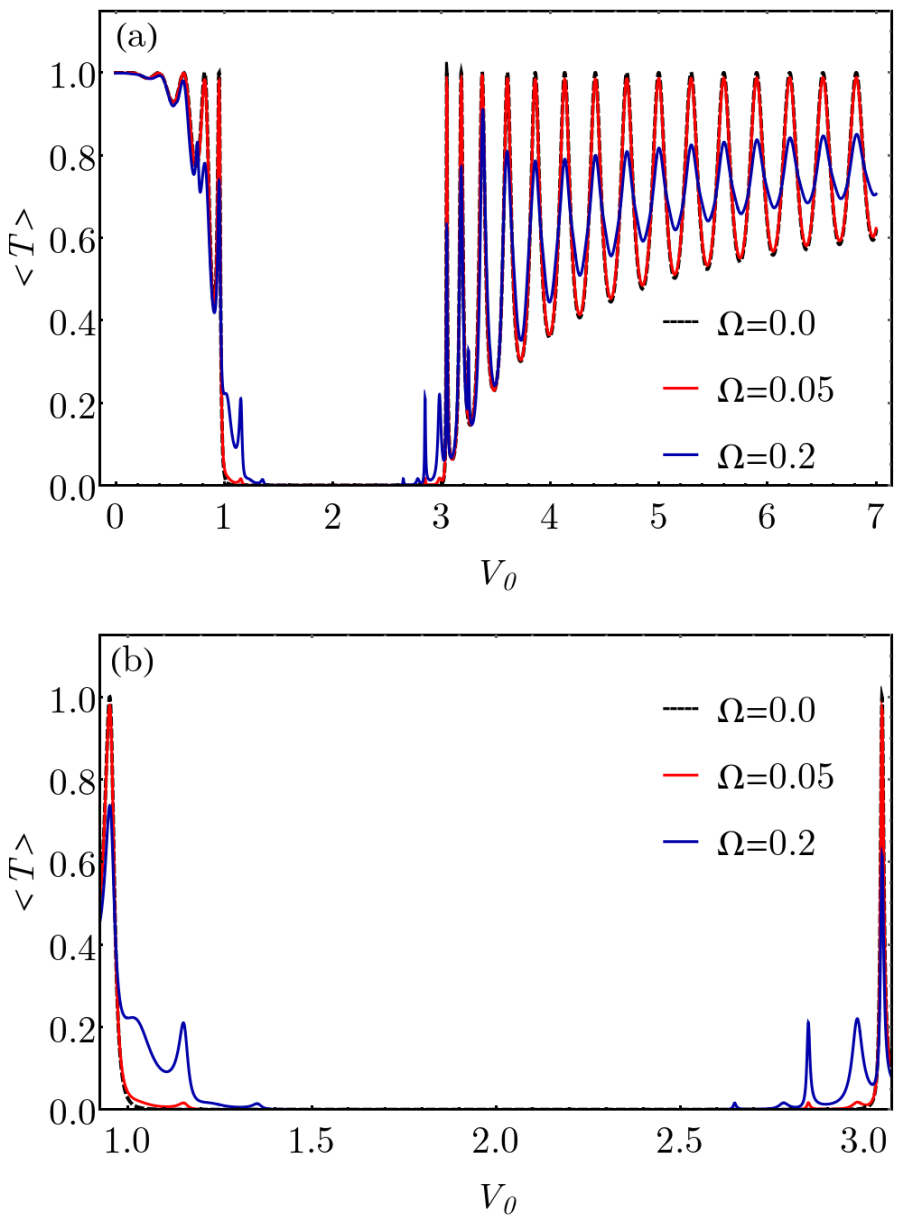

Figure 6.3: Panel (a): $\langle T\rangle$ as a function of barrier height $V_{0}$ for the indicated values of the oscillation amplitude $\Omega$. Additional parameters: $E_{0}=2 m c^{2}, \omega=0.2, L=10$. Panel (b): Zoom into the interval $E_{0}-m c^{2}<V_{0}<E_{0}+m c^{2}$ of panel (a).

Figures 6.2 6.4 show $\langle T\rangle$ as a function of $V_{0}$ for the weakly relativistic, relativistic, and ultrarelativistic cases (when $E_{0}$ is close to $m c^{2}, E_{0}=2 m c^{2}$ and $E_{0}=10 m c^{2}$, respectively). The dashed black curve - as a reference - corresponds to the case of $\Omega=0$ (nonoscillating barrier) in all figures 1 . The most important point that Figs. 6.2 6.4 have in common is that for $\Omega=0$ (and oscillations with small amplitude) $\langle T\rangle$ is practically unity when $V_{0} \ll E_{0}$; it is almost zero when $E_{0}-m c^{2}<V_{0}<E_{0}+m c^{2}$ and converges (in an oscillating way) to 1 again, when $V_{0}>E_{0}+m c^{2}$. This is a well-known behavior, that can be understood readily by investigating Eq. (6.16): The solutions in region 2 (see Fig. 6.1) are propagating waves in the first case, real exponentials in the evanescent domain $\left(E_{0}-m c^{2}<V_{0}<E_{0}+m c^{2}\right)$ and propagating waves again when $V_{0}>E_{0}+m c^{2}$. In

\footnotetext{
${ }^{1}$ This has already been discussed and shown at the end of Chapter 3 .
} 
other words, $\langle T\rangle$ reproduces the Klein paradox [27, 100 103] for small values of $\Omega$.
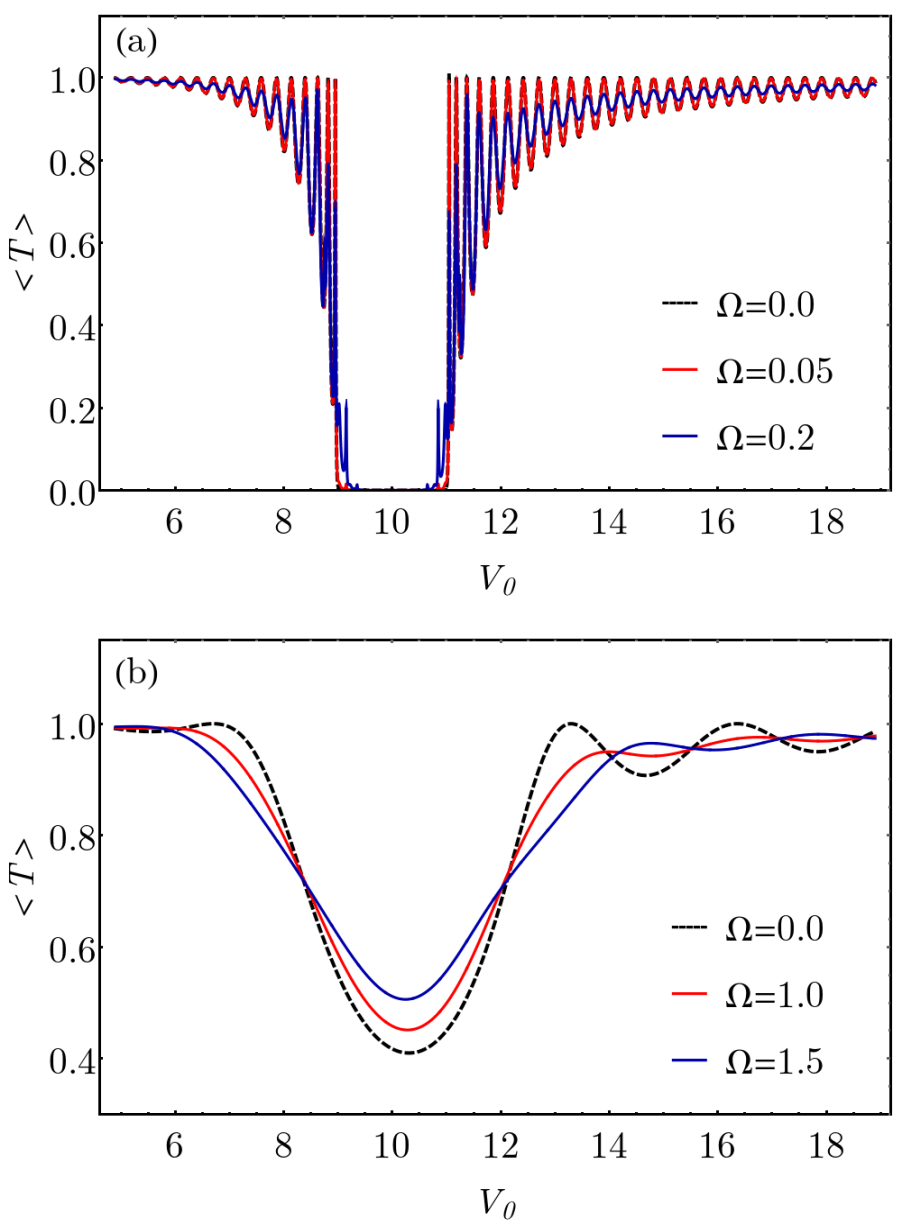

Figure 6.4: $\langle T\rangle$ as a function of barrier height $V_{0}$ for the indicated values of the oscillation amplitude $\Omega$. Additional parameters in panel (a): $E_{0}=10 m c^{2}, \omega=$ $0.2, L=10$, panel (b): $E_{0}=10 m c^{2}, \omega=0.2, L=1$.

The oscillations that can be seen in Figs. 6.26.4 are signatures of quantum mechanical interference: There are maxima (minima) in $\langle T\rangle$ when the spinor valued waves interfere constructively (destructively) at $z=L$. When the ratio $\Omega / \omega$ is small, terms corresponding to wave numbers $k_{0}$ and $k_{0}^{\prime}$ dominate the dynamics. For larger values of $\Omega / \omega$, the expansion (6.11) in terms of Bessel functions contains numerous frequency components resulting in more complex oscillation patterns in Figs. 6.2 6.4.

The figures show an additional, important effect, namely the gradual disappearance of the pronounced flat minimum of $\langle T\rangle\left(V_{0}\right)$ as either $L$ is decreased, or $\Omega$ increased. The first case is related to the role of the evanescent solutions, since tunneling becomes increasingly efficient when the width of region 2 is decreased. When the amplitude of the potential oscillations is increased, more and more frequency components play a relevant role in the dynamics. Some of them corresponds to (quasi)energies $E_{n}$ that are higher than the oscillating barrier, and consequently the related part of the spinor valued waves are transmitted with a high probability. 
This effect is still present in the case when the energy of the incoming spinor $E_{0}$ is below the minimum of the oscillating potential:

$$
E_{0}-m c^{2}<V_{0}-\hbar \Omega
$$

Without oscillations, $\langle T\rangle=T$ would be practically zero in this case. Figure 6.5 corresponds to parameter values where Eq. (6.27) is satisfied and $T<10^{-7}$ when $\Omega=0$. However, as we can see in the figure, orders of magnitude higher cycleaveraged transmission probabilities arise when $\Omega=0.3$ (in natural units.) The dependence of $\langle T\rangle$ on the frequency $\omega$ shown in Fig. 6.5 tells us that although lower values of $\omega$ with a fixed $\Omega$ means that more frequencies $\omega_{n}$ should be taken into account, this effect is weaker than the fact that higher values of $\omega$ corresponds to larger steps in the ladder $\omega_{n}=\omega_{0}+n \omega$. That is, as a tendency, $\langle T\rangle(\omega)$ is an increasing function in the parameter range given by Eq. (6.27).

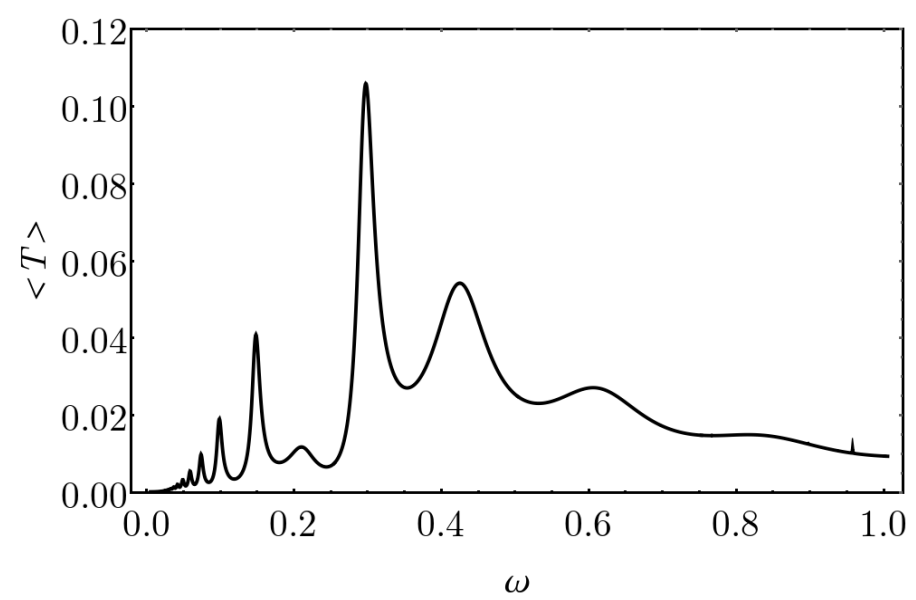

Figure 6.5: $\langle T\rangle$ as a function of $\omega$, for parameters $E_{0}=2.5 m c^{2}, V_{0}=1.75, L=$ $10, \Omega=0.2$. Note that the transmission probability in the static case for the same parameters (evanescent solutions) has the order of magnitude of $10^{-6}$. Note that the physical relevance of the abrupt changes seen in this figure will be analyzed in detail in Subsec. 6.3.3,

\subsubsection{Wave-packet generation and propagation}

In this subsection, we examine the dynamics of the scattering. It is instructive to investigate the space and time dependent quantities

$$
\rho(z, t)=\Psi^{\dagger}(z, t) \Psi(z, t), \quad j(z, t)=c \Psi^{\dagger}(z, t) \alpha_{3} \Psi(z, t)
$$

that satisfy the one-dimensional continuity equation

$$
\frac{\partial}{\partial t} \rho(z, t)=-\frac{\partial}{\partial z} j(z, t) .
$$


The Dirac spinor $\Psi$ in Eq. (6.28) above stands for $\Psi_{i}, i=1,2,3$, depending on whether the space coordinate $z$ is in region 1,2 or 3 , respectively. Note that without potential oscillation, i.e., for $\Omega=0, \rho$ does not depend on time, and consequently $j$ is constant as a function of $z$. Considering an oscillating potential, the space-time dependence of both quantities are considerably more interesting, and sheds light on the cycle-averaged results presented in the previous subsection.
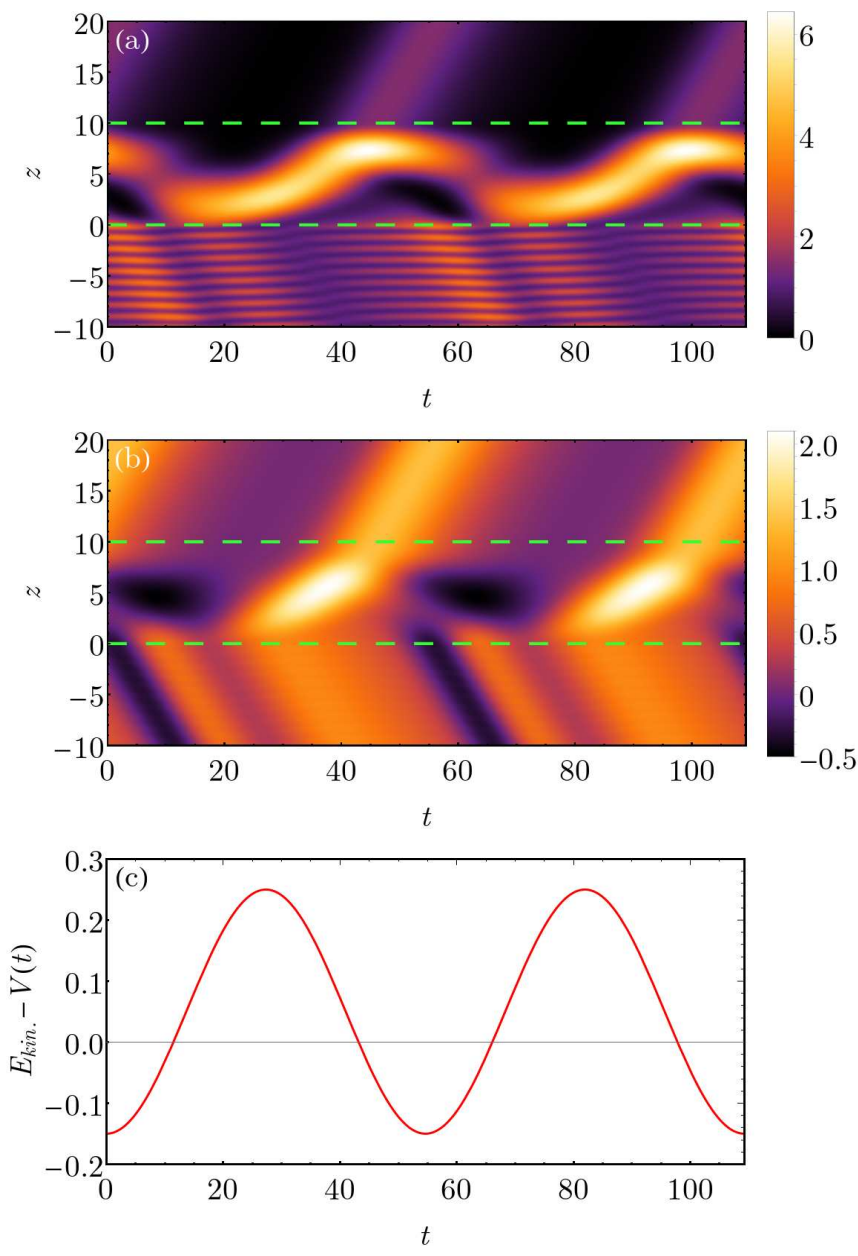

Figure 6.6: Density plot of $\rho(z, t)$ in panel (a), and of $j(z, t)$ in panel (b), and plot of $E_{k i n}-V(t)=E_{0}-m c^{2}-V(t)$ in panel (c), for the parameters $L=10, V_{0}=1.95 m c^{2}$, $E_{0}=3 m c^{2}$, and $\Omega=0.2$.

The physical phenomena being responsible for the results presented so far are most visible by focusing on parameters yielding $\langle T\rangle=\langle R\rangle=1 / 2$. Figures [6.6 and 6.7 show $\rho(z, t)$ and $j(z, t)$ in this case, for different values of $\Omega$. As previously, the patterns that can be seen are more complex for a larger amplitude of the potential oscillations, but the qualitative features of Figs. 6.6 and 6.7 are the same. Considering the probability density, it has certain pronounced maxima in region 2 (the value of $\rho$ at these points can be larger than anywhere else by a factor of two), i.e., we observe a kind of temporal "trapping" of the population inside the oscillating barrier. 

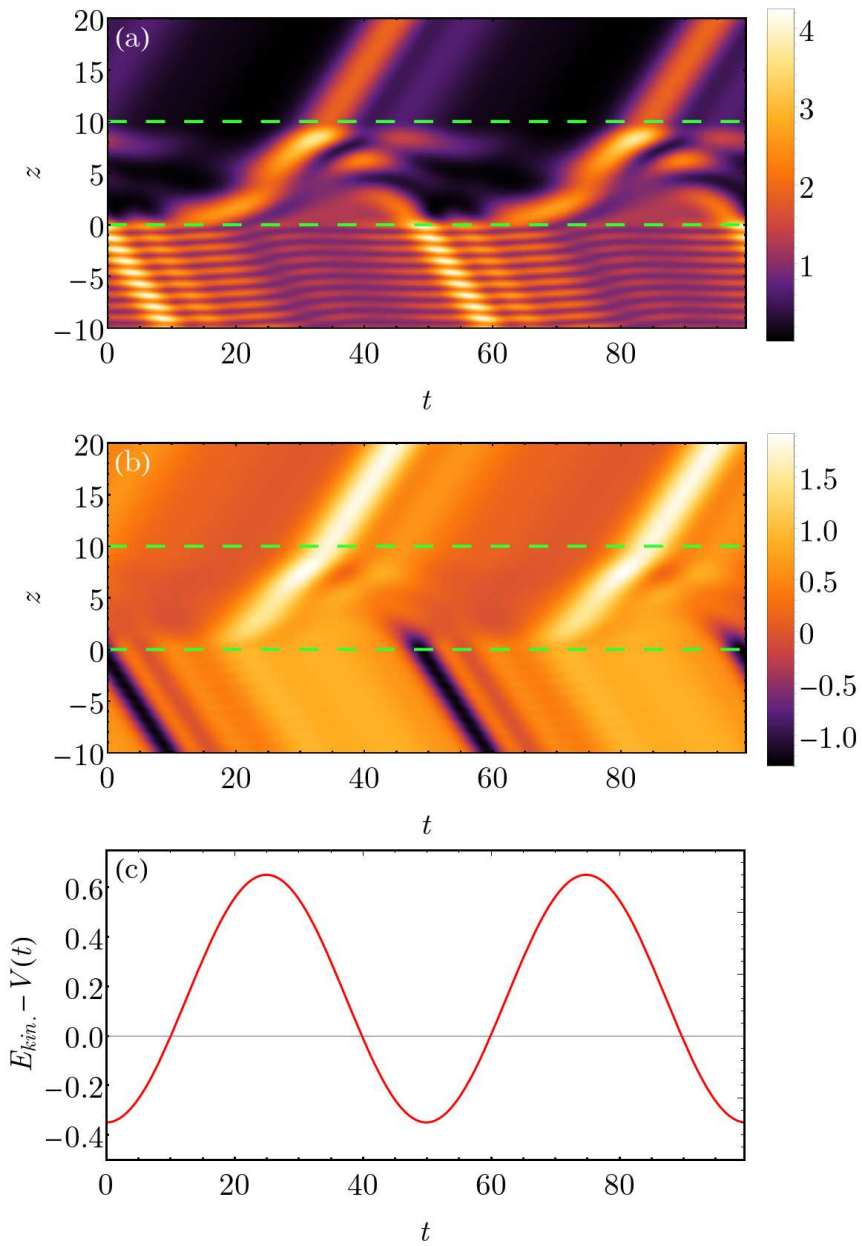

Figure 6.7: Density plot of $\rho(z, t)$ in panel (a), and of $j(z, t)$ in panel (b), and plot of $E_{k i n}-V(t)=E_{0}-m c^{2}-V(t)$ in panel (c), for the parameters $L=10, V_{0}=1.85 m c^{2}$, $E_{0}=3 m c^{2}$, and $\Omega=0.5$.

We can also see structured wave-packets that propagate in the positive (negative) $z$ direction in region 3 (1) due to the "pumping" (see, e.g., Refs. [81, 88, 109, 110]) caused by the oscillating barrier. Considering the time intervals when these wavepackets are released, it is instructive to see panel (c) in Figs. 6.6 and 6.7, where $E_{0}-m c^{2}-V(t)$ is plotted as a function of time. The difference of kinetic energy $E_{k i n}=E_{0}-m c^{2}$ and the time-dependent potential is shown. When $E_{k i n}-V(t)$ is positive, the potential barrier is lower than $E_{0}$, and we see wave packets leaving the central region in the forward direction (transmission). Oppositely, when $E_{k i n}-$ $V(t)<0$, we have mainly reflection.

The space-time behavior of the current density resembles that of $\rho$, but in this case the sign contains an additional information. In region $3, j$ is by construction always positive, although its magnitude varies. In this region $\rho$ and $j$ have very similar space-time dependence. For $z<0$, however, both the incoming and the reflected spinor valued wave functions contribute to the current density, and their interference can result in negative or positive $j$ (depending on whether $\widetilde{\Psi_{1}}$ or $\psi_{\text {in }}$ is the domi- 
nant, respectively.) Note that when $\langle R\rangle \approx 1, j(z, t)$ is practically zero except region 1 , where it represents a truly alternating current, with $\max \left[j_{1}(t)\right] \approx-\min \left[j_{1}(t)\right]$. Obviously, in this case the cycle average of the current is zero everywhere.

\subsubsection{Fano-type resonances}

As is known, whenever the energy of a scattering state coincides with that of a bound state, or in other words, these two different kinds of eigenstates happen to belong to the same degenerate energy level, then the transition probability between the states becomes large and a resonance occurs in the transmission spectra. In general, this effect is known as a Fano resonance [82, 83].

The role of Fano-type resonances has been discussed earlier in the context of the model of gapless graphene [92], which has a different dispersion relation than the one discussed here. Reference [92] presents a detailed analysis of these resonances for the case of a potential well, in the context of a two-dimensional massless Dirac equation. The way the plots of the transmission probability vs. incident energy in Ref. [92] depend on the most important model parameters is a description of the Fano-type resonances which is complementary to ours. By calculating the Wigner delay time [111, 112], they also predict the temporal trapping that we are going to show below explicitly.

In our present case a Fano-type resonance may occur if the energy of the scattered electron, after losing a number of quanta $n \hbar \omega$, coincides with the bound state energy $\epsilon$ of a Dirac particle in the time-independent potential, lying between $-m c^{2}$ and $m c^{2}$ :

$$
E_{0}+n \hbar \omega=\epsilon, n=-1,-2, \ldots
$$

In the following we focus on positive values of $V_{0}$, as is depicted in Fig. 6.1, For $L=1$, one usually finds a single bound state of the static potential barrier, which simplifies the interpretation of the results. The energy eigenvalues $\epsilon$ corresponding to these states are in the range of $\left[-m c^{2}, m c^{2}\right]$, thus they are evanescent in regions 1 and 3, where the potential is zero. Inspecting the positions of the resonances in Fig. 6.8, we find that they appear when

$$
E_{0}+n \hbar \omega \approx \epsilon
$$

with $n$ being integer. Note that we cannot expect exact equality in Eq. (6.31), since AC Stark shift modifies the energy levels. In the investigated parameter ranges, the relative difference of the left end right hand sides of Eq. (6.31) was around 5\% for low barriers (in the sense that $V_{0}$ is not considerably larger than $\hbar \Omega$ ), and it 

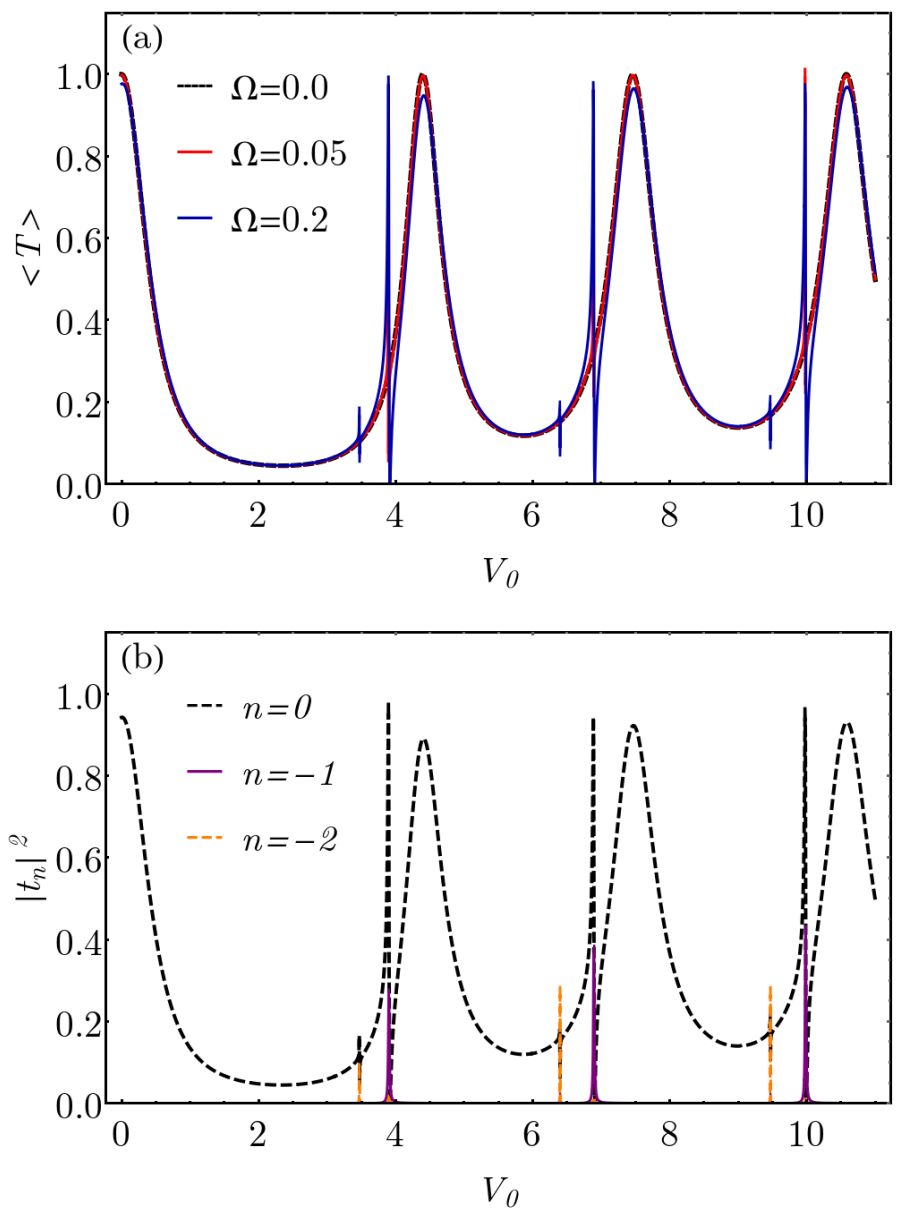

Figure 6.8: Panel (a): $\langle T\rangle$ as a function of barrier height $V_{0}$ for the indicated values of the oscillation amplitude $\Omega$. Additional parameters: $E_{0}=1.1 m c^{2}, \omega=0.2, L=1$. Panel (b): Sideband transmission amplitudes $t_{n}$ as a function of barrier height $V_{0}$, for comparison with the $\Omega=0.2$ curve of panel (a). Note that the curves corresponding to $n=-1$ and $n=-2$ have been rescaled (divided by a factor of 100 ).

decreased for larger values of $V_{0}$.

As one can expect, resonances corresponding to increasing magnitudes of $n$ are weaker. According to the terminology that is often used, in spite of the fact that the potential oscillations are not quantized, we may say that the probability of higher order processes that involve 2, 3, etc. excitation quanta ("photons") are considerably lower than that of "single photon" processes. However, when the amplitude of the oscillation increases, higher order resonances get more pronounced.

Panel (b) of Fig. 6.8 shows a clear example that whenever there is a resonance in $\langle T\rangle$, the transmitted amplitude $t_{0}$ corresponding to the incoming electron's energy has a sharp minimum. At the same value of $V_{0}$, one of the coefficients $t_{n}$ (that belong to $\omega_{n}=E_{0} / \hbar+n \omega$, with $n<0$ ) has a peak. We can clearly identify the peaks corresponding to $n=-1$ and -2 in Fig. 6.8 b).

As an example for a third order resonance, Fig. 6.9 shows $\rho(z, t)$ for parameter values where $t_{-3}$ has the highest magnitude amongst all transmission coefficients. 


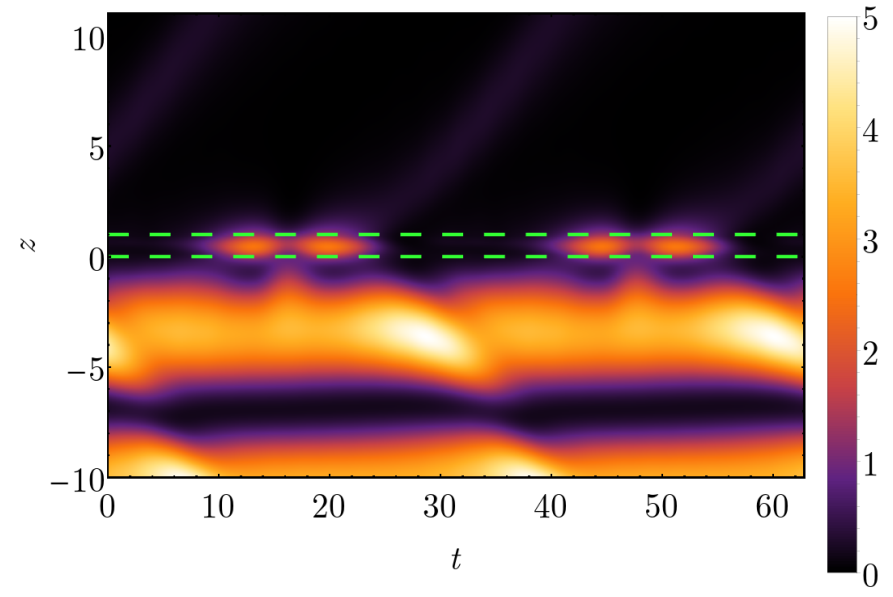

Figure 6.9: Density plot of $\rho(z, t)$, for $L=1, V_{0}=3.97 m c^{2}, E_{0}=1.1 m c^{2}$ and $\Omega=1.4$.

As we can see, the fact that the incoming electron excites a localized bound state appears in this figure as an increase of the electron density. Note that this temporal trapping in region 2 is considerably more pronounced than in the cases seen in Figs. 6.6 and 6.7, the maximal value of $\rho(z, t)$ inside the oscillating potential is five times larger than anywhere else.

Figures 6.8 and 6.9 demonstrate that the abrupt changes in the cycle averaged transmission and reflection probabilities are due to Fano-type resonances as described by Eq. (6.31). Note that this kind of behavior can appear in principle for higher energies as well, but then the order of the process [the values of $n$ in Eq. (6.31)] is so high, that it means only a practically invisible correction for the transmission probabilities.

Finally, let us analyze to what extent the effects presented so far are relevant for graphene. According to Ref. [106] a band gap $\Delta$ as large as $0.26 \mathrm{eV}$ can appear in epitaxially grown graphene on $\mathrm{SiC}$ substrate. The electronic structure of the graphene layer has been modified and the degeneracy of the Dirac point at the intersection of the valence and the conduction bands could be removed by growing the sample on a $\mathrm{SiC}$ layer. As shown by the measurements, this band gap plays the role of the energy difference of $2 m c^{2}$ that separates positive and negative energy eigenstates of the massive Dirac equation we considered. Our findings are relevant when $\hbar \Omega, V_{0}$ and $\hbar \omega$ has the same order of magnitude as $\Delta$. The characteristic frequency $\omega / 2 \pi$ is in the $\mathrm{THz}$ regime ( $\hbar \omega \approx \Delta / 2$ gives $\omega=25 \mathrm{THz}$ ), which is in the experimentally achievable range. That is, generation of wave-packets, the existence of alternating relativistic currents in the reflected region as well as the appearance of Fano-type resonances, can be visible also in the case of the graphene. We also note that the nonrelativistic version of a similar problem has been considered in Refs. [113, 114] in the context of multiphoton ionization. Besides its relevance to 
graphene with a band gap, this work may also contribute to the manipulation of relativistic charged particle beams by powerful laser pulses [115 117].

\subsection{Summary}

We presented a relativistic model of scattering of massive Dirac particles on a timeperiodic rectangular potential barrier, using Floquet's theory. We used the dependence of the cycle-averaged transmission probability on the barrier height to describe the quasistationary behavior of the system, in the case of a weakly relativistic, relativistic and ultrarelativistic incident particle. We explored the details of the transport with the help of space- and time-dependent currents and densities, which show explicitly that the oscillating barrier generates wave packets from the incident plane wave. We explained in detail the Fano-type resonances with the interplay of the sideband states generated by the oscillating potential and the bound states of the barrier, and showed the corresponding temporal population trapping in the barrier region. Finally we discussed the relevance of our results to graphene with an induced band gap. 


\section{Summary of the thesis}

\section{Introduction}

Quantum scattering by time-harmonic potentials is an important and vivid research area. It provides deep understanding of a rich variety of interesting and partly unusual phenomena in strongly driven quantum systems. For strong excitations, the highly inelastic photon-induced processes that involve the absorption/emission of one or a few photons can be appropriately described by using classical, periodic fields. In this intensity regime, Floquet's theory is proved to be one of the most efficient methods. Although in this case the exciting field that oscillates with a frequency of $\omega$ is not quantized, the corresponding quasienergies are separated by integer multiples of $\hbar \omega$. This means that for an inelastic process, the material response will contain frequency components that are integer multiples of $\omega$, and, e.g., in transport processes, the transmitted energy spectrum will contain sidebands around the input energy.

\section{Objectives}

The objective of the work presented in this $\mathrm{PhD}$ thesis was to examine the role of the time-periodic excitation in quantum mechanical scattering problems. If this excitation can not be considered as a perturbation with a small amplitude, anharmonic effects are observable. This complex dynamics can be described by Floquet's theory (see the next section) which is the basis of the theoretical methods presented in this thesis. With this approach, the fundamental quantum effects like the interference of matter waves in strong external fields can be examined as well as the appearance of harmonics.

We investigated the general properties of quantum mechanical processes in the presence of oscillating external fields via three examples. Besides exploring fundamental effects, a second, equally important aim of our research was to determine properties that are specific to the physical systems that we consider, with the focus being on the possible applications. 
We studied two one-dimensional models, where initially free particle waves were excited by localized, periodic external fields. The simplest interpretation of these models can be a beam of charged quantum mechanical particles that interacts with an oscillating field in a finite domain. The one-dimensional approach is valid either if the excitation induces changes in the dynamics along the propagation direction (like in the case of an external field that is linearly polarized in this direction), or if additional constraints (that are not taken into account in our model) ensure onedimensional propagation. Quantum wires provide a prominent example for the second case. When e.g., these wires are fabricated using GaAs/GaInAs heterojunctions, the framework of effective mass approximation allows us to consider the conduction band electrons as free particles [118]. Our relativistic model, where the Dirac equation is considered, can be related to charge carrier propagation in graphene. The usual analogy to which we can refer here is based on the linear dispersion relation of the graphene. (More strictly, because the Dirac equation describes massive particles and has a band gap of $m c^{2}$, our model is applicable for the description of graphene samples with an induced band gap.) In both cases, the physical systems that are closely related to our model meant an additional motivation, since having understood the fundamental mechanisms, we could also investigate what effects can be used to control the electron dynamics in nanoscale electronic devices. Excitation by light pulses is of outstanding importance from this viewpoint, because they mean a very versatile control tool, their properties can be varied experimentally in a wide parameter range. Therefore our plan was to explore what properties of the transport (scattering) processes can be modified by changing the parameters of the excitation.

We also planned to investigate a three-dimensional example. Concretely, we aimed to describe the scattering of electrons on a nano-particle, that is modeled by a hard sphere (i.e, an impenetrable, sphere shaped obstacle.) Keeping in mind the possibility of the optical control, we wanted to describe the process in the presence of laser light. According to the traditional description of three-dimensional scattering, we planned to calculate differential cross sections, and their dependence on the various parameters. We wanted to analyze these results in order to gain an insight into the dynamics of the process.

The results discussed in the thesis indicate that all the research objectives have been accomplished. Moreover, we experienced additional effects that could not be foreseen before the actual calculations. The physical background of these effects are also explained in the thesis. 


\section{Methods}

We planned to use a method that is based on Floquet's theory - an approach that has many times been proven to fit problems with periodic excitations perfectly. The method is not a perturbative one, the interaction with the oscillating fields can be described "to all orders", numerically exactly. This allows the investigation of all the nonlinear processes that appear in strongly driven systems.

Time-periodic systems are described by a Hamiltonian $H(t)=H(t+T)$, where the time period $T=2 \pi / \omega$ and $\omega$ is the angular frequency of the excitation. Based on Floquet's theorem, the wave function can be written in the form $|\Psi(t)\rangle=$ $\exp (-i \epsilon t / \hbar)|\Phi(t)\rangle$, where $|\Phi(t)\rangle$ is the so-called Floquet state, whose periodicity is the same as that of the Hamiltonian, i.e., $|\Phi(t)\rangle=|\Phi(t+T)\rangle$. The Floquet quasienergy $\epsilon$ is a real parameter and is defined up to the integer multiples of $\hbar \omega$. In other words, it can be reduced to a zone with a width of $\hbar \omega$. As an analogy to solid-state physics, this zone and the quasienergy $\epsilon$ correspond to the first Brillouin zone and to the quasi wave vector, respectively. Due to their periodicity, the Floquet states can be expanded into Fourier series, which is the reason why the eigenvalue equations can be transformed into an infinite dimensional matrix equation. Practically, the linear system of equations are solved by including only a finite number of the Floquet channels.

\section{Scientific results}

In the following, I present a brief summary of the new scientific results discussed in the thesis which are collected in five thesis points. The publications connected to my statements are listed at the end of the dissertation and cited in each title.

\section{T1. Scattering of charged particles in a Ramsey-like setup: transmission resonances [P3]}

- I constructed a quantum mechanical model in which charged particles (e.g. electrons) are scattered by a time-oscillating electric field in a spatially separated (Ramsey-like) setup [43]. I analyzed the cycle-averaged transmission probabilities as the function of the energy of the incoming electrons $E_{0}$, and identified transmission resonances in the spectrum.

- In order to interpret the results, I created a model, based on a classical physical consideration, by replacing the oscillating electric fields with static potential barriers of heights equal to the ponderomotive energy of the electron. 
- I proved that the static double-barrier system is a proper first approximation in finding the transmission resonances. For low values of $E_{0}$, the oscillating model has transmission resonances around the energy eigenvalues of the static model. I concluded that the localized states, which exist between the two potential barriers, are the reason for the appearance of the resonances.

\section{T2. Scattering of charged particles in a Ramsey-like setup: phase dependence [P3]}

- In the model examined in [P3], I also analyzed the dependence of the cycleaveraged transmission probability $\langle T\rangle$ on the separation distance $d$ and the phase difference $\varphi_{0}$ between the two optical fields. I found that $\langle T\rangle$ is quasiperiodic in $d$, and the transmission probability can change as much as $50 \%$ as a function of $\varphi_{0}$.

- With the examination of the space- and time-dependent probability density and current, I analyzed the scattering process in the case of low and high transmission probabilities, and I interpreted the dynamics in these limiting cases using classical terms.

- I showed that in order to control the transmission by changing the phase $\varphi_{0}$, the parameters of the electric fields must correspond to a ponderomotive potential close to the energy of the particle beam.

\section{T3. Describing laser-assisted electron scattering with spheri- cal Gordon-Volkov states [P2]}

- Based on the work of Varró and Ehlotzky [61], I investigated the electron scattering on a hard sphere in the presence of a laser field. I derived the spherical Gordon-Volkov states using the translational addition theorem of spherical harmonics [63, 64]. I reduced the Fourier spectrum of these states to a series of hypergeometric functions. The resulting analytic expression significantly simplifies the calculation of the spectrum.

- I examined the differential cross sections for different Floquet channels in the weak-field limit. I found that the Floquet channels indexed by $n \neq 0$ get more populated for increasing electric field strengths. For increasing electron energies, $E_{0}$, new scattering channels open up similarly to the model presented in [P3]. 


\section{T4. Relativistic electron scattering on an oscillating potential barrier: cycle-averaged transmission probabilities [P1]}

- I studied the scattering of relativistic electrons on an oscillating potential barrier in one dimension. By examining the cycle-averaged transmission probabilities $\langle T\rangle$, I observed that the Klein paradox is also visible in the oscillating case similarly to the one-dimensional relativistic static scattering. That is, the transmission probability approaches 1 for increasing potential heights $V_{0}$.

- I also showed that when the barrier heights are within the band gap of $2 m c^{2}$, the cycle-averaged transmission probability can take non-zero values, if the oscillation amplitude is large enough or the oscillation is localized in a narrow region.

\section{T5. Relativistic electron scattering on an oscillating potential barrier: wave-packet generation, Fano-type resonances [P1]}

- In the model studied in [P1], in order to understand the details of the transmission spectrum, I examined the space- and time-dependent probability density and current. I identified the effect of "temporary trapping" inside the oscillating potential barrier.

- For a low incoming electron energy $E_{0}$, I discovered Fano-type resonances [82] in the transmission probability. Using the Dirac equation, I calculated the bound states and the corresponding energies of the static relativistic potential barrier, which I identified to be the reason for the appearance of these resonances. 


\section{Összefoglalás}

\section{Bevezetés}

Az időben periodikus potenciálokon bekövetkező kvantummechanikai szórás egy lendületesen fejlődő, fontos kutatási terület. Segítségével számos érdekes jelenség érthetô meg az erôsen gerjesztett rendszerekben. Az optikai kontroll, a lézerfény által kísért szórás vagy a transzportfolyamatok kiváló példák annak megmutatására, hogy a váltakozó mezô jelenléte erôsen rugalmatlan folyamatot eredményezhet. A kvantummechanikai részecskék optikai kontrollja ígéretes alkalmazások széles skáláját nyújtja például az ultragyors elektronikában [33, 34], képalkotásban [35, 36] vagy a kvantuminformatikában [37, 38]. Napjainkban a lézerfény által kísért szórás kiemelkedô szerepet kapott többféle kutatási területen, mint például az ultrarövid (attoszekundumos) elektron impulzusok létrehozásában [68, 69], a négydimenziós képalkotásban és az ultragyors elektronmikroszkópiában [70, 71] vagy a fotonindukált közeltér mikroszkópiában [36, 50]. Az időfüggó potenciálokon történố elektrontranszportot kiemelkedő tudományos érdeklődés övezi, hiszen a kísérleti technikáknak az elmúlt évtizedekben végbemenő fejlődése lehetôvé tette az elméleti eredmények közvetlen alkalmazását a mezo- és nanoszkopikus méretú eszközökben [3, 84].

\section{Célkitûzések}

A disszertációban bemutatott doktori munka célja az volt, hogy az időben periodikus potenciálok szerepét vizsgáljuk különbözô kvantummechanikai szórási problémákban. Ha ez a gerjesztést jelentố potenciál nem tekinthetô kis amplitúdójú perturbációnak, akkor jól megfigyelhetô anharmonikus jelenségek lépnek fel.

Az alapvetô effektusok feltérképezése mellett célunk volt a konkrétan vizsgált esetekben az adott kvantumrendszer specifikus tulajdonságainak a vizsgálata, a lehetséges alkalmazások keresése. Két egydimenziós modellt tanulmányoztunk, amelyek kapcsán a szabadon terjedô kvantummechanikai síkhullámok periodikus gerjesztésre adott válaszára voltunk kíváncsiak. Relativisztikus részecskék esetén, a grafén ismert, lineáris diszperziós relációjára alapozva, ez a módszer a periodikus 
kapufeszültségekkel modulált grafénben lezajló elektrontranszport modellezésére is alkalmas. Itt azt vizsgáltuk meg, hogy az ismert relativisztikus effektusok, mint például a Klein-paradoxon, milyen gyakorlati alkalmazásokat is felvillantó módon jelennek meg periodikus gerjesztés esetén. Nemrelativisztikus részecskék esetén a szilárdtestfizikai analógia optikai terekkel befolyásolt vezetési sávbeli elektrondinamikát jelent. Természetesen a legkézenfekvőbb alkalmazás mindkét modell esetén a töltött részecskékból álló nyaláb dinamikájának a leírása. A fizikai háttér megértése után fontos kérdés volt, hogy a gerjesztés paramétereinek a megváltoztatásával hogyan érhetô el például a kimenô részecskék energiájának a szúrése.

Célul tüztük ki ezen felül egy háromdimenziós modell vizsgálatát is, amelyben töltött részecskék (pl. elektronok) egy "kemény gömb"-bel modellezett nanorészecskén szóródnak. A jelenség lehetséges optikai kontrollját is figyelembe véve a szórást elektromágneses tér jelenlétében terveztük vizsgálni. A fố kiszámítandó mennyiség itt a differenciális hatáskeresztmetszet, amelynek az elemzése módot adhat a folyamat részleteinek tanulmányozására.

A dolgozatban tárgyalt eredmények fényében elmondható, hogy a fenti kutatási elképzeléseket sikeresen valósítottuk meg. Emellett számításaink során olyan jelenségeket is tapasztaltunk, amelyek a célok kitúzése idején nem voltak elôreláthatóak. Ezen jelenségek fizikai hátterének magyarázata szintén a dolgozattal kapcsolatos kutatómunka eredményei közé tartozik.

\section{Módszerek}

Periodikus időfüggéssel bíró rendszereket például a Floquet-elméleten alapuló módszerrel lehet hatékonyan leírni, amely a szilárdtestfizikában ismeretes Bloch-tétel analógiája az idôperiodicitásnak (a térperiodicitás helyett). G. Floquet 1883-ban írt cikke alapozta meg ennek a megközelítésnek a matematikai alapjait [1]. A módszert először 1965-ben J. Shirley alkalmazta kvantummechanikai rendszerekre: kétnívós atom kölcsönhatását vizsgálta lézerfénnyel, amelyet egyetlen frekvenciával rendelkezô klasszikus mezóként vett figyelembe [2].

Az időben periodikus rendszerek kvantummechanikai leírása egy időben periodikus $H(t)=H(t+T)$ Hamilton operátorral történik, ahol $T=2 \pi / \omega$ a periódusideje, $\omega$ pedig a körfrekvenciája a gerjesztésnek. Floquet tétele alapján az időfüggó Schrödinger egyenlet megoldását adó hullámfüggvény a $|\Psi(t)\rangle=\exp (-i \epsilon t / \hbar)|\Phi(t)\rangle$ alakban írható fel, ahol $|\Phi(t)\rangle$ az ún. Floquet állapot, amelynek periodicitása ugyanaz mint a Hamilton operátornak, vagyis $|\Phi(t)\rangle=|\Phi(t+T)\rangle$. Az $\epsilon$ az ún. Floquet kvázienergia, amely egy valós paraméter és $\hbar \omega$ egész számú többszöröséig van egyértelmúen meghatározva, vagyis egy $\hbar \omega$ széles "zónára" redukálható. Ez a kvázienergia 
a szilárdtestfizikában ismeretes kvázi-hullámszámnak, míg az elôbb említett zóna az első Brillouin-zónának felel meg analóg módon. A Floquet-állapotok periodicitásuknak köszönhetôen Fourier sorba fejhetôk, emiatt lehetséges a sajátérték-egyenletek egy végtelen dimenziós mátrix egyenletté alakítása. Ily módon a külső periodikus gerjesztést nemperturbatív módon vesszük figyelembe.

Amennyiben a hullámfüggvényeket Floquet-féle alakra hozzuk és a peremfeltételeket is figyelembe vesszük, a rendszer egyértelmüen definiált. A végtelen lineáris algebrai egyenletrendszert úgy oldjuk meg a gyakorlatban, hogy csak egy véges, $2 N+1$ harmonikus komponenst veszünk figyelembe. Az $N$ egész számot az előírt számolási pontosság határozza meg; még több harmonikus komponens belefoglalásával tetszólegesen lehet finomítani az eredmények pontosságát.

\section{Tudományos eredmények}

Az alábbiakban röviden ismertetem a disszertációban bemutatott új tudományos eredményeket öt tézispontban összefoglalva. A megállapításaimhoz kapcsolódó publikációkat a disszertáció végén található lista gyújti össze, illetve a tézispontok címében hivatkozom.

\section{T1. Töltött részecskék szóródása Ramsey-féle elrendezésben: transzmissziós rezonanciák [P3]}

— Töltött részecskék (pl. elektronok) idôben oszcilláló elektromos mezôn való szóródásának kvantummechanikai modellezését végeztem térben szeparált, ún. Ramsey-féle elrendezésben [43]. Az időátlagolt transzmissziós valószínúségeknek az elektronok bejövő $E_{0}$ energiájától való függését elemeztem, és transzmissziós rezonanciákat azonosítottam a spektrumban.

- Az eredmények értelmezése céljából megvizsgáltam egy olyan, klasszikus megfontolások alapján kidolgozott modellt, amelyben az időfüggő elektromos teret helyettesítettem az elektron ponderomotoros energiájának megfelelô magasságú sztatikus potenciálgáttal.

- Bebizonyítottam, hogy a transzmissziós rezonanciák megtalálásához jó elsô közelítés a kettôs sztatikus potenciálgát rendszer. Alacsony $E_{0}$ értékek esetén a rezgố modellnek transzmissziós rezonanciái vannak a sztatikus modell energia sajátértékei körül. Azt a következtetést vontam le, hogy a rezonanciák megjelenését a két potenciálgát között lokalizált állapotok okozzák. 


\section{T2. Töltött részecskék szóródása Ramsey-féle elrendezésben: fázisfüggés [P3]}

- A [P3] munkában vizsgált modellben a periódusra átlagolt $\langle T\rangle$ transzmissziós valószínûség $d$ szeparációs távolságtól és $\varphi_{0}$ fáziskülönbségtôl való függését is elemeztem. Azt találtam, hogy $\langle T\rangle$ kváziperiodikus $d$-ben, valamint akár 50\%kal is megváltozhat a $\varphi_{0}$ függvényében.

- A valószínûségi áram tér- és időfüggésének vizsgálatával elemeztem a szórást kicsi és nagy transzmissziós valószínűség esetén, és ezekben a határesetekben klasszikus gondolatmenet alapján értelmeztem a dinamikát.

- Megmutattam, hogy a transzmissziós valószínúség $\varphi_{0}$ fázissal történő kontrollálásához olyan külsố elektromos teret érdemes alkalmazni, amely a részecskenyaláb energiájához közeli ponderomotoros potenciált jelent.

\section{T3. Lézerfény által kísért elektronszórás leírása gömbi Gordon- Volkov állapotokkal [P2]}

- Egy kemény gömbbel modellezett nanorészecskén történő elektronszórást vizsgáltam lézertér jelenlétében Varró és Ehlotzky [61] munkája alapján. Származtattam a gömbi Gordon-Volkov állapotokat a gömbhullámok transzlációs addíciós tétele segítségével [63, 64]. Ezek Fourier spektrumának kiszámítását egy, a hipergeometrikus függvényekból álló sorra vezettem vissza. A kapott analitikus kifejezés a spektrum kiszámítását jelentősen leegyszerúsíti.

- Megvizsgáltam a szórási hatáskeresztmetszeteket gyenge-tér határesetben a különböző Floquet csatornák esetén. Megállapítottam, hogy az $n \neq 0$-val jelölt Floquet csatornák növekvő térerôsség értékek esetén jobban betöltődnek, továbbá hogy növekvố $E_{0}$ elektron energia esetén új szórási csatornák nyílnak meg a [P3] munkában tárgyalt modellhez hasonlóan.

\section{T4. Relativisztikus elektronszórás rezgô potenciálgáton: peri- ódusra átlagolt transzmissziós valószínûségek [P1]}

— Egydimenziós relativisztikus elektronok rezgő potenciálgáton történô szórását tanulmányoztam. A $\langle T\rangle$ időátlagolt transzmissziós valószínúségek vizsgálata során kimutattam, hogy rezgő esetben is megfigyelhető a Klein paradoxon a relativisztikus sztatikus szóráshoz hasonlóan. Ez azt jelenti, hogy növekvô $V_{0}$ átlagos potenciálmagasság esetén a transzmissziós valószínúség 1-hez közelít. 
- Megmutattam azt is, hogy amikor $V_{0}$ a $2 m c^{2}$ nagyságú "tiltott sávban"-ban van, akkor az időátlagolt transzmissziós valószínúség nem nulla értéket is felvehet, ha az oszcilláció amplitúdója elegendően nagy, vagy ha az oszcilláció elegendően keskeny tartományon lokalizálódik.

\section{T5. Relativisztikus elektronszórás rezgô potenciálgáton: hul- lámcsomag generálás és a Fano-típusú rezonanciák [P1]}

- A [P1] munkában tanulmányozott modellben a transzmissziós spektrum részleteinek megértése céljából megvizsgáltam a tér- és időfüggô valószínúségi sứrûséget és áramot, amelynek alapján az ideiglenes "csapdázódás" jelenségét mutattam ki a rezgô potenciálgáton belül.

- Alacsony $E_{0}$ bejövô elektron energia esetén a transzmissziós valószínúségben Fano-típusú rezonanciákat [82] fedeztem fel. A Dirac egyenlet segítségével kiszámoltam a relativisztikus potenciálgát kötött állapotait és a megfelelő energiákat, amelyekkel megmagyaráztam a Fano-típusú rezonanciák megjelenésének okát. 


\section{Publications}

\section{Refereed research papers related to the thesis:}

[P1] L. Zs. Szabó, M. G. Benedict, A. Czirják, and P. Földi, Relativistic electron transport through an oscillating barrier: Wave-packet generation and Fano-type resonances, Phys. Rev. B 88 (7), 075438 (2013);

doi:10.1103/PhysRevB.88.075438

[P2] S. Varró, L. Zs. Szabó, and A. Czirják, Laser-assisted electron scattering on a nano-sphere, Nucl. Instr. Meth. Phys. Res. B 369, 29 (2016);

doi:10.1016/j.nimb.2015.10.064

[P3] L. Zs. Szabó, M. G. Benedict, and P. Földi, Scattering of charged particles on two spatially separated time-periodic optical fields, Phys. Rev. A 96 (6), 063419 (2017); doi:10.1103/PhysRevA.96.063419

\section{Additional refereed research papers:}

[A4] A. Szenes, B. Bánhelyi, L. Zs. Szabó, G. Szabó, T. Csendes, and M. Csete, Enhancing diamond color center fluorescence via optimized plasmonic nanorod configuration, Plasmonics 12 (4), 1263 (2017); doi:10.1007/s11468-016-0384-1

[A5] A. Szenes, B. Bánhelyi, L. Zs. Szabó, G. Szabó, T. Csendes, and M. Csete, Improved emission of SiV diamond color centers embedded into concave plasmonic core-shell nanoresonators, Sci. Rep. 7 (1), 13845 (2017); doi:10.1038/s41598-017-14227-w

[A6] I. Magashegyi, L. Zs. Szabó, and P. Földi, Ultrashort laser-pulse-driven currents in conductors: one-dimensional model for local excitation in the singleelectron picture with quadratic dispersion, J. Opt. Soc. Am. B 35 (5), A116 (2018); doi:10.1364/JOSAB.35.00A116 


\section{Bibliography}

[1] G. Floquet, Sur les équations différentielles linéaires à coefficients périodiques, Ann. École Norm. Sup. 12, 47 (1883); url:https://eudml.org/doc/80895

[2] J. H. Shirley, Solution of the Schrödinger equation with a Hamiltonian periodic in time, Phys. Rev. 138 (4B), B979 (1965); doi:10.1103/PhysRev.138.B979

[3] S. Kohler, J. Lehmann, and P. Hänggi, Driven quantum transport on the nanoscale, Phys. Rep. 406 (6), 379 (2005); doi:10.1016/j.physrep.2004.11.002

[4] T. Bilitewski and N. R. Cooper, Scattering theory for Floquet-Bloch states, Phys. Rev. A 91 (3), 033601 (2015); doi:10.1103/PhysRevA.91.033601

[5] S.-I Chu, Recent Developments in Semiclassical Floquet Theories for IntenseField Multiphoton Processes in Advances in Atomic and Molecular Physics (eds. D. R. Bates and B. Bederson), Vol. 21, pp. 197-253, Academic Press (1985); doi:10.1016/S0065-2199(08)60143-8

[6] J. Z. Kamiński and F. Ehlotzky, Phase control of scattering resonances in intense bichromatic laser fields, Phys. Rev. A 50 (5), 4404 (1994);

doi:10.1103/PhysRevA.50.4404

[7] S. Varró and F. Ehlotzky, Phase-dependent on- and off-shell effects in reflection of electrons from an impenetrable potential wall in a bichromatic laser field, J. Phys. B 28, 2729 (1995); doi:10.1088/0953-4075/28/13/023

[8] B. H. Bransden and C. J. Joachain, Physics of Atoms and Molecules, Second Edition, Prentice Hall (2003); ISBN:978-0582356924

[9] H. Sambe, Steady states and quasienergies of a quantum-mechanical system in an oscillating field, Phys. Rev. A 7 (6), 2203 (1973);

doi:10.1103/PhysRevA.7.2203

[10] A. Eckardt and E. Anisimovas, High-frequency approximation for periodically driven quantum systems from a Floquet-space perspective, New J. Phys. 17 (9), 093039 (2015); doi:10.1088/1367-2630/17/9/093039 
[11] J. D. Jackson, Classical Electrodynamics, Third Edition, Wiley, New York, NY (1998); ISBN:978-0471309321

[12] W. Pauli, Relativistic field theories of elementary particles, Rev. Mod. Phys. 13 (3), 203 (1941); doi:10.1103/RevModPhys.13.203

[13] M. Göppert-Mayer, Über Elementarakte mit zwei Quantensprüngen, Ann. Phys. 401 (3), 273 (1931); doi:10.1002/andp.19314010303

[14] L. D. Landau and E. M. Lifsic, Mechanika, Second Edition, Tankönyvkiadó, Budapest, (1984); ISBN:963-1779521

[15] W. E. Lamb, Fine structure of the hydrogen atom. III, Phys. Rev. 85 (2), 259 (1952); doi:10.1103/PhysRev.85.259

[16] A. D. Bandrauk, F. Fillion-Gourdeau, and E. Lorin, Atoms and molecules in intense laser fields: gauge invariance of theory and models, J. Phys. B 46 (15), 153001 (2013); doi:10.1088/0953-4075/46/15/153001

[17] W. Gordon, Der Comptoneffekt nach der Schrödingerschen Theorie, Z. Phys. 40 (1-2), 117 (1926); doi:10.1007/BF01390840

[18] D. M. Wolkow, Über eine Klasse von Lösungen der Diracschen Gleichung, Z. Phys. 94 (3-4), 250 (1935); doi:10.1007/BF01331022

[19] H. A. Kramers, Collected Scientific Papers, North-Holland, Amsterdam (1956)

[20] W. C. Henneberger, Perturbation method for atoms in intense light beams, Phys. Rev. Lett. 21 (12-16), 838 (1968); doi:10.1103/PhysRevLett.21.838

[21] J. Bergou and S. Varró, Wavefunctions of a free electron in an external field and their application in intense field interactions. II. Relativistic treatment, J. Phys. A 13 (8), 2823 (1980); doi:10.1088/0305-4470/13/8/030

[22] M. Boca, On the properties of the Volkov solutions of the Klein-Gordon equation, J. Phys. A 44 (44), 445303 (2011); doi:10.1088/1751-8113/44/44/445303

[23] M. Boca and V. Florescu, The completeness of Volkov spinors, Rom. J. Phys. 55 (5-6), 511 (2010);

url:http://www.nipne.ro/rjp/2010_55_5-6/0511_0526.pdf

[24] P. A. M. Dirac, The quantum theory of the electron, Proc. Royal Soc. A 117 (778), 610 (1928); doi:10.1098/rspa.1928.0023

[25] W. Greiner, Relativistic Quantum Mechanics. Wave Equations, Third Edition, Springer-Verlag, Berlin (2000); doi:10.1007/978-3-662-04275-5 
[26] B. Thaller, The Dirac Equation, Springer-Verlag, Berlin (1992); doi: $10.1007 / 978-3-662-02753-0$

[27] O. Klein, Die Reflexion von Elektronen an einem Potentialsprung nach der relativistischen Dynamik von Dirac, Z. Phys. 53 (3-4), 157 (1929); doi:10.1007/BF01339716

[28] A. Calogeracos and N. Dombey, History and physics of the Klein paradox, Contemp. Phys. 40 (5), 313 (1999); doi:10.1080/001075199181387

[29] W. Greiner, B. Müller, and J. Rafelski, Quantum Electrodynamics of Strong Fields, Springer-Verlag, Berlin (1985); doi:10.1007/978-3-642-82272-8

[30] S. Varró and F. Ehlotzky, Scattering of electrons by a one-dimensional squarewell potential in a powerful low-frequency radiation field, J. Opt. Soc. Am. B 7 (4), 537 (1990); doi:10.1364/JOSAB.7.000537

[31] S. Varró and F. Ehlotzky, Redistribution of electron energies at the interface between laser-radiation-filled space and vacuum, J. Phys. B 31 (9), 2145 (1998); doi: $10.1088 / 0953-4075 / 31 / 9 / 025$

[32] F. Krausz and M. Ivanov, Attosecond physics, Rev. Mod. Phys. 81 (1), 163 (2009); doi:10.1103/RevModPhys.81.163

[33] F. Krausz and M. I. Stockman, Attosecond metrology: from electron capture to future signal processing, Nat. Photonics 8, 205 (2014); doi:10.1038/nphoton.2014.28

[34] E. Gruber, R. A. Wilhelm, R. Pétuya, V. Smejkal, R. Kozubek, A. Hierzenberger, B. C. Bayer, I. Aldazabal, A. K. Kazansky, F. Libisch, A. V. Krasheninnikov, M. Schleberger, S. Facsko, A. G. Borisov, A. Arnau, and F. Aumayr, Ultrafast electronic response of graphene to a strong and localized electric field, Nat. Commun. 7, 13948 (2016); doi:10.1038/ncomms13948

[35] A. Feist, N. Bach, N. Rubiano da Silva, T. Danz, M. Möller, K. E. Priebe, T. Domröse, J. G. Gatzmann, S. Rost, J. Schauss, S. Strauch, R. Bormann, M. Sivis, S. Schäfer, and C. Ropers, Ultrafast transmission electron microscopy using a laser-driven field emitter: Femtosecond resolution with a high coherence electron beam, Ultramicroscopy 176, 63 (2017); doi $10.1016 /$ j.ultramic.2016.12.005

[36] B. Barwick, D. J. Flannigan, and A. H. Zewail, Photon-induced near-field electron microscopy, Nature 462, 902 (2009); doi:10.1038/nature08662 
[37] D. Kim, S. G. Carter, A. Greilich, A. S. Bracker, and D. Gammon, Ultrafast optical control of entanglement between two quantum-dot spins, Nat. Phys. 7, 223 (2011); doi:10.1038/nphys1863

[38] R.-B. Liu, W. Yao, and L. J. Sham, Quantum computing by optical control of electron spins, Adv. Phys. 59 (5), 703 (2010); doi:10.1080/00018732.2010.505452

[39] P. L. Kapitza and P. A. M. Dirac, The reflection of electrons from standing light waves, Math. Proc. Camb. Philos. Soc. 29 (2), 297 (1933); doi: $10.1017 /$ S0305004100011105

[40] P. L. Gould, G. A. Ruff, and D. E. Pritchard, Diffraction of atoms by light: The near-resonant Kapitza-Dirac effect, Phys. Rev. Lett. 56 (8), 827 (1986); doi:10.1103/PhysRevLett.56.827

[41] D. L. Freimund, K. Aflatooni, and H. Batelaan, Observation of the KapitzaDirac effect, Nature 413, 142 (2001); doi:10.1038/35093065

[42] F. J. García de Abajo, A. Asenjo-Garcia, and M. Kociak, Multiphoton absorption and emission by interaction of swift electrons with evanescent light fields, Nano Lett. 10 (5), 1859 (2010); doi:10.1021/nl100613s

[43] N. F. Ramsey, A molecular beam resonance method with separated oscillating fields, Phys. Rev. 78 (6), 695 (1950); doi:10.1103/PhysRev.78.695

[44] K. E. Echternkamp, A. Feist, S. Schäfer, and C. Ropers, Ramseytype phase control of free-electron beams, Nat. Phys. 12, 1000 (2016); doi: $10.1038 /$ nphys 3844

[45] A. Feist, K. E. Echternkamp, J. Schauss, S. V. Yalunin, S. Schäfer, and C. Ropers, Quantum coherent optical phase modulation in an ultrafast transmission electron microscope, Nature 521, 200 (2015); doi:10.1038/nature14463

[46] M. Kozák, J. McNeur, K. J. Leedle, H. Deng, N. Schönenberger, A. Ruehl, I. Hartl, J. S. Harris, R. L. Byer, and P. Hommelhoff, Optical gating and streaking of free electrons with sub-optical cycle precision, Nat. Commun. 8, 14342 (2017); doi:10.1038/ncomms14342

[47] J. Breuer and P. Hommelhoff, Laser-based acceleration of nonrelativistic electrons at a dielectric structure, Phys. Rev. Lett. 111 (13), 134803 (2013); doi:10.1103/PhysRevLett.111.134803 
[48] P. Dombi, A. Hörl, P. Rácz, I. Márton, A. Trügler, J. R. Krenn, and U. Hohenester, Ultrafast strong-field photoemission from plasmonic nanoparticles, Nano Lett. 13 (2), 674 (2013); doi:10.1021/nl304365e

[49] P. Rácz, Z. Pápa, I. Márton, J. Budai, P. Wróbel, T. Stefaniuk, C. Prietl, J. R. Krenn, and P. Dombi, Measurement of nanoplasmonic field enhancement with ultrafast photoemission, Nano Lett. 17 (2), 1181 (2017); doi: $10.1021 /$ acs.nanolett.6b04893

[50] S. T. Park, M. Lin, and A. H. Zewail, Photon-induced near-field electron microscopy (PINEM): theoretical and experimental, New J. Phys. 12, 123028 (2010); doi:10.1088/1367-2630/12/12/123028

[51] S. Haroche, Nobel Lecture: Controlling photons in a box and exploring the quantum to classical boundary, Rev. Mod. Phys. 85 (3), 1083 (2013); doi:10.1103/RevModPhys.85.1083

[52] J. Z. Kamiński, E. Saczuk, and F. C. Vèlez, Phase control of resonant tunneling in nanostructures, Ann. Phys. 525 (1-2), 118 (2013); doi:10.1002/andp.201200162

[53] S. Aktas, H. Kes, F. K. Boz, and S. E. Okan, Control of a resonant tunneling structure by intense laser fields, Superlattices Microstruct. 98, 220 (2016); doi:10.1016/j.spmi.2016.08.018

[54] A. F. M. Anwar, A. N. Khondker, and M. R. Khan, Calculation of the traversal time in resonant tunneling devices, J. Appl. Phys. 65 (7), 2761 (1989); doi: $10.1063 / 1.342766$

[55] M. Krüger, M. Schenk, and P. Hommelhoff, Attosecond control of electrons emitted from a nanoscale metal tip, Nature 475, 78 (2011); doi:10.1038/nature10196

[56] I. S. Gradshteyn and I. M. Ryzhik, Table of Integrals, Series and Products, Seventh Edition, Academic Press, San Diego (2007); ISBN:978-0123736376

[57] W. Li and L. E. Reichl, Floquet scattering through a time-periodic potential, Phys. Rev. B 60 (23), 15732 (1999); doi:10.1103/PhysRevB.60.15732

[58] E. Saczuk and J. Z. Kamiński, Resonant tunnelling in the presence of intense laser fields, Phys. Status Solidi B 240 (3), 603 (2003); doi: $10.1002 /$ pssb.200301898 
[59] H. Yamamoto, Resonant tunneling condition and transmission coefficient in a symmetrical one-dimensional rectangular double-barrier system, Appl. Phys. A 42 (3), 245 (1987); doi:10.1007/BF00620608

[60] A. Dutt and S. Kar, Smooth double barriers in quantum mechanics, Am. J. Phys. 78 (12), 1352 (2010); doi:10.1119/1.3481701

[61] S. Varró and F. Ehlotzky, Scattering by a hard sphere in a laser field, Z. Phys. D 8 (3), 211 (1988); doi:10.1007/BF01436943

[62] B. Friedman and J. Russek, Addition theorems for spherical waves, Quart. Appl. Math. 12, 13 (1954); doi:10.1090/qam/60649

[63] S. Stein, Addition theorems for spherical wave functions, Quart. Appl. Math. 19, 15 (1961); doi:10.1090/qam/120407

[64] O. R. Cruzan, Translational addition theorems for spherical vector wave functions, Quart. Appl. Math. 20, 33 (1962); doi:10.1090/qam/132851

[65] M. V. Fedorov, Atomic and Free Electrons in a Strong Laser Field, World Scientific, Singapore (1997); doi:10.1142/3320

[66] J. Z. Kamiński and F. Ehlotzky, Electron-atom scattering and electron-ion recombination in a powerful laser field, J. Mod. Opt. 50 (3-4), 621 (2003); doi: $10.1080 / 09500340308233555$

[67] T. Brabec and F. Krausz, Intense few-cycle laser fields: Frontiers of nonlinear optics, Rev. Mod. Phys. 72 (2), 545 (2000); doi:10.1103/RevModPhys.72.545

[68] P. B. Corkum and F. Krausz, Attosecond science, Nat. Phys. 3, 381 (2007); doi: $10.1038 /$ nphys 620

[69] S. Varró and Gy. Farkas, Attosecond electron pulses from interference of above-threshold de Broglie waves, Laser Part. Beams 26 (1), 9 (2008); doi: $10.1017 /$ S0263034608000037

[70] W. E. King, G. H. Campbell, A. Frank, B. Reed, J. F. Schmerge, B. J. Siwick, B. C. Stuart, and P. M. Weber, Ultrafast electron microscopy in materials science, biology, and chemistry, J. Appl. Phys. 97 (11), 111101 (2005); doi: $10.1063 / 1.1927699$

[71] A. H. Zewail, Four-dimensional electron microscopy, Science 328 (5975), 187 (2010); doi:10.1126/science.1166135 
[72] S. T. Park and A. H. Zewail, Enhancing image contrast and slicing electron pulses in $4 D$ near field electron microscopy, Chem. Phys. Lett. 521, 1 (2012); doi:10.1016/j.cplett.2011.11.031

[73] N. Morrison and C. H. Greene, Laser-assisted electron-argon scattering at small angles, Phys. Rev. A 86 (5), 053422 (2012);

doi:10.1103/PhysRevA.86.053422

[74] L. W. Garland, A. Jaron, J. Z. Kamiński, and R. M. Potvliege, Off-shell effects in laser-assisted electron scattering at low frequency, J. Phys. B 35 (13), 2861 (2002); doi:10.1088/0953-4075/35/13/302

[75] J. A. Gaunt, The triplets of helium, Proc. Royal Soc. A 122 (790), 513 (1929); doi:10.1098/rspa.1929.0037

[76] L. C. Biedenharn, J. D. Louck, Angular Momentum in Quantum Physics: Theory and Application in Encyclopedia of Mathematics and its Applications (ed. G.-C. Rota), Vol. 8, Cambridge University Press, Cambridge (1984); doi: $10.1017 / \mathrm{CBO} 9780511759888$

[77] P. K. Tien and J. P. Gordon, Multiphoton process observed in the interaction of microwave fields with the tunneling between superconductor films, Phys. Rev. 129 (2), 647 (1963); doi:10.1103/PhysRev.129.647

[78] M. Büttiker and R. Landauer, Traversal time for tunneling, Phys. Rev. Lett. 49 (23), 1739 (1982); doi:10.1103/PhysRevLett.49.1739

[79] M. Moskalets and M. Büttiker, Adiabatic quantum pump in the presence of external ac voltages, Phys. Rev. B 69 (20), 205316 (2004); doi:10.1103/PhysRevB.69.205316

[80] M. Wagner and W. Zwerger, Characteristic scaling parameters for tunneling in strong time-dependent electric fields, Phys. Rev. B 55 (16), R10217 (1997); doi:10.1103/PhysRevB.55.R10217

[81] M. Moskalets and M. Büttiker, Floquet scattering theory of quantum pumps, Phys. Rev. B 66 (20), 205320 (2002); doi:10.1103/PhysRevB.66.205320

[82] U. Fano, Effects of configuration interaction on intensities and phase shifts, Phys. Rev. 124 (6), 1866 (1961); doi:10.1103/PhysRev.124.1866

[83] A. E. Miroshnichenko, S. Flach, and Y. S. Kivshar, Fano resonances in nanoscale structures, Rev. Mod. Phys. 82 (3), 2257 (2010); doi: $10.1103 /$ revmodphys. 82.2257 
[84] W. Lu and C. M. Lieber, Nanoelectronics from the bottom up, Nat. Mater. 6, 841 (2007); doi:10.1038/nmat2028

[85] G. Burmeister and K. Maschke, Scattering by time-periodic potentials in one dimension and its influence on electronic transport, Phys. Rev. B 57 (20), 13050 (1998); doi:10.1103/PhysRevB.57.13050

[86] G. Burmeister and K. Maschke, Bound states revealed by time-periodic perturbing scattering potentials, Phys. Rev. B 59 (7), 4612 (1999); doi: $10.1103 /$ PhysRevB.59.4612

[87] B. H. Wu and J. C. Cao, Analysis of spin pumping in asymmetric ring conductors with the Aharonov-Casher effect, Phys. Rev. B 75 (11), 113303 (2007); doi:10.1103/PhysRevB.75.113303

[88] F. Romeo, R. Citro, and M. Marinaro, Quantum pumping and rectification effects in Aharonov-Bohm-Casher ring-dot systems, Phys. Rev. B 78 (24), 245309 (2008); doi:10.1103/PhysRevB.78.245309

[89] P. Földi, M. G. Benedict, O. Kálmán, and F. M. Peeters, Quantum rings with time-dependent spin-orbit coupling: Spintronic Rabi oscillations and conductance properties, Phys. Rev. B 80 (16), 165303 (2009); doi: $10.1103 /$ PhysRevB.80.165303

[90] Z. Wu, J. Li, and K. S. Chan, Charge pumping in monolayer graphene driven by a series of time-periodic potentials, Phys. Lett. A 376 (12-13), 1159 (2012); doi $10.1016 /$ j.physleta.2012.01.043

[91] C. Sinha and R. Biswas, Transmission of electron through monolayer graphene laser barrier, Appl. Phys. Lett. 100 (18), 183107 (2012); doi:10.1063/1.4710525

[92] W.-T. Lu, S.-J. Wang, W. Li, Y.-L. Wang, C.-Z. Ye, and H. Jiang, Fano-type resonance through a time-periodic potential in graphene, J. Appl. Phys. 111 (10), 103717 (2012); doi:10.1063/1.4721653

[93] K. S. Novoselov, A. K. Geim, S. V. Morozov, D. Jiang, Y. Zhang, S. V. Dubonos, I. V. Grigorieva, and A. A. Firsov, Electric field effect in atomically thin carbon films, Science 306 (5696), 666 (2004); doi: 10.1126 /science.1102896

[94] K. S. Novoselov, A. K. Geim, S. V. Morozov, D. Jiang, M. I. Katsnelson, I. V. Grigorieva, S. V. Dubonos, and A. A. Firsov, Two-dimensional 
gas of massless Dirac fermions in graphene, Nature 438, 197 (2005); doi: $10.1038 /$ nature04233

[95] A. F. Young and P. Kim, Quantum interference and Klein tunnelling in graphene heterojunctions, Nat. Phys. 5, 222 (2009); doi:10.1038/nphys1198

[96] B. Huard, J. A. Sulpizio, N. Stander, K. Todd, B. Yang, and D. Goldhaber-Gordon, Transport measurements across a tunable potential barrier in graphene, Phys. Rev. Lett. 98 (23), 236803 (2007); doi:10.1103/PhysRevLett.98.236803

[97] T.-T. Tang, Y. Zhang, C.-H. Park, B. Geng, C. Girit, Z. Hao, M. C. Martin, A. Zettl, M. F. Crommie, S. G. Louie, Y. R. Shen, and F. Wang, A tunable phonon-exciton Fano system in bilayer graphene, Nat. Nanotechnol. 5, 32 (2010); doi:10.1038/nnano.2009.334

[98] W. Zawadzki and T. M. Rusin, Zitterbewegung (trembling motion) of electrons in semiconductors: a review, J. Phys. Condens. Matter 23 (14), 143201 (2011); doi: $10.1088 / 0953-8984 / 23 / 14 / 143201$

[99] J. Cserti and Gy. Dávid, Unified description of Zitterbewegung for spintronic, graphene, and superconducting systems, Phys. Rev. B 74 (17), 172305 (2006); doi:10.1103/PhysRevB.74.172305

[100] P. E. Allain and J. N. Fuchs, Klein tunneling in graphene: optics with massless electrons, Eur. Phys. J. B 83, 301 (2011); doi:10.1140/epjb/e2011-20351-3

[101] S. De Leo and P. P. Rotelli, Barrier paradox in the Klein zone, Phys. Rev. A 73 (4), 042107 (2006); doi:10.1103/PhysRevA.73.042107

[102] S. De Leo and P. P. Rotelli, Dirac equation studies in the tunneling energy zone, Eur. Phys. J. C 51 (1), 241 (2007); doi:10.1140/epjc/s10052-007-0297-4

[103] S. D. Sarma, S. Adam, E. H. Hwang, and E. Rossi, Electronic transport in two-dimensional graphene, Rev. Mod. Phys. 83 (2), 407 (2011); doi:10.1103/RevModPhys.83.407

[104] M. I. Katsnelson, N. S. Novoselov, and A. K. Geim, Chiral tunnelling and the Klein paradox in graphene, Nat. Phys. 2, 620 (2006); doi:10.1038/nphys384

[105] M. Barbier, G. Papp, and F. M. Peeters, Snake states and Klein tunneling in a graphene Hall bar with a pn-junction, Appl. Phys. Lett. 100 (16), 163121 (2012); doi:10.1063/1.4704667 
[106] S. Y. Zhou, G.-H. Gweon, A. V. Fedorov, P. N. First, W. A. de Heer, D.-H. Lee, F. Guinea, A. H. Castro Neto, and A. Lanzara, Substrateinduced bandgap opening in epitaxial graphene, Nat. Mater. 6, 770 (2007); doi: $10.1038 /$ nmat2003

[107] M. R. Setare and D. Jahani, Klein tunneling of massive Dirac fermions in single-layer graphene, Physica B: Condensed Matter 405 (5), 1433 (2010); doi:10.1016/j.physb.2009.12.015

[108] Z.-Z. Cao, Y.-F. Cheng, and G.-Q. Li, Massive Dirac electron tunneling through a time-periodic potential in single layer graphene, Phys. Lett. A 375 (45), 4065 (2011); doi:10.1016/j.physleta.2011.08.074

[109] E. Perfetto, M. Cini, and S. Belucci, Pumping through a Luttinger liquid ring threaded by a time-varying magnetic field, Phys. Rev. B 87 (3), 035412 (2013); doi:10.1103/PhysRevB.87.035412

[110] M. F. Ludovico and L. Arrachea, Pumping charge with ac magnetic fluxes and the dynamical breakdown of Onsager symmetry, Phys. Rev. B 87 (11), 115408 (2013); doi:10.1103/PhysRevB.87.115408

[111] E. P. Wigner, Lower limit for the energy derivative of the scattering phase shift, Phys. Rev. 98 (1), 145 (1955); doi:10.1103/PhysRev.98.145

[112] F. T. Smith, Lifetime matrix in collision theory, Phys. Rev. 118 (1), 349 (1960); doi:10.1103/PhysRev.118.349

[113] S. Varró and F. Ehlotzky, High-order multiphoton ionization at metal surfaces by laser fields of moderate power, Phys. Rev. A 57 (1), 663 (1998); doi:10.1103/PhysRevA.57.663

[114] S. Varró and F. Ehlotzky, The multiphoton photo-effect and harmonic generation at metal surfaces, J. Phys. D 30 (22), 3071 (1997);

doi: $10.1088 / 0022-3727 / 30 / 22 / 003$

[115] C. G. R. Geddes, Cs. Toth, J. van Tilborg, E. Esarey, C. B. Schroeder, D. Bruhwiler, C. Nieter, J. Cary, and W. P. Leemans, High-quality electron beams from a laser wakefield accelerator using plasma-channel guiding, Nature 431, 538 (2004); doi:10.1038/nature02900

[116] J. Fuchs, P. Antici, E. d'Humières, E. Lefebvre, M. Borghesi, E. Brambrink, C. A. Cecchetti, M. Kaluza, V. Malka, M. Manclossi, S. Meyroneinc, P. Mora, J. Schreiber, T. Toncian, H. Pépin, and P. Audebert, Laser-driven proton 
scaling laws and new paths towards energy increase, Nat. Phys. 2, 48 (2006); doi:10.1038/nphys199

[117] W. P. Leemans, B. Nagler, A. J. Gonsalves, Cs. Tóth, K. Nakamura, C. G. R. Geddes, E. Esarey, C. B. Schroeder, and S. M. Hooker, GeV electron beams from a centimetre-scale accelerator, Nat. Phys. 2, 696 (2006); doi:10.1038/nphys418

[118] S. Datta, Electronic transport in mesoscopic systems, Cambridge University Press, Cambridge (1995); doi:10.1017/CBO9780511805776 